Examining the Contribution of Responsivity Factors to the Dynamic Risk Assessment for Offender Re-Entry

by

\title{
Daniela Corno
}

\begin{abstract}
A thesis submitted to the Faculty of Graduate and Postdoctoral Affairs in partial fulfillment of the requirements for the degree of
\end{abstract}

\author{
Master of Arts \\ in \\ Psychology \\ Carleton University \\ Ottawa, Ontario \\ (C)2021 \\ Daniela Corno
}




\begin{abstract}
The risk-need-responsivity model has been shown to be an effective method for reducing recidivism rates (Andrews \& Bonta, 2010). While the risk and need principles have garnered much attention in previous research, responsivity factors are not as well understood, especially when considering specific responsivity factors. The current study examined the use of three specific responsivity factors - trauma, mental health, and selfefficacy in conjunction with the Dynamic Risk Assessment for Offender Re-entry (DRAOR) in predicting recidivism and informing case planning and management. Archival data were used from the Iowa Department of Corrections database to create a sample of male justice-involved persons $(\mathrm{N}=3,703)$ who had been assessed within the first year of their supervision start date. Linear regressions revealed relationships between all three responsivity factors and both total DRAOR scores and items of interest. Logistic regressions revealed relationships between all three responsivity factors and recidivism. However, only trauma and self-efficacy incrementally predicted recidivism when added to the DRAOR. The overall best model for predicting recidivism included total DRAOR scores, trauma, and self-efficacy. When considering all relationships examined, the current study demonstrates the usefulness of these three items in case management and planning as well as the importance of considering specific responsivity factors and attending to needs in order to assist justice-involved persons in achieving better outcomes.
\end{abstract}




\section{Acknowledgements}

First and foremost, I would like to thank my supervisor, Dr. Ralph Serin for providing me with the opportunity to conduct this research. Thank you for your support, guidance, and ability to always bring humour and lightheartedness into our meetings to ease stress. I would like to thank Dr. Craig Bennell and Dr. Diana Majury for helping me fine-tune and improve the quality of this project. I also need to thank Dr. Cecilia Jorgenson for her patience in answering my never-ending statistics questions as well as Dr. Kate Pardoel for taking so much time out of her busy schedule to share her knowledge of the DRAOR and help me work out my analysis plan.

Second, this project would not have been possible without the Iowa Department of Corrections. I am eternally grateful to them for sharing their valuable data.

Finally, I would like to thank my family for being such a strong support system, my peers in my cohort (Karen and Jayme in particular) for allowing me to bounce ideas off of them and helping me solve problems, and $\mathrm{G}$ for always supporting me and reminding me of how capable I am. The imposter syndrome is strong, but these people made it so much easier to push past! 
Table of Contents

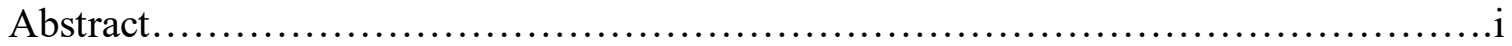

Acknowledgements.............................................................

List of Tables........................................................... vi

List of Figures......................................................... vii

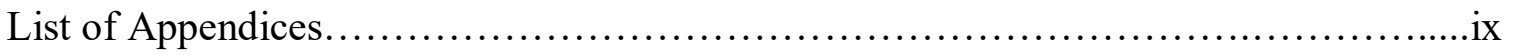

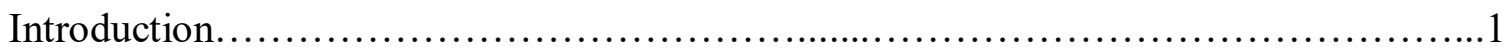

Risk-Need-Responsivity Model.........................................1

Trauma..................................................................

Adverse Childhood Experiences.................................7

Trauma and Recidivism........................................9

Mental Health....................................................... 11

Substance Use.............................................12

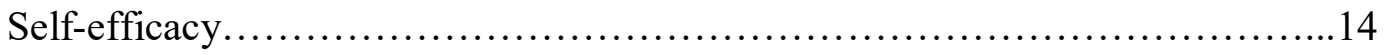

Risk Factors..................................................... 16

Static Risk Factors...............................................16

Dynamic Risk Factors.........................................16

Protective Factors................................................... 17

Risk Assessment...................................................... 18

Trauma Assessment in the Criminal Justice System..........................19

Iowa Department of Corrections.......................................20

Dynamic Risk Assessment for Offender Re-entry..........................21

Predictive Validity...........................................22 


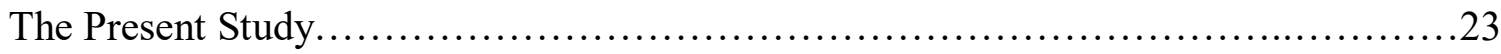

Research Questions...................................................24

Study 1: Trauma............................................24

Study 2: Mental Health..........................................25

Study 3: Self-efficacy.........................................27

Study 4: Model Fitting........................................28

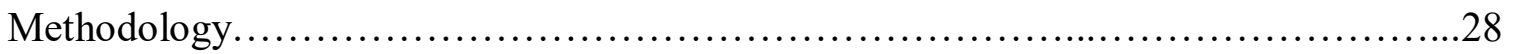

Participants...................................................... 28

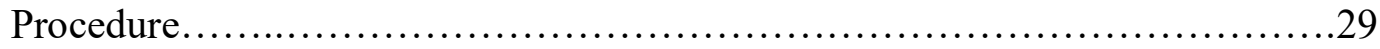

Measures..........................................................29

Outcome Data........................................................ 33

Data Analytic Plan.................................................... 34

Results................................................................ 37

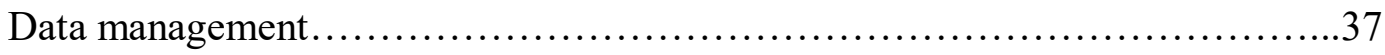

Preliminary Analyses................................................... 39

Chi-square Analyses............................................ 39

Correlations Between Variables of Interest...........................43

Study 1: Trauma...................................................... 45

Study 2: Mental Health............................................52

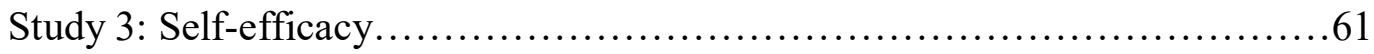

Study 4: Model Fitting.............................................. 70

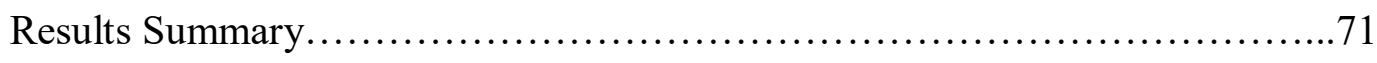

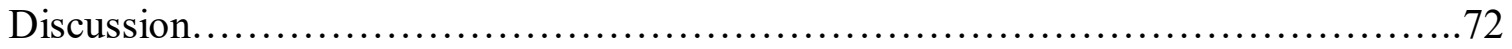


Study 1: Trauma................................................. 72

Study 2: Mental Health................................................ 73

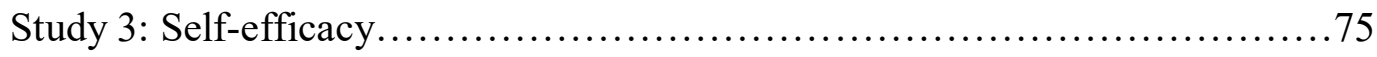

Study 4: Model Fitting................................................. 77

Overall Discussion................................................... 78

Limitations and Future Directions...................................... 79

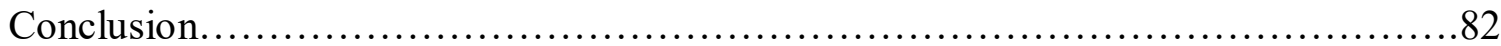

References.............................................................. 83 


\section{List of Tables}

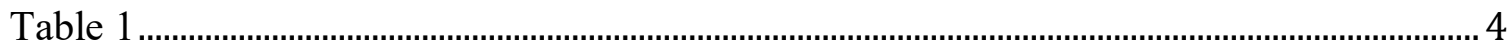

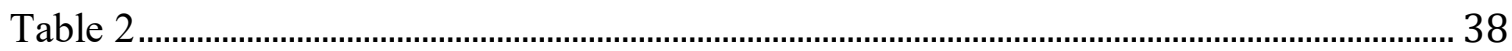

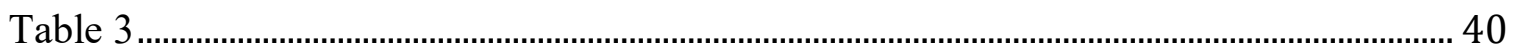

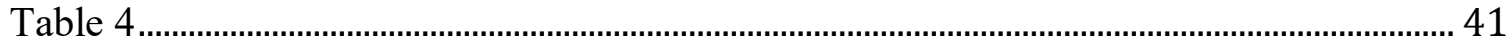

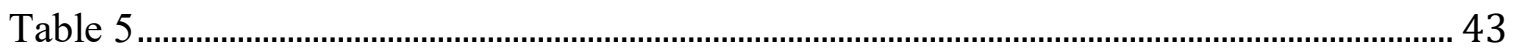

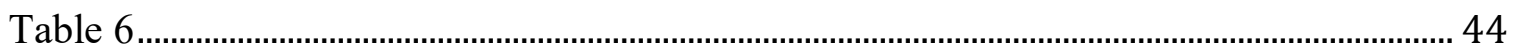

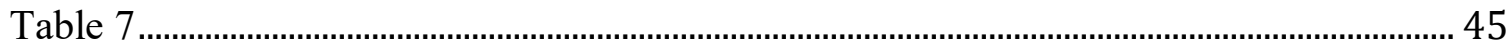

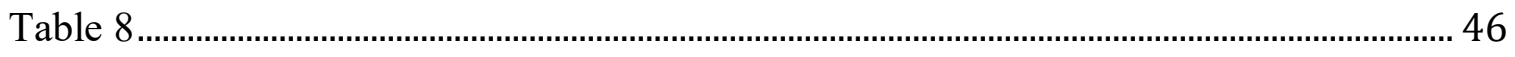

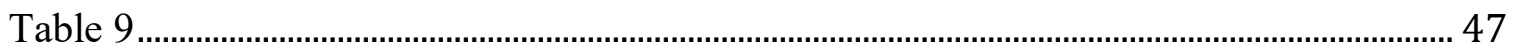

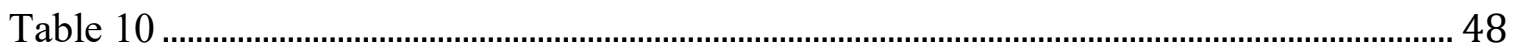

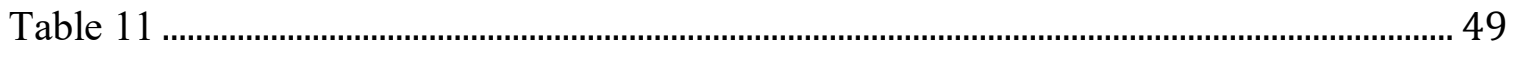

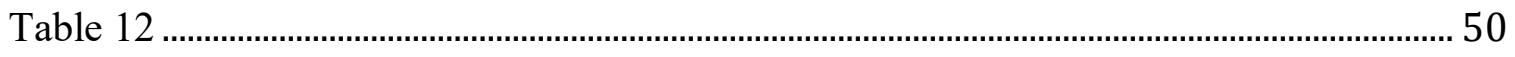

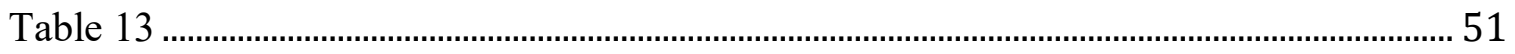

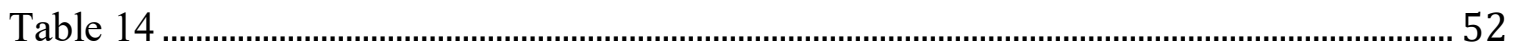

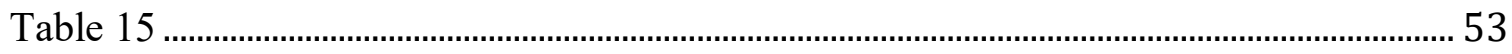

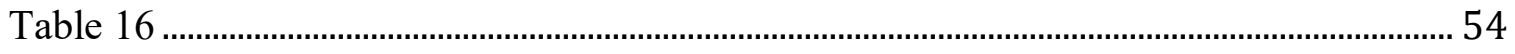

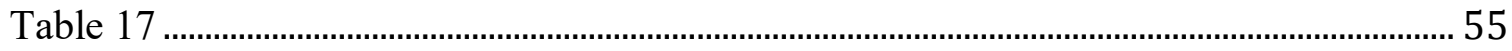

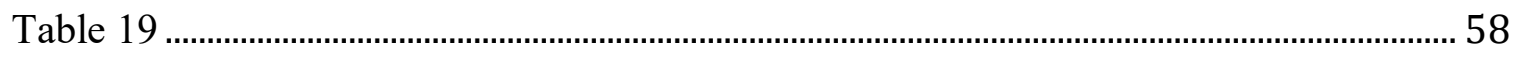

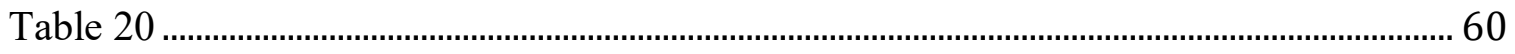




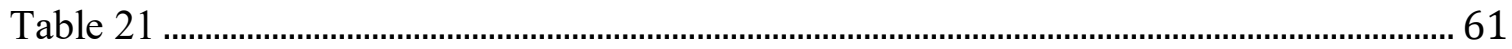

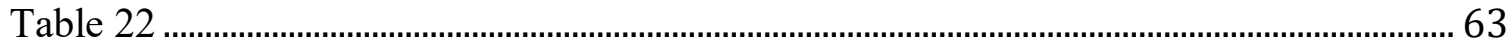

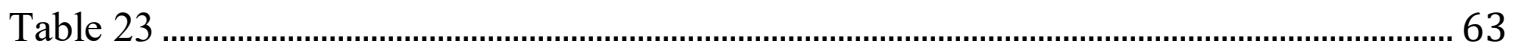

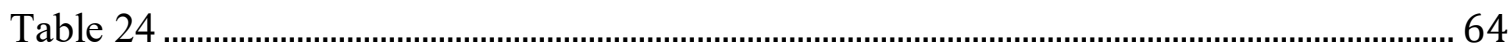

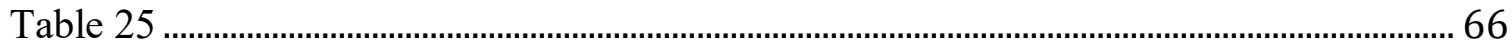

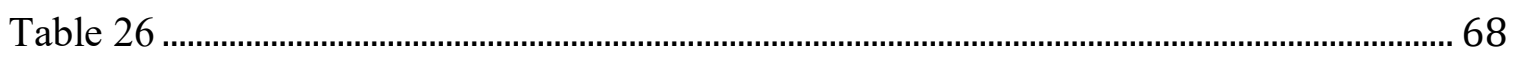

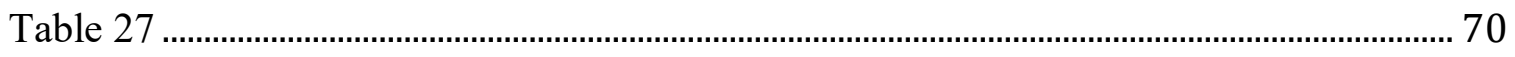

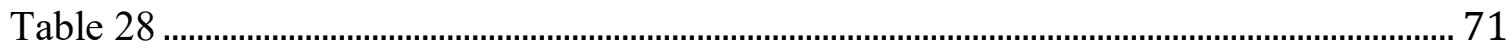

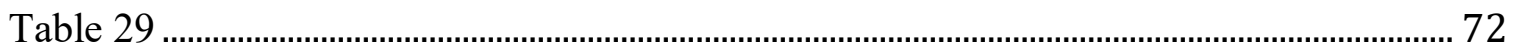




\section{List of Figures}

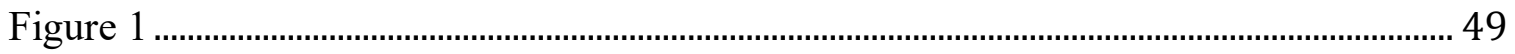

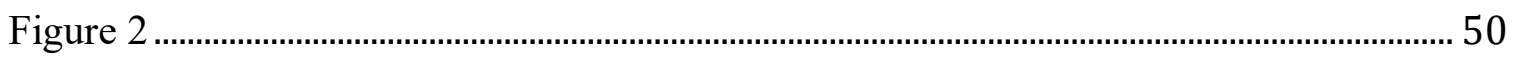

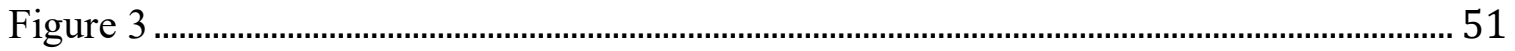

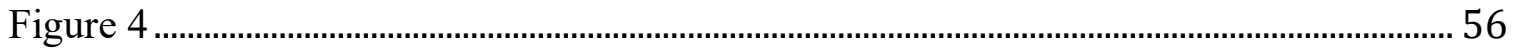

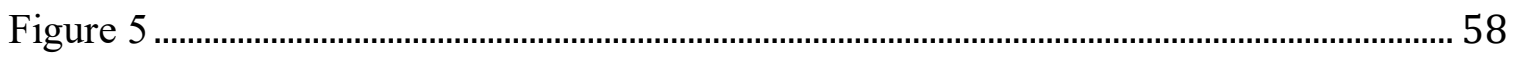

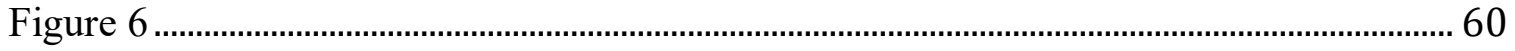

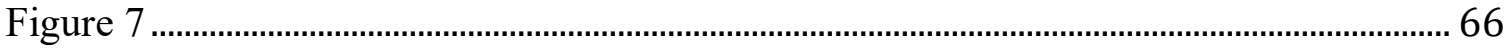

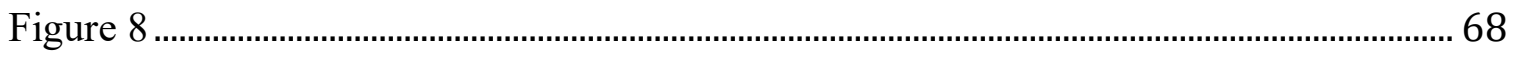

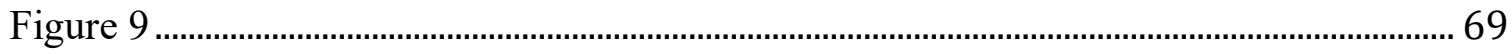




\section{List of Appendices}

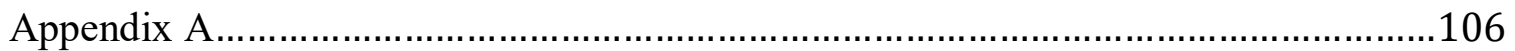

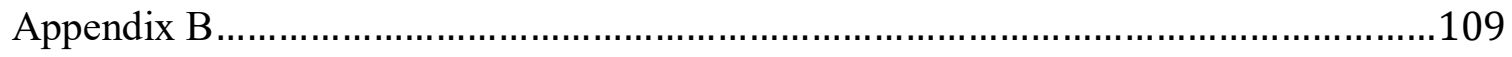

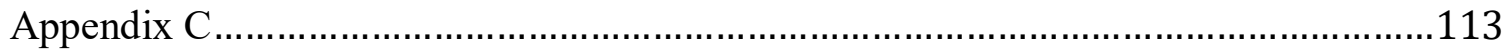


Examining the Contribution of Responsivity Factors to the Dynamic Risk Assessment for

\section{Offender Re-Entry}

The current study aimed to extend a blended risk-need-responsivity (RNR) and desistance approach to criminal conduct by examining purported responsivity factors to better understand outcomes for justice-involved persons. Trauma, mental health, and selfefficacy are specific responsivity factors that have been shown to be associated with recidivism risk in varying capacities. Given that the Iowa Department of Corrections supplements their recidivism risk assessments with additional measures of these specific responsivity factors, it is essential to determine the usefulness of these items with respect to case planning and management. Using an archival dataset, the contributions of trauma, mental health, and self-efficacy problems were considered.

\section{Risk-Need-Responsivity Model}

When the RNR model is followed in various forms of intervention, success rates are highest in terms of recidivism reduction. It is designed to inform how justice-involved persons should be assessed based on risk presented, what needs are present, and ideal types of environments in which to address those needs (Smith et al., 2009). Effective RNR use can reduce recidivism by up to $35 \%$ in community settings (Andrews \& Bonta, 2010; Andrews \& Bonta, 2006; Bonta \& Andrews, 2007). Following RNR relies on addressing all three factors (i.e., risk principles, need principles, and responsivity principles). The risk principle posits that the level of service must be matched to the justice-involved person's risk to reoffend. This can be achieved through the use of various risk assessment tools. The need principle posits that criminogenic needs must be assessed and targeted in treatment. Criminogenic needs (i.e., dynamic risk factors directly 
related to criminal behaviour) have been widely studied, leading to the creation of the central eight that are major predictors of criminal behaviour: history of criminal behaviour; antisocial personality/temperament; antisocial peers/associates; criminal thinking; family or marital problems; school or work problems; lack of pro-social leisure/recreational activities; and substance abuse (Andrews \& Bonta, 2006). Finally, the responsivity principle posits that interventions must be tailored and obstacles to treatment must be attended to in order to maximize an individual's ability to benefit from rehabilitative intervention. This is achieved by targeting non-criminogenic needs (i.e., those that are not directly related to criminal behaviour but can influence treatment outcome either by enhancing successes or creating barriers).

Responsivity factors can further be broken down into those that are general and those that are specific. General responsivity refers to best practices in treatment that will apply to all justice-involved persons. This relies on the relationship principle (i.e., having a warm, respectful, collaborative alliance between client and therapist) and the structuring principle (i.e., influencing the direction of change towards prosociality). Specific responsivity refers to individual factors that can help personalize treatment. This is done by focusing on personal-cognitive-social factors such as strengths, learning style, personality, motivation, and bio-social characteristics like gender and race.

When appropriately matched, responsivity factors will facilitate treatment and lead to improved outcomes. However, if not adequately tailored, barriers may be created that hinder treatment success. A large-scale meta-analysis done by Smith and colleagues (2009) examining the effectiveness of the principles of RNR determined that treating justice-involved persons produces noticeable recidivism reductions, and that the 
effectiveness of treatment is dependent on the risk level of the client, the type of treatment, and the learning needs of the client (i.e., attending to responsivity needs). Using appropriate treatments for clients was associated with greater average reductions in recidivism compared to treatment methods that were inappropriate (i.e., failed to meet the principles of RNR; $r=0.29$ vs. $r=0.04$, respectively). In particular, cognitive behavioural interventions showed the highest consistent reductions in recidivism, leading to a $15 \%$ reduction compared to the control group, while other treatment interventions showed smaller rates. Most studies to date have focused more on general responsivity factors as opposed to specific responsivity factors, suggesting a gap warranting future examination. Despite this literature gap, research has demonstrated the importance of attending to all principles of RNR (Gendreau, Goggin, et al., 2006; Gendreau, Smith, et al., 2006; Smith et al., 2009).

The current study examines three potential responsivity factors (i.e., trauma, mental health, and self-efficacy problems) and their influence on community supervision outcomes for justice-involved persons.

\section{Trauma}

Notably, trauma has received limited consideration both as an antecedent to crime and as an impediment to treatment. The American Psychological Association (APA) defines trauma as "an emotional response to a terrible event" (APA, 2020). Typically, one becomes overwhelmed and their ability to cope is reduced (Herman, 1997; Hien et al., 2009; van der Kolk et al., 2007). The type of experience that causes trauma in an individual is subjective, varying widely. A review of trauma literature done by Madera (2016) identified eighteen events most commonly seen as having the potential to be 
traumatic. These eighteen events can be grouped into interpersonal violence (e.g., child abuse, assault), non-intentional trauma (e.g., accidents, natural disasters), intentional trauma (e.g., robbery), and traumatic loss (e.g., death of a loved one; see Table 1 for complete list).

Table 1

Types of Traumatic Events Identified in the Trauma Literature

Child neglect

Child abuse (physical, sexual, emotional)

Assault (physical or sexual)

Intimate partner violence

Witnessing death or serious injury

Serious accident

Natural disasters

Severe automobile accidents

Separation for a parent or child

Source: Madera, J. E. E. (2016). The cumulative impact of trauma exposure and

recidivism after incarceration among black men [unpublished PhD thesis]. The City

University of New York, New York.

Any traumatic event can be experienced differently depending on the circumstances

within which the event occurred, an individual's genetic predisposition, and an

individual's personality. Madera's (2016) review found five circumstances most often

influencing an individual's response to trauma. These include age when the trauma

occurred (childhood, adolescence, adulthood, old age); the individual's relationship to the perpetrator (family member, acquaintance, authority figure, etc.); whether the event was intentional or unintentional (e.g., physical/sexual assault vs. a natural disaster); the location of the event; and the length of the exposure (single event vs. ongoing abuse/exposure). Additionally, genetic predisposition, personality, coping style, support system, and environment tend to be factors in how an individual experiences a traumatic event (Madera, 2016). 
Prisoners report rates of trauma experienced prior to incarceration that are higher compared to the general population. Briere and colleagues (2016) found that in a sample of 490 individuals from the general population, the mean number of trauma exposures was 2.2 and $3.9 \%$ met the criteria for a diagnosis of post-traumatic stress disorder (PTSD). The top three traumas that individuals were exposed to were motor vehicle accidents, threatened assault, and physical assault. Individuals with only one traumatic event had a $0 \%$ likelihood of developing PTSD and individuals exposed to six or more had $12 \%$ likelihood. Comparing this to a sample of 96 inmates, the mean number of trauma exposures was 6.3 and $47.9 \%$ met the criteria for a PTSD diagnosis. Similar to the general population, the top three traumas were still motor vehicle accidents, physical assault, and threatened assault. However, inmates had significantly more frequent endorsements of all traumas compared to the general population, with the exception of combat and natural disasters. Inmates who had experienced only one traumatic exposure had a 16.7\% likelihood of developing PTSD and inmates who experienced six or more had $63.9 \%$ likelihood. In the general population, women were more likely to experience childhood sexual abuse whereas in the prison population there was no significant gender difference (Briere et al., 2016).

Kubiak (2004) found the rate of PTSD to be over 50\% in a sample of 199 prisoners, with women having higher rates of PTSD ( $60 \%$ of women and $53 \%$ of men) and experiencing more events than men (an average of 4.57 events for women and 3.27 events for men). Cook and colleagues (2005) found rates to be as high as $81 \%$ for female inmates experiencing five or more traumas. Adding to this high rate of trauma, Cook et al. (2005) found that a lack of place to live for at least seven days put women between 
2.19 and 5.62 times more likely to have experienced at least 14 traumatic events. Looking at children, child protective services estimated that a total of $681,000(9.1$ per 1,000$)$ children were victims of maltreatment in the United States in 2011, with incidences including neglect, physical abuse, sexual abuse, threatened abuse, parents' drug/alcohol abuse, or lack of supervision (National Center for Injury Prevention and Control, 2013).

Despite both genders exhibiting high rates of PTSD in prison populations, men and women tend to exhibit differences in their most commonly experienced types of trauma and the way they experience it. Women are most likely to have experienced childhood sexual abuse whereas males are most likely to have witnessed violence (Miller \& Najavits, 2012). In a sample of 51 juvenile male inmates, it was found that $30-50 \%$ of their sample had witnessed severe violence at home such as physical assault or death or witnessed homicide outside the home (Erwin et al., 2000). Erwin and colleagues (2000) also found that community violence accounted for the highest rates among men.

Women are more likely to internalize their trauma - exhibiting by way of self-harm, eating disorders, addiction, and avoidance. Men are more likely to externalize their trauma - exhibiting violence, substance abuse, crime, and hyper-arousal (Miller \& Najavits, 2012). While both are at higher risk for substance abuse, Kubiak (2004) found that women with PTSD were more likely to relapse than those without. No significant differences were found for men.

Regarding trauma, researchers have distinguished between traumatic experiences and stressful life experiences. Traumatic experiences tend to be more extreme with stronger potential for actual physical or psychological harm to either the individual in question or someone close to them (e.g., physical or sexual assault, witnessing a shooting). Stressful 
life experiences tend to be less extreme although these more common experiences are still distressing and taxing (e.g., divorce, job loss; Maschi et al., 2018). Though traumatic experiences are more likely to lead to PTSD, both traumatic experiences and stressful life experiences are linked to criminal behaviour (Maschi et al., 2018; Maschi et al., 2015; Maschi et al., 2011; Maschi, 2006;).

\section{Adverse Childhood Experiences}

A well-documented measure of trauma is adverse childhood experiences, commonly known as ACEs. Created by Felitti et al. (1998), ACEs are specific negative childhood events initially found to be associated with leading causes of death. There are ten ACEs in total. Half pertain to childhood maltreatment (physical abuse, sexual abuse, emotional abuse, physical neglect, and emotional neglect) and half pertain to traumatic childhood events (violent treatment towards mother, household substance abuse, household mental illness, parental separation or divorce, and having an incarcerated household member). ACE scores are determined by summing the number of exposures an individual has experienced. Each exposure is counted as one, regardless of how many times the exposure has occurred. ACEs have been linked to a range of poor outcomes including increased chances of heart disease, skeletal fractures, chronic lung disease, cancer, and liver disease (Anda et al., 2010; Anda et al., 2006; Chartier et al., 2010; Dube et al., 2003). While links to poorer health outcomes (the original focus of ACEs) have been thoroughly documented, researchers have begun to examine whether they predict negative social outcomes such as delinquent behaviour. 


\section{ACEs and Criminal Behaviour}

Research has shown that ACEs are linked to a variety of circumstances associated with risk factors related to criminal behaviour and criminal behaviour itself. In terms of risk factors, higher ACE scores have been associated with higher instances of heavy drinking and substance use (Bellis et al., 2014). In terms of direct criminal behaviour, having higher ACE scores are associated with having spent one night or more in prison or a police station, higher risks of reoffending, and shorter time to recidivism (Baglivio et al., 2014; Bellis et al., 2014; Benda, 2005; Moylan et al., 2010). Baglivio and colleagues (2014) found that youth who are high-risk for reoffending as defined by Positive Achievement Change Tool (PACT) assessment scores were more likely than low-risk youth to have an ACE score of three or more. Youth who are low-risk were also 35.6 times more likely to report having zero ACE indicators as compared to high-risk youth. Furthermore, ACEs appear to be highly associated with violent crime. For instance, higher ACEs are associated with higher prevalence of hitting someone, recent involvement in violence, and committing violent offenses (Barrett et al., 2014; Bellis et al., 2014; Chen et al., 2011; Cicchetti \& Manly, 2001; Duke et al., 2010; Fox et al., 2015; Lattimore et al., 1995; Yu-Ling Chiu et al., 2011). Specifically, Duke and colleagues (2010) found that among adolescents, each additional ACE exposure increased risk of violence perpetration by $35-144 \%$, suggesting that a blunt measure of trauma such as ACEs is sufficiently informative to predict outcomes. Fox and colleagues (2015) examined the likelihood of individuals becoming either serious, violent, and chronic justice-involved persons or "one and done" justice-involved persons. ACE scores were found to be predictors of serious, violent, and chronic offending, with risk increasing by 
$35 \%$ for each additional ACE, even when controlling for gender, race, age of onset, impulsivity, peer influence, and family income.

ACEs in general have been shown to have a cumulative effect with adverse outcomes increasing for each additional ACE present, regardless of which ACE is it (Anda et al., 2010; Baglivio \& Epps, 2015; Dong et al., 2004). However, one study did find that, in particular, having an incarcerated family member, ACEs involving sexual abuse, living with someone incarcerated, or abusing drugs were the strongest ACE predictors of individuals having higher overall ACE scores (Bellis et al., 2014)

\section{Trauma and Recidivism}

Though limited research has specifically looked at the effect of traumatic experiences on recidivism, initial results have been found suggesting a link between the two. Looking broadly at any objective or subjective trauma experience, both were positive and significant predictors of self-reported recidivism for justice-involved persons with violent offense histories, justice-involved persons with drug offense histories, and justice-involved persons who are minorities (Maschi et al., 2018). For all groups, recidivism was predicted by a greater number of traumatic experiences and a greater reported impact as a result of these experiences (Maschi et al., 2018).

Studies have looked at trauma specifically in an intra-family setting using both ACEs and other measures. When looking at ACEs and juvenile justice-involved persons, the number of traumatic exposures is positively and significantly related to the likelihood of recidivism, defined as any new law violation within one year of completed service (Wolff \& Baglivio, 2017). Wolff and colleagues (2017) further confirmed these results, regardless of youths' gender and race or ethnic subgroup. 
Benda (2005) examined the relationship between exposure to childhood physical and sexual abuse and recidivism, finding both types of exposure to be strong predictors of shorter time to recidivism in both women and men. When using other measures to define intra-family trauma, similar results have been found. Looking at juvenile justice-involved persons, childhood maltreatment, parental neglect, and intra-family violence or abuse were found to be predictive of both general recidivism (Barrett et al., 2014) and violent recidivism (Lattimore et al., 1995) as defined by any new law violation following release. In adult populations, childhood maltreatment defined as physical neglect was significantly related to increased rates of self-reported reoffending, compared to justiceinvolved persons who had not reported being maltreated as a child (Kim et al., 2016; Smith \& Thornberry, 1995). When looking at childhood physical and sexual abuse, exposure is related to both increases in parole violations and shorter time to recidivism as defined by any new felony or parole violation (Benda, 2005; Benda \& Toombs, 2002).

When looking at adults serving life sentences, including general trauma significantly improved model prediction for both general reoffending (explaining up to $19.3 \%$ of the variance) and violent reoffending (explaining up to $26.2 \%$ of the variance). Narrowing it down to specific trauma type, troubles related trauma (i.e., being caught up in a riot, witnessing a bombing, shooting, or killing, mention of someone close being shot, seriously injured, or intimidated) was a unique predictor of both general and violent reoffending (Dalsklev et al., 2019).

PTSD specifically is also related to increased recidivism rates as defined by general recidivism (any arrest for any new charge), serious recidivism (arrest for a new felony charge), and general violence recidivism (Miles-McLean et al., 2019; Sadeg \& 
McNiel, 2015, 2013). Kubiak (2004) found that 17\% of individuals with PTSD experienced either a new arrest or parole revocation compared to $6 \%$ of the non-PTSD group. PTSD is also associated with increased risk for reoffending when using risk assessment measures (Ardino et al., 2013). Though the link between PTSD and recidivism has been supported, there are limitations to using PTSD as a predictor, given that the majority of individuals who have experienced trauma do not go on to develop PTSD (Santiago et al., 2013).

\section{Mental health}

Mental health has a well-established relationship with delinquency, with 20-40\% of persons who have severe mental illness coming into contact with the criminal justice system at least once in their lives and up to $56 \%$ of state prison inmates meeting the criteria for a mental health problem (James \& Glaze, 2006; Swanson et al., 2001). Compared to the general population, justice-involved persons have higher rates of mental health problems (Baillargeon et al., 2009). In particular, a meta-analysis of sixty-two studies found a two- to four-fold increase of psychotic illnesses and major depression as well as a ten-fold increase in antisocial personality disorder among justice-involved persons compared to the general population in both the US and the UK (Fazel \& Danesh, 2002). Looking twenty-four months post-release, Smith \& Trimboli (2010) found that $65 \%$ of those with a mental health disorder had recidivated compared to only $51 \%$ with no diagnosis. When looking specifically at violent reoffending, Grann and colleagues (2008) found rates as high as 31.3\%. Though comparisons have not been widely studied, there is some evidence of gender differences. McReynolds and colleagues (2010) found that females with comorbid substance use and affective disorder, specifically, were four 
times more likely to reoffend than females without, whereas males with the same diagnostic profile had only about half the level of increased recidivism risk. Additionally, Short and colleagues (2013) found comorbid substance use and schizophrenia increased the likelihood of criminal behaviour, with schizophrenia being an especially strong predictor for female violence.

Notably, high rates of recidivism risk for justice-involved persons with mental illnesses may be due to unmet treatment needs (Baillargeon et al., 2009; Lovell et al., 2002). When looking at released justice-involved persons who received mental health services while incarcerated, criminal history factors remained significant risk factors for recidivism, but clinical risk factors (i.e., history of substance abuse) were not, suggesting this sample modeled those of the general justice-involved person population (Fisher et al., 2014). Additionally, Bonta and colleagues (1998) found that predictors such as criminal history, antisocial personality, substance abuse, and family dysfunction are important for both mentally disordered justice-involved persons and general justice-involved persons, equally. Further, it has been shown that receiving case management services while incarcerated led to justice-involved persons being significantly more likely to receive case management services when released into the community, which is associated with significantly lower risk of reoffending as well as significantly longer time to recidivism (Ventura et al., 1998).

\section{Substance Use}

The association between mental illness and recidivism appears to be exacerbated by co-occurring substance use. Rates of substance use disorder among inmates with mental health illnesses are as high as 75\% (Skeem et al., 2011; Skeem et al., 2006). As 
previously mentioned, Smith and Trimboli (2010) found 65\% of their sample with overall mental illness recidivated. Rates of recidivism were highest when justice-involved persons had comorbid substance use and non-substance use diagnoses (67\%) compared to those who had only a substance disorder (55\%), a non-substance use mental health disorder (49\%), or no mental health disorders (51\%). Fifty-five percent of justiceinvolved persons with only a substance use diagnosis recidivated, lower than both groups previously mentioned. Further demonstrating that substance use is a driving force behind mental health and recidivism, Wilson and colleagues (2011) saw 68\% of justice-involved persons with a dual diagnosis of mental illness and substance use recidivated, compared to $50 \%$ of justice-involved persons with a diagnosis of mental illness alone. Moreover, Guebert \& Olver (2014) found that substance use and conduct disorder, specifically, were related to recidivism among youth charged with serious/violent offenses.

The relationship between mental illness and substance use in relation to recidivism is even further complicated when trauma is involved. This is particularly relevant given the high rates of trauma among justice-involved persons, which can lead to compounding effects (James \& Glaze, 2006). Martin and colleagues (2015) found that $45 \%$ of their sample of inmates had experienced trauma and that trauma was associated with higher rates of substance use and mental health issues, and that this increased recidivism. Similar to the previously mentioned findings for conduct disorder by Guebert and Olver (2014), Barrett and colleagues (2014) reported a diagnosis of conduct disorder (i.e., diagnosis relating to aggressive behaviour) to be the strongest predictor of delinquency among juvenile justice-involved persons with a history of parental maltreatment and foster care. Importantly, a diagnosis of PTSD was associated with a 
higher likelihood of recidivism, with the risk for rearrest at comparable levels to justiceinvolved persons with substance use disorders (Sadeh \& McNeil, 2015). These equally high-risk factors appear to have compounding effects, making a vulnerable population even more vulnerable. That is, justice-involved persons with mental illnesses are at a significantly higher risk of trauma exposure, which could lead to PTSD, which, in turn, has strong associations with drug use and violent behaviour (Chilcoat \& Breslau, 1998; Choe et al., 2008; Goff et al., 2007; MacManus et al., 2012; Mueser et al., 1998; Sadeh et al., 2014; Teplin et al., 2005).

\section{Self-efficacy}

An area that might mitigate the effects of trauma and mental health may be selfefficacy. Self-efficacy is concerned with individuals' beliefs about their ability to accomplish tasks, stick to goals, and succeed in situations (Bandura, 1994). It follows two assumptions: efficacy expectations and outcome expectancy. Efficacy expectations relate to the confidence an individual needs to attain a desired behaviour. Outcome expectancy relates to an individual's belief that their behaviour will actually produce the outcome they are striving for (Bandura, 1978; 1977). Having higher self-efficacy enhances an individual's accomplishments and well-being, as their beliefs about themselves will determine how they think, behave, and motivate themselves (Bandura, 1994; Bandura \& Locke). As self-efficacy increases, individuals may feel they have more internal resources that will aid them in solving problems and achieving goals. Over time these internal resources will develop into cognitive strategies and applied decision skills and will be equated with positive self-worth (Bandura, 1977; Sheier et al., 2000). Stronger self-efficacy affects goal setting, approaches to challenges, visualization, and motivation. 
Those with stronger self-efficacy will be more likely to set higher goal challenges for themselves, approach these challenges as tasks to be mastered rather than threats to be avoided, and be more likely to visualize success scenarios. They will also be more likely to attribute failures to a lack of effort rather than a lack of ability, leading them to persevere longer and be more resilient (Bandura, 1994).

Self-efficacy and motivation are concepts used often in intervention strategies that utilize a transtheoretical approach (Wells-Parker et al., 2000). Research has shown that the process of goal setting to enact change is mediated by self-efficacy. The goal setting process should ideally incorporate self-efficacy and confidence principles to define realistic goals that are within the capacity of the individual (Lee et al., 2007; Locke \& Latham, 1990). Employing proper goal setting has shown reductions in predicted recidivism rates among justice involved persons who have committed domestic violence offenses (Lee et al., 2007).

Self-efficacy has been studied in a variety of areas such as academic performance (Bassi et al., 2007; Gonida \& Leondari, 2011; Gutman \& Midgley, 2000; Scott et al., 2008), work performance (Locke \& Latham, 1990; Pomaki et al., 2009), and smoking cessation (DiClemente, 1981). An analysis of nine meta-analyses examining various fields supported the influence self-efficacy has on motivation and performance (Bandura \& Locke, 2003). However, the link between self-efficacy and an individual's ability to motivate themselves and achieve goals has been sorely understudied in the area of delinquency. Some preliminary evidence has shown that higher self-efficacy is related to lower rates of recidivism (Benda, 2001; Carroll et al., 2013), but more research needs to 
be done. Of interest is how these responsivity factors (i.e., trauma, self-efficacy, and mental health) relate to risk and outcome.

\section{Risk Factors}

Risk factors can be broken down at the most basic level into static and dynamic. Dynamic are then further broken down into stable and acute (Hanson \& Harris, 2000). All types give different information and together can inform an accurate profile for risk.

\section{Static Risk Factors}

Static risk factors are those that are historical and not able to be changed by individual effort. These include factors such as criminal history, age at first arrest, current age, and more. Static factors are useful for predicting who is at long-term risk to reoffend, but have limitations, as they cannot predict when at at-risk individual may reoffend, nor address areas to be targeted for preventing future reoffending (Hanson \& Harris, 2000).

\section{Dynamic Risk Factors}

In contrast to static risk factors, dynamic risk factors are those that have the potential for change either over time or through interventions, leading to corresponding increases or decreases in recidivism (Hanson et al., 2007; Hanson \& Harris, 2000). These can be further broken down into stable and acute dynamic risk factors. Stable dynamic risk factors are those that are not expected to change quickly or frequently (i.e., are relatively stable over periods of months or years). One example would be criminal thinking. Due to their slow changing nature, focusing on stable dynamic risk factors tends to create enduring improvements in risk. Acute dynamic risk factors are those that are expected to change quickly (i.e., over days or hours). One example would be negative mood. These are more strongly related to the timing of reoffending as opposed to long- 
term recidivism potential (Hanson \& Harris, 2000). Benefits to using dynamic risk factors include a better ability to assess intervention efforts by looking at change that has been made (Chadwick, 2014; Serin et al., 2016).

\section{Protective Factors}

While looking at risk in a multitude of ways has led to increases in predicting recidivism and better case planning, solely looking at risk only focuses on the likelihood of crime occurring. Protective factors, on the other hand, focus on factors related to crime desistance (Polaschek, 2016). These are made up of both internal (e.g., prosocial identity) and external (e.g., social support) strengths that can assist in desistance. Using the theoretical framework proposed by Fitzpatrick (1997), protective factors may follow a mediation model where the impact of risk factors is mediated by protective factors or may follow a buffer model where risk factors only impact on behaviour when protective factors are low or absent. Further, having more protective factors leads to more protection against risk (Lodewijks et al., 2010).

There are multiple ways of looking at protective factors, suggesting that protective factors are not merely the absence of risk. Protective factors may be the opposite of risk, whereby they exist on one side of a continuum and any factor could be scored as either a strength or a risk (e.g., prosocial peers are protective, whereas antisocial peers are a risk; Polaschek, 2016). Protective factors may also be independent entities that do not have corresponding risk factors (e.g., high involvement in religious activities; Polaschek, 2016; Ullrich \& Coid, 2011). Though most research has focused on assessing protective factors as the opposite of risk (Harris \& Rice, 2015), both have been supported in literature (Polaschek, 2016). 
The majority of research done on protective factors has looked at juvenile justiceinvolved persons. This could be due to the fact that adolescents are still developing and thus are more greatly affected by protective factors. Additionally, identifying problem behaviours early may prevent future criminal behaviour (Ullrich \& Coid, 2011). Research has demonstrated that protective factors reduce the risk of aggression and general, violent, and nonviolent reoffending in adolescents (Lodewijks et al., 2010; Richard, 2004; Viljoen et al., 2012) and that protective factors being present during adolescence predicted lower rates of general offending in adulthood (Cox et al., 2018). Further, the addition of protective factors demonstrated significantly higher amounts of variance explained by dynamic risk factors alone (Lodeqijks et al., 2010).

\section{Risk Assessment}

Risk assessment practices have evolved over time. Initially, first generation risk assessment favoured unstructured clinical approaches (Bonta, 1996). However, these have shown to be the least predictive as they rely on the assessor's knowledge and experience, which may not always be comprehensive and/or accurate (Andrews et al., 2006; Hanson, 2009; Hanson \& Morton-Bourgon, 2009; Harris \& Hanson, 2010). Following this, second generation risk assessments focused on primarily static risk predictors using an atheoretical approach in an attempt to be more standardized and objective (Bonta, 1996). This approach fell out of favour because using primarily static risk predictors does not allow for a complete, meaningful picture to be created as these are factors that cannot be changed through effort and are not personalized to the justiceinvolved person (Yesberg \& Polaschek, 2015). Furthermore, actuarial tools make it 
difficult to determine risk management plans and intervention strategies as they offer little guidance (Wong \& Gordon, 2006).

To strengthen risk assessment tools by creating a more complete picture of risk, third-generation tools added in dynamic risk factors guided by theory (Hanson \& Harris, 2000). While these helped to create a more complete assessment, a meta-analysis done by Campbell, French, and Gendreau (2009) found them to only be marginally more predictive compared to second-generation tools. This led to the current, fourth generation tools that further incorporated case planning and focusing on responsivity factors (Andrews et al., 2006).

In addition to these generations of risk assessments, structured professional judgment (SPJ) tools are another approach to determining risk. SPJ tools make decisions using evidence-based guidelines. Instead of providing total scores as a representation of recidivism probability, SPJs provide recommendations and likely scenarios (Hart \& Logan, 2011). Research has suggested that SPJ instruments are reliable and valid means of assessing risk (Otto \& Douglas, 2010; Wilson et al., 2013). In the current study, the risk assessment approach is the Dynamic Risk Assessment for Offender Reentry (DRAOR; Serin, 2007), an SPJ case-planning instrument.

\section{Trauma Assessment in the Criminal Justice System}

Trauma informed correctional care (TICC) has been gaining attention within the criminal justice system. TICC approaches correctional care through a trauma lens by considering that it creates a unique correctional environment by way of protective mechanisms such as psychological or physical avoidance, aggression, or arousal. It acknowledges trauma and its associated symptoms, encourages staff training and 
awareness, and promotes procedures that minimize the risk of re-traumatization of inmates (Briere \& Scott, 2013; Freedman \& Hemenway, 2000; Miller \& Najavits, 2012; van der Kolk, 2014). Though employing a trauma lens is gaining traction, there are few well-established, systematic measures of trauma being utilized within correctional settings. With PTSD being a common focus of TICC literature, this may suggest that clinical assessments are being utilized most often. Additionally, as specific experiences that often lead to trauma have been thoroughly established in the literature, client case files and histories may serve as a marker for which individuals require TICC. In the current study the Iowa Department of Corrections routinely assesses trauma and related sequelae as part of the case planning approach.

\section{Iowa Department of Corrections}

Iowa Department of Corrections uses an RNR model to establish an effective and efficient management system throughout its nine institutions. They house approximately 8,200 individuals and supervise approximately 40,500 individuals in the community with parole supervision levels ranging from minimal to intensive. Of their justice-involved persons on community supervision, approximately $64 \%$ are on probation and $13 \%$ are on parole. In terms of community supervision closure outcomes, only 59\% are successful with the three-year prison return recidivism rate being 38.8\% (Iowa Department of Corrections, 2019a). Given that the average daily cost per justice-involved person in prison is $\$ 74.66$ USD per day, compared to $\$ 6.12$ per day per justice-involved person on parole/probation supervision (Iowa Department of Corrections, 2019b), it is imperative from both a social and economic standpoint to address high recidivism rates. 
As part of their case management, parole and probation officers with Iowa Department of Corrections assess justice-involved persons' risk for reoffending using the Dynamic Risk Assessment for Offender Re-entry (DRAOR; Serin, 2007) as well as supplemental items such as trauma, mental health, and self-efficacy. Though they are leaning towards TICC by assessing trauma experienced, this is only a one-item measure and there is little information on what is done in terms of case management and support if an individual scores high on this item. Other standardized measures of trauma do not appear to be employed.

\section{Dynamic Assessment for Offender Re-entry}

The Dynamic Risk Assessment for Offender Re-entry (DRAOR; Serin, 2007) scale is a structured professional judgment instrument that assesses stable and acute dynamic risk factors as well as protective factors. It was developed to aid probation and parole officers in the ongoing assessment of their clients' risk to inform case planning, case management, and risk management strategies. It identifies justice-involved persons within risk groups and assists in determining which justice-involved persons are at high risk for recidivism. Stable dynamic risk factors are focused on attitude, trait, and behaviour problems. Acute dynamic risk factors are focused on situation, mood, and behaviour factors. The DRAOR adopts the theoretical framework that protective factors are independent and conceptually distinct from risk. These protective factors focus on prosocial perceptions and prosocial connectedness. By including protective factors to assess desistance from crime, officers are able to assess both the internal and external mechanisms that may be supporting a justice-involved person while on probation or 
parole, as more protective factors means there is a greater chance of avoiding problematic behaviours (Chadwick, 2014; Serin et al., 2016).

Total scores can range from -12 to 26 . Cut-off scores were recently created as suggestions for supervision intensity adjustment to further aid in risk management (Serin \& Chadwick, 2017). Categorizations include low, moderate, moderate/high, and high (see Appendix A). Serin and Chadwick (2017) propose that initial supervision levels based on a static risk measure (Iowa Risk Assessment) should be decreased by one level when justice-involved persons are classified as low, increase by one level when justiceinvolved persons are classified as moderate/high or high, and remain unchanged when justice-involved persons are classified as moderate.

\section{Predictive Validity}

A range of studies has found the DRAOR to be a significant predictor of recidivism. Initially piloted on samples of justice-involved persons in New Zealand and Iowa, the DRAOR is a moderate predictor of overall recidivism risk $(\mathrm{AUC}=.66 ; 95 \% \mathrm{CI}$ $=[.62, .69])$. Each subscale is also a moderate predictor of both technical violations and general recidivism $($ Stable: $\mathrm{AUC}=.60 ; 95 \% \mathrm{CI}=[.56, .64]$; Acute: $\mathrm{AUC}=.65,95 \% \mathrm{CI}$ $=[.61, .69] ;$ Protective: AUC $=.67 ; 95 \% \mathrm{CI}=[.63, .70]$; Serin $\&$ Prell, 2012). A validation study done by Yesberg and Polaschek (2015) found DRAOR total scores, stable, acute, and protective subscales predicted new reconvictions (moderate AUCs, from .57 to .62) and reimprisonment (moderate AUCs, from 5.9 to .62) for high-risk male justice-involved persons. Breaches of parole convictions were only significantly predicted by the protective subscale $($ AUC $=.58)$. Hanby $(2013)$ found the DRAOR be moderately to largely predictive of any reconviction (AUCs ranging from .66 to .72) and 
moderately predictive of criminal reconvictions (AUCs ranging from .62 to .67). Serin et al. (2016) found the both total DRAOR and subscale scores to be predictors of technical parole violations (moderate to strong AUCs ranging from .66 to .71), serious parole violations (moderate to strong AUCs ranging from .66 to .72) and new crimes (moderate AUCs ranging from .67 to .70). Additionally, Chadwick (2014) found the DRAOR to significantly predict technical violations (moderate AUCs ranging from .57 to .61) but not general or violent recidivism. Though studies have slightly varying findings, overall the DRAOR demonstrates moderate predictive validity with adult male justice-involved persons.

The DRAOR was created using research conducted with predominantly male populations and most pilot work and validation has been done with male justice-involved persons. Given this, validation studies have been conducted to look at the validity of the DRAOR with other populations. A second validation study done by Yesberg and colleagues (2015) determined the DRAOR total score significantly predicted time to recidivism for both women, $\chi^{2}(1, N=133)=13.90, p<.001$, and men, $\chi^{2}(1, N=133)=$ $5.15, p=.023$. The acute subscale score was the only subscale to make a unique contribution to recidivism prediction for women. This suggests that the DRAOR is useful for both men and women justice-involved persons.

\section{The Present Study}

Currently, the importance of attending to risks and needs of justice-involved persons following an RNR model has been well researched but responsivity factors and their relative contributions to risk assessment and management have been under-studied with corrections populations. The current study was broken down into four parts to 
examine the contribution of the responsivity factors trauma, self-efficacy, and mental health to risk assessment in a sample of US male probationers using archival DRAOR data with the goal of better understanding outcomes for justice-involved persons.

\section{Research Questions}

\section{Study 1: Trauma}

1. What is the relationship between trauma problems and DRAOR scores

a. DRAOR total scores

Hypothesis 1A: Justice-involved persons who are higher in trauma problems will have higher total DRAOR scores

b. Substance abuse item scores

Hypothesis 1B: Justice-involved persons who are higher in trauma problems will have higher substance abuse scores.

c. Antisocial tendency scores using the following items: peer associations, attitudes toward authority, and sense of entitlement Hypothesis 1C: Justice-involved persons who are higher in trauma problems will have higher antisocial tendencies scores.

d. Emotional distress scores using the following items: anger/hostility, negative mood, and impulse control Hypothesis 1D: Justice-involved persons who are higher in trauma problems will have higher emotional distress scores.

2. What is the relationship between trauma problems and recidivism?

Hypothesis 2: Justice-involved persons who are higher in trauma problems will have higher rates of recidivism. 
3. Does the addition of trauma problems to the DRAOR incrementally predict recidivism?

Hypothesis 3: Adding in the supplemental item for trauma problems will improve recidivism prediction over using the DRAOR alone.

4. What is the interaction between trauma problems and stable dynamic risk scores, acute dynamic risk scores, and protective factor scores, separately?

Hypothesis 4: Justice-involved persons who are high in trauma problems and high in protective factors will have lower rates of recidivism than those who are high in trauma problems and low in protective factors. No predictions are made regarding interactions between justice-involved persons who are high in trauma problems and high in protective factors and those who are low in trauma problems and low/high in protective factors. No predictions are made regarding the interactions between trauma problems and both stable and acute dynamic risk scores.

\section{Study 2: Mental Health}

1. What is the relationship between mental health problems and DRAOR scores

a. DRAOR total scores

Hypothesis 1A: Justice-involved persons who are higher in mental health problems will have higher total DRAOR scores

b. Substance abuse item scores

Hypothesis 1B: Justice-involved persons who are higher in mental health problems will have higher substance abuse scores. 
c. Antisocial tendency scores using the following items: peer associations, attitudes toward authority, and sense of entitlement Hypothesis 1C: Justice-involved persons who are higher in mental health problems will have higher antisocial tendencies scores.

d. Emotional distress scores using the following items: anger/hostility, negative mood, and impulse control Hypothesis 1D: Justice-involved persons who are higher in mental health problems will have higher emotional distress scores.

2. What is the relationship between mental health problems and recidivism? Hypothesis 2: Justice-involved persons who are higher in mental health problems will have higher rates of recidivism.

3. Does the addition of mental health problems to the DRAOR incrementally predict recidivism?

Hypothesis 3: Adding in the supplemental item for mental health problems will improve recidivism prediction over using the DRAOR alone.

4. What is the interaction between mental health problems and stable dynamic risk scores, acute dynamic risk scores, and protective factor scores, separately?

Hypothesis 4: Justice-involved persons who are high in mental health problems and high in protective factors will have lower rates of recidivism than those who are high in mental health problems and low in protective factors. No predictions are made regarding comparisons between justiceinvolved persons who are high in mental health problems and high in protective factors and justice-involved persons who are low in mental 
health problems and low/high in protective factors. No predictions are made regarding the interactions between mental health problems and both stable and acute dynamic risk scores.

\section{Study 3: Self-efficacy}

1. What is the relationship between self-efficacy problems and DRAOR scores?

a. DRAOR total scores

Hypothesis 1A: Justice-involved persons who are higher in self-efficacy problems will have higher total DRAOR scores

b. Substance abuse item scores

Hypothesis 1B: Justice-involved persons who are higher in self-efficacy problems will have higher substance abuse scores.

c. Antisocial tendency scores using the following items: peer associations, attitudes toward authority, and sense of entitlement Hypothesis 1C: Justice-involved persons who are higher in self-efficacy problems will have higher antisocial tendencies scores.

d. Emotional distress scores using the following items: anger/hostility, negative mood, and impulse control Hypothesis 1D: Justice-involved persons who are higher in self-efficacy problems will have higher emotional distress scores.

2. What is the relationship between self-efficacy problems and recidivism? Hypothesis 2: Justice-involved persons who are higher in self-efficacy problems will have higher rates of recidivism. 
3. Does the addition of self-efficacy problems to the DRAOR incrementally predict recidivism?

Hypothesis 3: Adding in the supplemental item for self-efficacy problems will improve recidivism prediction over using the DRAOR alone.

4. What is the interaction between self-efficacy problems and stable dynamic risk scores, acute dynamic risk scores, and protective factor scores, separately?

This research question is exploratory. Thus, no predictions are made regarding the interactions between self-efficacy problems and stable dynamic risk scores, acute dynamic risk scores, or protective factor scores.

\section{Study 4: Model Fitting}

1. What is the best model for predicting recidivism rates using DRAOR scores, mental health problems, self-efficacy problems, and trauma problems?

Hypothesis 1: The addition of mental health problems, self-efficacy problems, and trauma problems to the DRAOR will be most predictive of recidivism rates.

\section{Methodology}

\section{Participants}

Archival data from the Iowa Department of Corrections database were used. The sample was derived from a larger set of justice-involved persons serving community supervision orders in Iowa between March 2001 and November 2016, with the majority (85\%) having started their supervision between 2014 and 2016. A subset of 3,703 male justice-involved persons was used. All justice-involved persons who had been assessed within the first year (i.e., 12 months) of their supervision start date were included in the 
sample. The majority of justice-involved persons identify as Caucasian (75.2\%), followed by Black (22.3\%), Hispanic (6.4\%), American Indian or Alaskan Native (1.6\%) and Asian or Pacific Islander (0.9\%). The majority of justice-involved persons had completed their high school diploma or GED (70.5\%). The majority of justice-involved persons reported being single $(65.1 \%)$ at the time of supervision start. Using cut-off scores intended to aid in supervision intensity adjustment (Serin \& Chadwick, 2017), 35.1\% of the sample was low risk, 31.4\% was moderate risk, 33.4\% was moderate/high risk, and $1.2 \%$ was high risk. While all justice-involved persons in the sample were serving either a probation sentence, a parole sentence, or some other form of community supervision. The exact breakdown was not available.

\section{Procedure}

Data were collected and coded by staff of the Iowa Department of Corrections. All completed assessments were recorded as file notes and entered into the Iowa Corrections Offender Network (ICON). Demographic information, DRAOR scores, and collected recidivism data were provided electronically.

\section{Measures}

\section{Dynamic Risk Assessment for Offender Re-entry}

The DRAOR is a 19-item instrument that assesses risk for recidivism using three subscales: stable dynamic risk factors, acute dynamic risk factors, and protective factors to reflect a Transitional Model of Offender Change (Serin \& Lloyd, 2009; Serin et al., 2010). Typically, assessments are done on a monthly basis, but can be done more or less frequently as needed. All items utilize a three-point scale ranging from 0 to 2 . See Appendix A for DRAOR items and Appendix B for descriptions. 
Stable Dynamic Risk Subscale. Factors for this subscale include peer associations, attitudes towards authority, impulse control, problem-solving, sense of entitlement, and attachment with others. Items were drawn from research done by Andrews and Bonta (2010) and Hanson and Harris (2000). A score of 0 is assigned when a justice-involved person does not currently possess the risk factor in question. A score of 1 is assigned when the variable demonstrates a slight problem or it is not clear based on the information the officer has gathered. A score of 2 is assigned when the variable in question poses a definite problem for the justice-involved person.

Acute Dynamic Risk Subscale. Factors for this subscale include substance abuse, anger, victim access, negative mood, employment, interpersonal relationships, and living situation. A score of 0 is assigned when a justice-involved person does not currently possess the risk factor in question. A score of 1 is assigned when the variable demonstrates a slight problem or it is not clear based on the information the officer has gathered. A score of 2 is assigned when the variable in question poses a definite problem for the justice-involved person.

Protective Subscale. Factors for this subscale include responsiveness to advice, prosocial identity, high expectations, cost/benefits, social support, and social control. Items were informed by desistance literature, particularly focusing on Maruna (2001) and Sampson and Laub (2005). A score of 0 is assigned when the item in question is not a protective factor for the justice-involved person. A score of 1 is assigned when the item could be a potential asset or there is not enough information to make a definitive selection. A score of 2 is assigned when the item in question is a definite asset. 
For research purposes, summing the acute and stable scores and subtracting the protective score provides a total score. Total scores range from -12 to 26 . Lower scores denote high protective factors and low risk whereas higher scores denote low protective factors and high risk. However, in practice, a total score is not calculated. Rather, a summary is created by totalling items in each subscale that illustrates problem areas for supervision officers to address via case planning.

\section{Trauma score}

Trauma is assessed using a one-item measure as part of the supplemental factors added to the DRAOR by Iowa Department of Corrections for case planning purposes. The item assesses trauma experienced or as it relates to vicarious trauma. Here, trauma is defined as a very difficult or unpleasant experience that causes someone to have mental or emotional problems, usually for a long time. Supervision officers rate an individual's level of trauma experienced on a three-point scale ranging from 0 to 2 . A score of 0 indicates there is no apparent problem. This would be assigned to an individual with either no history of trauma or no current issues associated with past trauma. A score of 1 indicates a slight problem. This would be assigned to an individual with past or current trauma that caused past issues but is currently causing few issues with current daily living. A score of 2 indicates a definite problem. This would be assigned to an individual whose trauma experienced is impacting their daily living. Ratings are determined using information from case files and communication between the PO and the justice-involved person. Informational details such as type of trauma, when trauma occurred, or total occurrences are not provided in this study. See Appendix C for full item description. 


\section{Mental health score}

Mental health is assessed using a one-item measure as part of the supplemental factors added to the DRAOR by the Iowa Department of Corrections for case planning purposes. The item is specific to a mental health issue or diagnosis and considers mental health issues and diagnoses as part of daily routine and living. Supervision officers rate an individual's mental health on a three-point scale ranging from 0 to 2 . A score of 0 indicates that there is no apparent problem. This would be assigned when there is either no known history or no current issues of mental health problems. A score of 1 indicates there is a slight problem. This would be assigned when some mental health issues are present but the individual is still able to meet the demands of daily living. The individual may be stabilized on prescribed medication or in therapy that is deemed beneficial. A score of 2 indicates there is a definite problem. This would be assigned when the individual's mental health issues interfere with daily living. They may be taking prescribed medication or attending therapy but the individual is still not stabilized or the methods being employed are not effective. This would also apply when an individual is refusing to take medication as prescribed. Ratings are determined using records and personal communication between the PO and the justice-involved person. Informational details such as what the diagnosis or issue is are not provided in this study. See Appendix C for full item description.

\section{Self-efficacy score}

Self-efficacy is assessed using a one-item measure as part of the supplemental factors added to the DRAOR by Iowa Department of Corrections for case planning purposes. The item assesses the ability to set goals to increase success potential. 
Supervision officers rate an individual's level of self-efficacy on a three-point scale ranging from 0 to 2 . A score of 0 indicates there is no apparent problem. This would be assigned when an individual has the ability to set and achieve goals and also feels that he/she can achieve reasonable goals. A score of 1 indicates there is a slight problem. This would be assigned when an individual demonstrates limited ability to set or achieve goals and is uncertain of their ability to do so. An individual assigned this rating would demonstrate low confidence levels. A score of 2 indicates a definite problem. This would be assigned when an individual has not demonstrated the ability to set or achieve goals. An individual assigned this rating would be unfocused or lacking in drive. Ratings are determined using information from case records and communication between the $\mathrm{PO}$ and the justice-involved person. Given that higher scoring on the self-efficacy item denotes higher problems, the present study treated self-efficacy as a potential risk factor (rather than a strength or protective factor) to be consistent with the way the Iowa Department of Corrections is treating it. See Appendix C for full item description. These three supplemental items represent holistic assessments of factors potentially impacting clients' current quality of life and adjustment.

\section{Outcome Data}

Recidivism was defined as any return to prison within one-year (i.e., 12 months) post-supervision start date. This included technical violations, new non-violent crimes (i.e., general recidivism), and violent recidivism. Technical violations included breaches of supervision conditions (e.g., abstaining from alcohol or drugs) or facility misconducts for justice-involved persons in community residential facilities (i.e., half-way houses). New non-violent crimes included all rearrests for drug related offenses, driving offenses, 
property offenses, or administrative crimes (e.g., tax evasion). Violent recidivism included any new violent crime (e.g., domestic abuse, assault, robbery, or murder). Any return to prison was based on rearrest info from the Iowa Corrections Offender Network, which tracks criminal activity throughout the state, but not nationally.

The decision to restrict recidivism analysis to one-year post-supervision start date was chosen based on research using the Post Conviction Risk Assessment (Flores et al., 2017). This comparison study found similar results when comparing the use of fixed time (i.e., a specified cut-off time) and variable time (i.e., time to recidivism regardless of amount of days) using 53,077 justice-involved persons. Predictive accuracy did not appear to vary as the length of follow-up time increased. AUC values reached levels above .70 at the three-month follow-up mark and reached .74 at the seven-month followup mark, remaining stable thereafter. This suggests that shorter follow-up periods will suffice when large sample sizes are being used. Further, the differing analytical techniques (i.e., cox regression vs. logistic regression) did not yield significant differences in recidivism prediction (Flores et al., 2017).

\section{Data Analytic Plan}

\section{Data management}

As only case files where the entire assessment was filled out were used, missingness was not an issue. Any outliers that were more than \pm 3 standard deviations away were to be removed. Regarding assumptions for using logistic regression, as there was a large number of cases $(n=3,703)$, the ratio of cases to variables was adequate. Data did not violate the assumption of independence of errors, as repeated measures data were not used. Though large sample sizes are generally robust, a Box-Tidwell test was 
performed to ensure there was a linear relationship between each predictor and the logit transform of the dependent variable (i.e., linearity in the logit; Tabachnick \& Fidell, 2013). Multicollinearity between the independent variables was checked using the variance inflation factor with a cut-off score of 10 . Though the large sample size likely made my dataset robust, adequacy of expected frequencies and power were assessed to ensure that all expected frequencies were greater than one and that no more than $20 \%$ were less than five (Tabachnick \& Fidell, 2013). Regarding assumptions for linear regression, linearity, homoscedasticity, normality, univariate and multivariate outliers, and multicollinearity were assessed.

\section{Preliminary analyses}

Initial group comparisons were done using chi-square analyses to look at prevalence rates of trauma, mental health, and self-efficacy across different risk categories of DRAOR scores. Chi-square analysis is useful for determining the relationship between two discrete variables (Tabachnick \& Fidell, 2013). This made it an appropriate analytical tool as the variables of interest (i.e., trauma, mental health, self-efficacy, and risk categories) were all discrete. Correlations were also run between all predictor and outcome variables.

\section{Variables of interest and DRAOR scores}

A series of linear regressions were used to analyze the relationship between trauma/mental health/self-efficacy and DRAOR total scores, antisocial tendency scores, and emotional distress scores. Linear regression was chosen due to the dependent variable (i.e., total DRAOR scores, antisocial tendency scores, emotional distress scores) being continuous in nature (Tabachnick and Fidell, 2013). For all linear regressions, 
dummy coding was used, as the predictors were categorical in nature. The level of no trauma/mental health/self-efficacy was used as the reference category. For the relationship between trauma/mental health/self-efficacy and substance abuse scores, a series of logistic regressions were used as the substance abuse scores were categorical in nature (i.e., coded as yes/no; Tabachnick \& Fidell, 2013).

\section{Variables of interest and recidivism}

A series of logistic regressions were used to analyze the relationship between trauma/mental health/self-efficacy and recidivism. Logistic regression was chosen due to the dependent variable (i.e., recidivism coded as yes/no) being categorical in nature (Tabachnick \& Fidell, 2013). Odds ratios of $1.68,3.47$, and 6.71 are considered to be small, moderate, and large effect sizes, respectively. These values correspond to Cohen's $\mathrm{d}$ values of $.20, .50$, and .80 , respectively (Chen et al., 2010).

\section{Incremental prediction}

A series of hierarchical logistic regressions were used to analyze the predictive validity of mental health/self-efficacy/trauma when added to the DRAOR. The goal was to determine if any of the responsivity predictors significantly improve the predictive ability of the regression model, above and beyond the accuracy provided by DRAOR scores. To do this, DRAOR total scores were entered into the model first, and the responsivity variables were entered into the model (independently) afterwards. Effect sizes were calculated using the same values as above.

Receiver operating characteristic curves (using areas under the curve) were also used as a supplemental analysis to give a broader picture about the predictive validity and allow more direct comparisons to existing DRAOR research. 


\section{Interaction with subscales}

A series of logistic regressions were used to analyze the interactions between trauma/mental health/self-efficacy and DRAOR subscales (i.e., stable dynamic risk scores; acute dynamic risk scores; protective factor scores). Logistic regression was chosen for the reasons as mentioned above. All three predictors were tested for interactions with the DRAOR subscales, regardless of whether they demonstrated significance (i.e., $\alpha<.05$ ) with DRAOR total scores. Effect sizes were calculated using the same values as above.

\section{Determining the best model}

Stepwise logistic regressions were used to analyze the best model for predicting recidivism rates using DRAOR scores, trauma, mental health, and self-efficacy. The results of subsequent analyses helped inform which predictors were entered into the final model and in what order. Effect sizes were assessed using the same values as above.

\section{Results}

\section{Data management}

\section{General}

Data were screened for both missingness and items being in valid ranges. As only case files where the entire assessment was filled out were used, missingness was not an issue. All items were in the valid ranges, thus no outliers needed removing.

\section{Logistic regression}

As there were a large number of cases $(n=3,703)$, the ratio of cases to variables was adequate. Data did not violate the assumption of independence of errors, as repeated measures data were not used. As noted earlier, though large sample sizes are generally 
robust, a Box-Tidwell test was performed to ensure there was a linear relationship between each predictor and the logit transform of the dependent variable (i.e., linearity in the logit; Tabachnick \& Fidel, 2013). Continuous predictors that were tested included DRAOR total scores, DRAOR subscale scores (stable dynamic, acute dynamic, protective) emotional distress subscale scores, and antisocial tendency subscale scores. As all variables included participants with scores of 0 , variables were transformed by adding a value of 1 to each score so that all would be higher than 0 and would be able to be $\log$ transformed. Logistic regressions for continuous variables and their log transformations revealed no significant interactions (Table 2). Thus, this assumption was met.

Table 2

Log transformations of continuous predictors

\begin{tabular}{lllll}
\hline Interaction & $\mathrm{B}(\mathrm{SE})$ & $\mathrm{OR}$ & $\mathrm{P}$-value & $95 \% \mathrm{CI}$ \\
\hline DRAOR Total*Log Transformed & $-0.10(.01)$ & 0.91 & .317 & {$[0.75,1.10]$} \\
$\begin{array}{l}\text { Acute Dynamic*Log } \\
\text { Transformed }\end{array}$ & $-0.21(.22)$ & 0.81 & .348 & {$[0.53,1.25]$} \\
$\begin{array}{l}\text { Stable Dynamic*Log } \\
\text { Transformed }\end{array}$ & $-0.34(.28)$ & 0.71 & .217 & {$[0.41,1.22]$} \\
$\begin{array}{l}\text { Protective*Log Transformed } \\
\text { Emotional Distress*Log }\end{array}$ & $-0.35(.20)$ & 0.71 & .085 & {$[0.47,1.05]$} \\
$\begin{array}{l}\text { Transformed } \\
\text { Antisocial Tendencies*Log }\end{array}$ & $-0.06(.52)$ & 0.94 & .910 & {$[0.34,2.63]$} \\
Transformed & $0.29(.57)$ & 1.34 & .608 & {$[0.44,4.07]$} \\
\hline
\end{tabular}

Adequacy of expected frequencies and power were assessed to ensure that all expected frequencies were greater than one and that no more than $20 \%$ were less than five (Tabachnick \& Fidell, 2013). This assumption as also met. 


\section{Linear regression}

In addition to the logistic regression assumption checks, assumptions for linear regression were performed. Specifically, linearity, homoscedasticity, normality, univariate and multivariate outliers, and multicollinearity were assessed. Normality, linearity, and homoscedasticity were assessed visually using histograms, P-P plots, and Q-Q plots. All variables appeared to be normally distributed and did not appear to violate linearity or homoscedasticity. As Kolmogorov-Smirnov's test of normality is not useful when using large datasets, only visual inspections were done (Tabachnick \& Fidell, 2013). No univariate or multivariate outliers were identified. As the variance inflation factor did not exceed 10, multicollinearity was not an issue.

\section{Preliminary analyses}

\section{Chi-square analyses}

Prevalence rates of trauma, mental health, and self-efficacy were examined across risk categories of DRAOR total scores. Risk categories of DRAOR total scores are broken down as low (-12 to 2$)$, moderate (3 to 9), moderate/high (10 to 22$)$, and high (23 to 26).

Trauma. There was a significant association between trauma and risk categories of DRAOR total scores, $X^{2}=271.11, p<.001, \varphi_{\mathrm{c}}=.20$. Higher risk cases were rated to have greater trauma problems. Post hoc analyses showed that as rates of trauma problems increased, individuals who are low risk significantly decreased (no trauma apparent problems, 75\%; slight problems, 18.6\%; definite problems, 6.4\%). Similar results were found for individuals who are moderate/high risk (no apparent trauma problems $45.1 \%$; slight problems $34.4 \%$; definite problems $20.5 \%$ ). For the moderate risk category, there 
were significantly higher frequencies of individuals who had no apparent trauma problems (59.8\%) compared to both individuals who had slight trauma problems $(29.8 \%)$ and definite trauma problems (10.4\%). There was no significant difference between individuals with slight trauma problems and individuals with definite trauma problems. For the high risk category, there were significantly higher frequencies of individuals with definite trauma problems (45.7\%) compared to both individuals with no apparent trauma problems (31.4\%) and slight trauma problems (22.9\%). There was no significant difference between frequency of individuals with no apparent trauma problems and individuals with slight trauma problems in the high risk group (Table 3).

Table 3

Frequencies of trauma scores across categories of DRAOR risk scores.

\begin{tabular}{lllll}
\hline Risk Category & Trauma L0 & Trauma L1 & Trauma L2 & Total \\
\hline Low & $891_{\mathrm{a}}$ & $221_{\mathrm{b}}$ & $76_{\mathrm{c}}$ & 1188 \\
Moderate & $645_{\mathrm{a}, \mathrm{b}}$ & $321_{\mathrm{b}}$ & $112_{\mathrm{a}}$ & 1078 \\
Moderate/high & $501_{\mathrm{a}}$ & $382_{\mathrm{b}}$ & $227_{\mathrm{c}}$ & 1110 \\
High & $11_{\mathrm{a}}$ & $8 \mathrm{a}$ & $16_{\mathrm{b}}$ & 35 \\
Total & 2048 & 932 & 431 & 3411 \\
\hline
\end{tabular}

Note. Each subscript letter denotes a subset of trauma categories whose column proportions do not differ significantly from each other at the .05 level.

Mental health. There was a significant association between mental health problems and risk categories of DRAOR total scores, $X^{2}=520.16, p<.001, \varphi_{\mathrm{c}}=.28$. Higher risk cases were rated to have greater mental health problems. Post hoc analyses showed that as rates of mental health problems increased, individuals who are low risk significantly decreased (no apparent mental health problems, 67.6\%; slight mental health problems, 26.4\%; definite mental health problems, $6.0 \%$ ). For the moderate risk category, there were significantly higher frequencies of individuals who had slight mental health 
problems (36.0\%) compared to individuals with definite mental health problems $(16.8 \%)$.

There were no significant differences between frequencies of individuals with no apparent mental health problems (47.2\%) and individuals with slight mental health problems. Nor was there a significant difference between frequencies of individuals with no apparent mental health problems and individuals with definite mental health problems for the moderate risk group. For the moderate/high risk category, prevalence rates significantly increased as mental health problems increased (no apparent mental health problems, $28.7 \%$; slight mental health problems, $34.9 \%$; definite mental health problems, 36.4\%). Finally, for the high risk category, there were significantly higher frequencies of individuals with definite mental health problems (65.7\%) compared to both individuals who had slight mental health problems (20.0\%) and individuals who had no apparent mental health problems (14.3\%). There were no significant differences between frequencies of individuals with no apparent mental health problems and individuals with slight mental health problems for the high risk group (Table 4).

\section{Table 4}

Frequencies of mental health scores across categories of DRAOR risk scores.

\begin{tabular}{lllll}
\hline Risk Category & Mental Health L0 & $\begin{array}{l}\text { Mental Health } \\
\text { L1 }\end{array}$ & Mental Health L2 & Total \\
\hline Low & $803_{\mathrm{a}}$ & $314_{\mathrm{b}}$ & $71_{\mathrm{c}}$ & 1188 \\
Moderate & $509_{\mathrm{a}, \mathrm{b}}$ & $388_{\mathrm{b}}$ & $181_{\mathrm{a}}$ & 1078 \\
Moderate/high & $319_{\mathrm{a}}$ & $387_{\mathrm{b}}$ & $404_{\mathrm{c}}$ & 1110 \\
High & $5_{\mathrm{a}}$ & $7 \mathrm{a}$ & $23_{\mathrm{b}}$ & 35 \\
Total & 1636 & 1096 & 679 & 3411 \\
\hline
\end{tabular}

Note. Each subscript letter denotes a subset of trauma categories whose column proportions do not differ significantly from each other at the .05 level.

Self-efficacy. There was a significant association between self-efficacy problems and risk categories of DRAOR total scores, $X^{2}=1147.49, p<.001, \varphi_{\mathrm{c}}=.41$. Higher risk 
cases were rated to have greater self-efficacy problems. Post hoc analyses showed that for the low risk category, prevalence rates significantly decreased as self-efficacy problems increased (no apparent self-efficacy problems, 70.6\%; slight self-efficacy problems, $27.1 \%$; definite self-efficacy problems, $2.3 \%$ ). For the moderate risk category, frequency rates were significantly higher for individuals with slight self-efficacy problems (57.5\%) compared to both individuals with no apparent self-efficacy problems $(32.3 \%)$ and individuals with definite self-efficacy problems (10.2\%). There were also significantly higher frequencies of individuals with no apparent self-efficacy problems compared to individuals with definite self-efficacy problems among those in the moderate risk category. For the moderate/high risk group, frequency rates were significantly higher for individuals with slight self-efficacy problems (52.3\%) compared to both individuals with no apparent self-efficacy problems (12.9\%) and individuals with definite self-efficacy problems $(34.8 \%)$. There were also significantly higher frequencies of individuals with definite self-efficacy problems compared to individuals with no apparent self-efficacy problems. Finally, for the high risk group, frequency rates of individuals with definite self-efficacy problems (77.1\%) were significantly higher compared to both individuals with slight self-efficacy problems (17.1\%) and individuals with no apparent self-efficacy problems (5.7\%). There were no significant differences between frequencies of high risk individuals with no apparent self-efficacy problems and individuals with slight selfefficacy problems (Table 5). 
Table 5

Frequencies of self-efficacy scores across categories of DRAOR risk scores.

\begin{tabular}{lllll}
\hline Risk Category & Self-efficacy L0 & Self-efficacy L1 & Self-efficacy L2 & Total \\
\hline Low & $839_{\mathrm{a}}$ & $322_{\mathrm{b}}$ & $27_{\mathrm{c}}$ & 1188 \\
Moderate & $348_{\mathrm{a}}$ & $620_{\mathrm{b}}$ & $110_{\mathrm{c}}$ & 1078 \\
Moderate/high & $143_{\mathrm{a}}$ & $581_{\mathrm{b}}$ & $386_{\mathrm{c}}$ & 1110 \\
High & $2 \mathrm{a}$ & $66_{\mathrm{a}}$ & $27_{\mathrm{b}}$ & 35 \\
Total & 1332 & 1529 & 550 & 3411 \\
\hline
\end{tabular}

Note. Each subscript letter denotes a subset of trauma categories whose column proportions do not differ significantly from each other at the .05 level.

\section{Correlations between variables of interest}

Bivariate correlations were calculated between all variables of interest. Aside from self-efficacy, which had negative significant correlations with other variables, all variables of interest had positive significant correlations. The majority of correlations were moderate, with some displaying strong associations (Table 6). 
Table 6

Correlations between variables of interest.

\begin{tabular}{|c|c|c|c|c|c|c|c|c|c|c|c|}
\hline & 1 & 2 & 3 & 4 & 5 & 6 & 7 & 8 & 9 & 10 & 11 \\
\hline 1. Total DRAOR Score ${ }^{\dagger}$ & 1 & .76 & .80 & -.90 & .26 & .34 & .56 & .65 & .58 & .38 & .22 \\
\hline 2. Stable Dynamic Risk ${ }^{\dagger}$ & & 1 & .55 & -.55 & .23 & .33 & .50 & .62 & .58 & .32 & .20 \\
\hline 3. Acute Dynamic Risk ${ }^{\dagger}$ & & & 1 & -.49 & .25 & .31 & .42 & .50 & .50 & .29 & .16 \\
\hline 4. Protective Factor & & & & 1 & -.18 & -.25 & -.49 & -.54 & -.44 & -.34 & -.20 \\
\hline 5. Trauma & & & & & 1 & .39 & .27 & .19 & .33 & .13 & $.04 *$ \\
\hline 6. Mental Health & & & & & & 1 & .34 & .26 & .56 & .21 & .10 \\
\hline 7. Self-efficacy & & & & & & & 1 & .43 & .42 & .27 & .18 \\
\hline 8. Antisocial Tendencies & & & & & & & & 1 & .55 & .35 & .20 \\
\hline 9. Emotional Distress & & & & & & & & & 1 & .33 & .17 \\
\hline 10. Substance Abuse & & & & & & & & & & 1 & .19 \\
\hline 11. Recidivism & & & & & & & & & & & 1 \\
\hline
\end{tabular}

Note. *Denotes correlation significant at .05 level; all other correlations significant at .01 level

${ }^{\dagger}$ Scales revised whereby items from new antisocial tendency, emotional distress, and substance abuse scales were taken out so as to avoid overlap in items being correlated. 


\section{Study 1: Trauma}

\section{Trauma and DRAOR scores}

Total DRAOR scores. Overall, there was a significant difference in total DRAOR scores relating from trauma problems, $F(2,3408)=154.50, p<.001, \mathrm{R}^{2}=.08$. Higher trauma problems were associated with higher total DRAOR scores. There was a significant difference between no apparent trauma problems and slight trauma problems, $t$ $=11.59, p<.001, r=.04$. Moving from no apparent trauma problems to slight trauma problems, total DRAOR scores increased by 3.38 units. There was also a significant difference between no apparent trauma problems and definite trauma problems, $t=15.56$, $p<.001, r=.07$. Moving from no apparent trauma problems to definite trauma problems, total DRAOR scores increased by 6.09 units (Table 7).

Table 7

Relationship between trauma problems and total DRAOR scores

\begin{tabular}{llllll}
\hline Trauma Category & $\mathrm{B}(\mathrm{SE})$ & $t$-value & $p$-value & $95 \% \mathrm{CI}$ & $r$ \\
\hline Slight trauma problems & 3.38 & 11.59 & $<.001$ & {$[2.81,3.95]$} & .04 \\
& $(.29)$ & & & & \\
$\begin{array}{l}\text { Definite trauma } \\
\text { problems }\end{array}$ & $\begin{array}{l}6.09 \\
(.39)\end{array}$ & 15.56 & $<.001$ & {$[5.32,6.86]$} & .07 \\
\hline
\end{tabular}

Substance abuse scores. Substance abuse scores were calculated using the substance abuse item in the acute dynamic risk subscale. Overall, there was a significant difference in likelihood of substance abuse relating from trauma problems, $X^{2}(2,3411)=$ 22.07, $p<.001$. Higher trauma scores were related to higher odds of substance abuse. Individuals with slight trauma problems were 1.35 times more likely to have a substance abuse problem than those with no apparent trauma problems, $p<.001$, indicating a less than small effect size. Individuals with definite trauma problems are 3.02 times more 
likely to have a substance abuse problem than those with no apparent trauma problems, $p$ $<.001$, indicating a small to moderate effect size.

Antisocial tendency scores. Antisocial tendency scores were calculated by summing scores from the peer associations, attitudes towards authority, and sense of entitlement items from the stable dynamic risk subscale. Overall, there was a significant difference in antisocial tendency scores relating from trauma problems, $F(2,3408)=$ $63.84, p<.001, R^{2}=.04$. Higher trauma scores were associated with higher antisocial tendency scores. There was a significant difference between no apparent trauma problems and slight trauma problems on antisocial tendency scores, $t=7.75, p<.001, r=.04$. Moving from no apparent trauma problems to slight trauma problems, antisocial tendency scores increased by .50 units. There was also a significant difference between no apparent trauma problems and definite trauma problems on antisocial tendency scores, $t=9.81, p$ $<.001, r=.09$. Moving from no apparent trauma problems to definite trauma problems, antisocial tendency scores increased by .85 units (Table 8 ).

Table 8

Relationship between trauma problems and antisocial tendency scores

\begin{tabular}{llllll}
\hline Trauma Category & $\mathrm{B}(\mathrm{SE})$ & $t$-value & $p$-value & $95 \% \mathrm{CI}$ & $r$ \\
\hline Slight trauma problems & 0.50 & 7.75 & $<.001$ & {$[0.37,0.62]$} & .04 \\
& $(.06)$ & & & & \\
$\begin{array}{l}\text { Definite trauma } \\
\text { problems }\end{array}$ & 0.85 & 9.81 & $<.001$ & {$[0.68,1.01]$} & .09 \\
\hline
\end{tabular}

Emotional distress scores. Emotional distress scores were calculated by summing the anger/hostility, negative mood, and impulse control items from both the stable dynamic risk and acute dynamic risk subscales. Overall, there was a significant difference in emotional distress scores relating from trauma problems, $F(2,3408)=$ 
204.75, $p<.001, R^{2}=.11$. Higher trauma scores were associated with higher emotional distress scores. There was a significant difference between no apparent trauma problems and slight trauma problems, $t=12.30, p<.001, r=.02$. Moving from no apparent trauma problems to slight trauma problems, emotional distress scores increased by .72 units.

There was also a significant difference between no apparent trauma problems and definite trauma problems, $t=18.49, p<.001, r=.03$. Moving from no apparent trauma problems to definite trauma problems, emotional distress scores increased by 1.44 units (Table 9).

Table 9

Relationship between trauma problems and emotional distress scores

\begin{tabular}{llllll}
\hline Trauma Category & $\mathrm{B}(\mathrm{SE})$ & $t$-value & $p$-value & $95 \% \mathrm{CI}$ & $r$ \\
\hline Slight trauma problems & 0.72 & 12.30 & $<.001$ & {$[0.60,0.83]$} & .02 \\
& $(.06)$ & & & & \\
$\begin{array}{l}\text { Definite trauma } \\
\text { problems }\end{array}$ & 1.44 & 18.49 & $<.001$ & {$[1.29,1.60]$} & .03 \\
\hline
\end{tabular}

\section{Trauma problems and recidivism}

Overall, there was a significant difference in likelihood of recidivism relating from trauma problems, $X^{2}=11.18, p=.004$. Individuals with slight trauma problems were 1.30 times more likely to recidivate than those with no apparent trauma problems, $p$ $=.001$, indicating a small effect size. There was no significant difference in likelihood of recidivating between individuals with no apparent trauma problems and individuals with definite trauma problems, n.s.

\section{Trauma problems and incremental prediction}

On their own, trauma scores were not more predictive than total DRAOR scores at predicting recidivism. Trauma scores did not predict recidivism scores above chance $(\mathrm{AUC}=.525)$. Total DRAOR scores, in contrast, displayed moderate predictive ability 
$($ AUC $=.643 ;$ Table 10$)$. When added to the measurement of DRAOR total scores, trauma scores significantly incrementally predicted recidivism, $X^{2}=6.85, p=.033$. When considering both trauma scores and total DRAOR scores, individuals with definite trauma problems were .76 times less likely to recidivate than those with no apparent trauma problems, $p=.018$. This indicates a small to moderate effect size. There were no significant differences between individuals with slight trauma problems and individuals with no apparent trauma problems, $n . s$.

Table 10

AUC analyses of the association between recidivism and both trauma problems and total DRAOR scores, separately

\begin{tabular}{lccccc}
\hline Scale & $\mathrm{N}$ & $\mathrm{AUC}$ & $\mathrm{SE}$ & $p$ & $95 \% \mathrm{CI}$ \\
\hline Trauma problems & 3411 & .53 & .01 & .013 & {$[.51, .54]$} \\
Total DRAOR Scores & 3411 & .64 & .01 & $<.001$ & {$[.62, .66]$} \\
\hline
\end{tabular}

\section{Interactions between trauma problems and DRAOR subscales}

Interactions were explored between trauma and stable dynamic scores, trauma and acute dynamic scores, and trauma and protective factor scores. There were no significant interactions between trauma scores and any DRAOR subscales (Figure 1-3; Table 11-13). 
Figure 1

Interaction between trauma problems and stable dynamic risk scores.

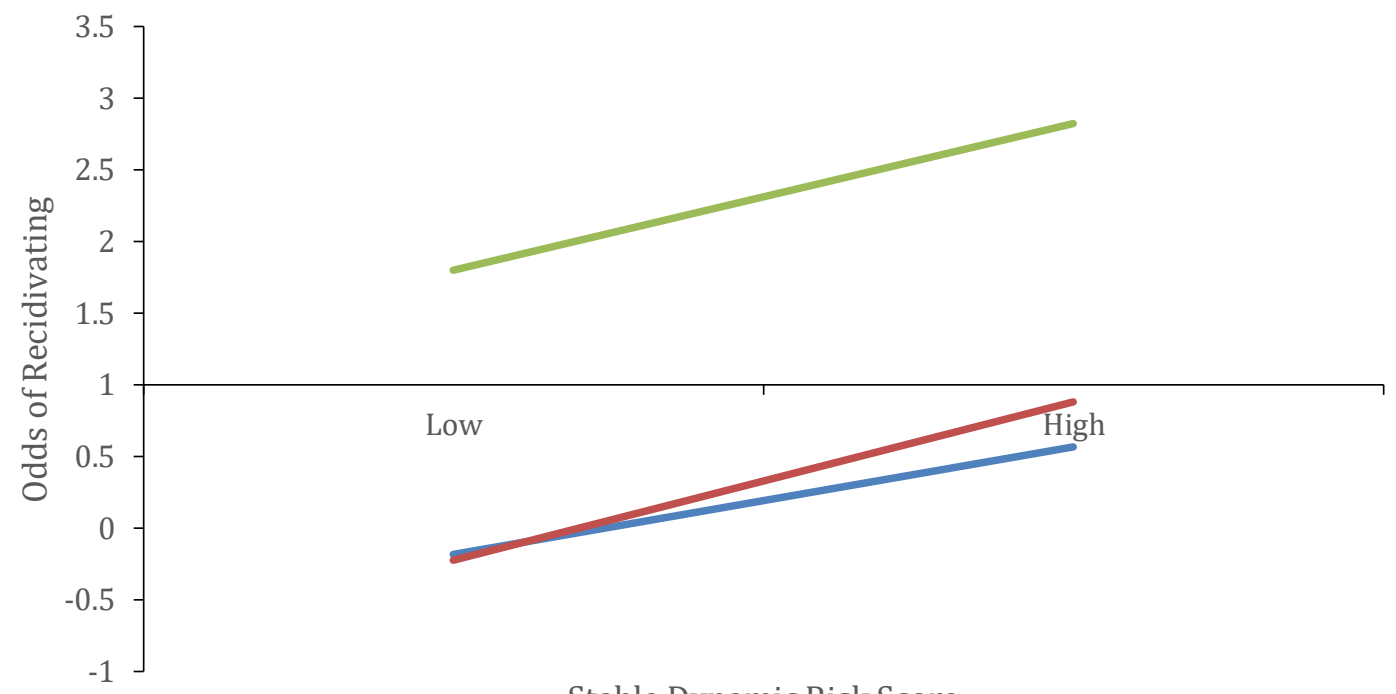

Stable Dynamic Risk Score

—Trauma L0 —Trauma L1 —Trauma L2

Table 11

Interaction between trauma problems and stable dynamic risk scores.

\begin{tabular}{llllll}
\hline Block & Predictor & B (SE) & OR & $95 \%$ CI & $X^{2}$ \\
\hline 1 & Trauma L1 & $0.10(.08)$ & 1.10 & {$[0.94,1.30]$} & $195.32^{* *}$ \\
& Trauma L2 & $-0.18(.08)$ & 0.84 & {$[0.67,1.05]$} & \\
& Stable Dynamic Score & $0.17(.08)^{* *}$ & 1.18 & {$[1.16,1.22]$} & \\
\hline 2 & Trauma L1 & $0.30(.19)$ & 1.35 & {$[0.93,1.96]$} & 3.08 \\
& Trauma L2 & $0.21(.28)$ & 1.23 & {$[0.71,2.14]$} & \\
& Stable Dynamic Score & $0.19(.02)^{* *}$ & 1.21 & {$[1.17,1.25]$} & \\
& Trauma L1*Stable & $-0.04(.03)$ & 0.96 & {$[0.91,1.02]$} & \\
& Dynamic Score & & & & \\
& Trauma L2*Stable & $-0.06(.04)$ & 0.94 & {$[0.87,1.02]$} & \\
& Dynamic Score & & & & \\
\hline
\end{tabular}

Note. OR $=$ Odds Ratio $; 95 \% \mathrm{CI}=95 \%$ Confidence Interval for Odds Ratio; $X^{2}=$ Chisquare. Trauma $\mathrm{L} 1=$ coded as 1 . Trauma $\mathrm{L} 2=$ coded as 2 . Trauma coded as 0 is reference category.

$* p<.05 ; * * p<.01$. 
Figure 2

Interaction between trauma problems and acute dynamic risk scores.

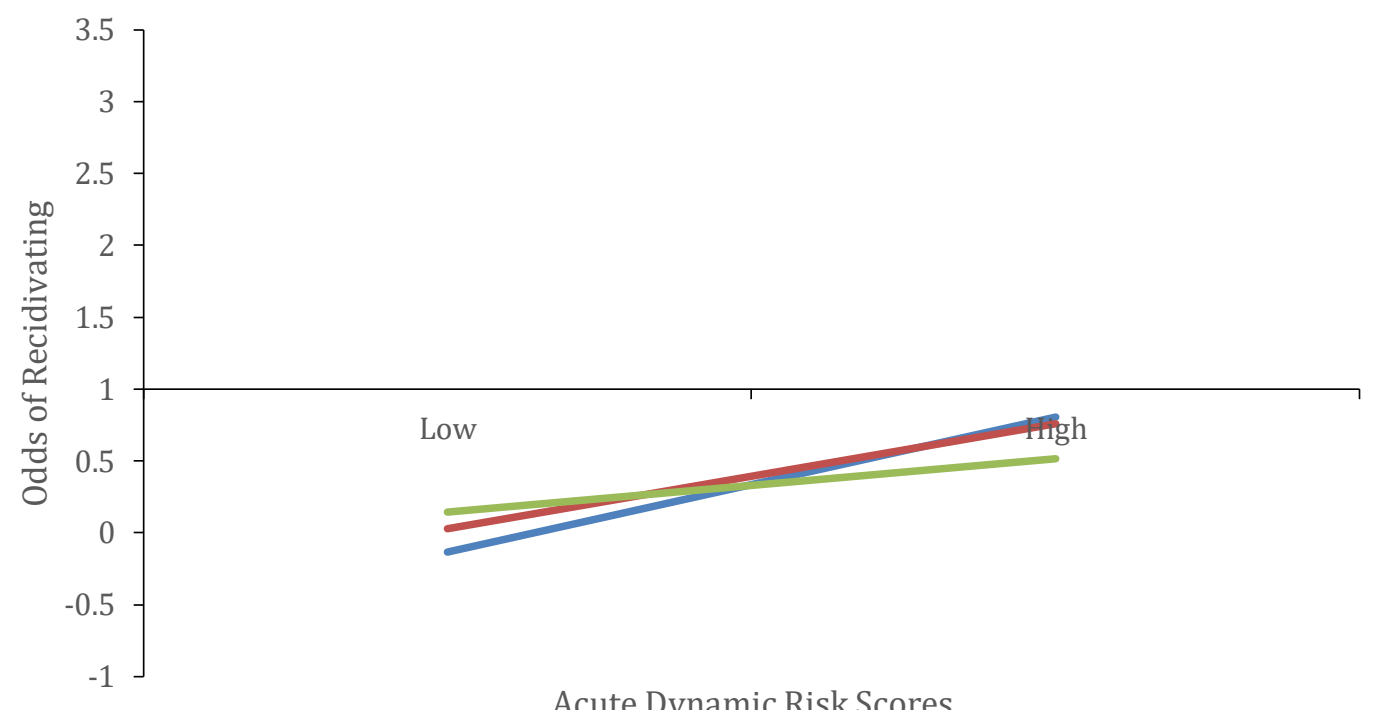

Acute Dynamic Risk Scores

-Trauma L0 —Trauma L1 —Trauma L2

\section{Table 12}

Interaction between trauma problems and acute dynamic risk scores.

\begin{tabular}{llllll}
\hline Block & Predictor & B (SE) & OR & $95 \%$ CI & $X^{2}$ \\
\hline 1 & Trauma L1 & $0.06(.08)$ & 1.06 & {$[0.90,1.25]$} & $137.90^{* *}$ \\
& Trauma L2 & $-0.23(.12)$ & 0.80 & {$[0.64,1.00]$} & \\
& Acute Dynamic Score & $0.14(.01)^{* *}$ & 1.15 & {$[1.12,1.18]$} & \\
\hline 2 & Trauma L1 & $0.27(.20)$ & 1.31 & {$[0.88,1.95]$} & 2.33 \\
& Trauma L2 & $0.11(.31)$ & 1.11 & {$[0.61,2.02]$} & \\
& Acute Dynamic Score & $0.16(.02)^{* *}$ & 1.17 & {$[1.13,1.21]$} & \\
& Trauma L1*Acute & $-0.03(.03)$ & 0.97 & {$[0.91,1.02]$} & \\
& Dynamic Score & & & & \\
& Trauma L2*Acute & $-0.05(.04)$ & 0.96 & {$[0.89,1.03]$} & \\
& Dynamic Score & & & & \\
\end{tabular}

Note. OR $=$ Odds Ratio; $95 \%$ CI $=95 \%$ Confidence Interval for Odds Ratio $X^{2}=$ Chisquare. Trauma $\mathrm{L} 1=$ coded as 1 . Trauma $\mathrm{L} 2=$ coded as 2 . Trauma coded as 0 is reference category.

${ }^{*} p<.05 ; * * p<.01$. 
Figure 3

Interaction between trauma problems and protective factor scores.

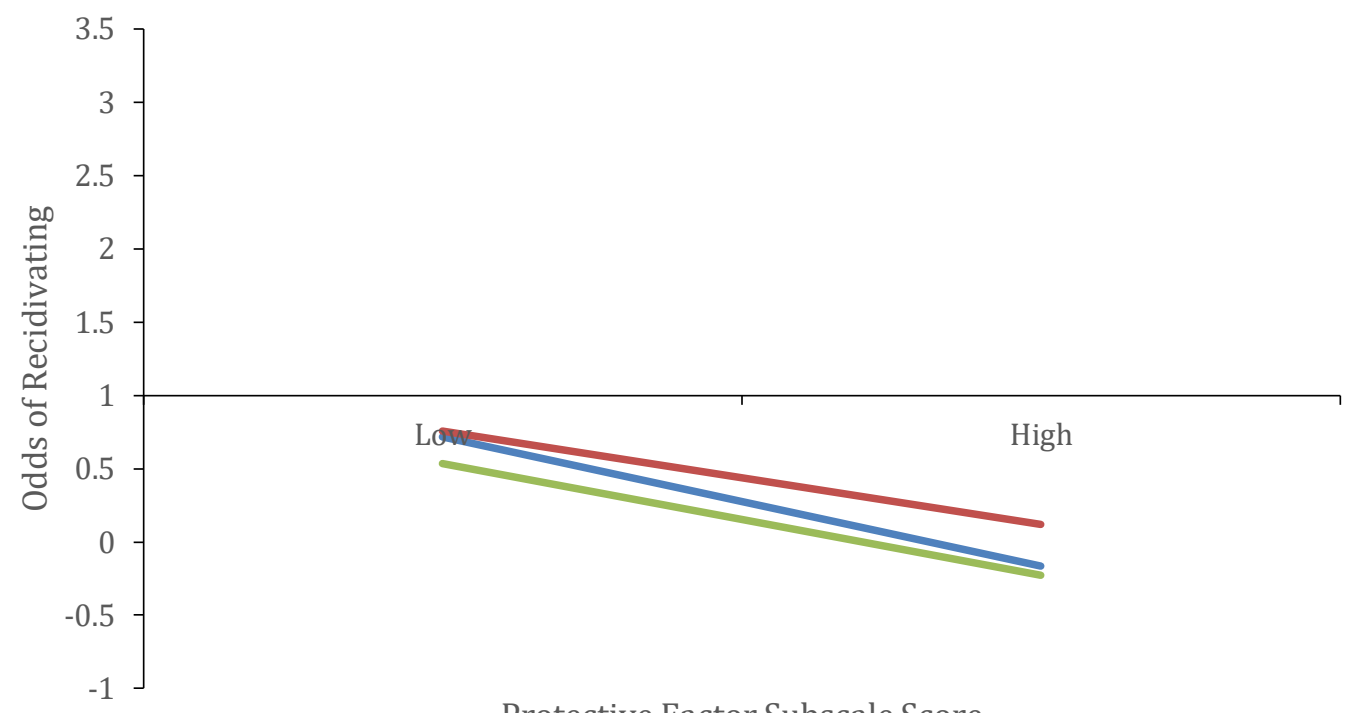

Protective Factor Subscale Score

$\longrightarrow$ Trauma L0 $\longrightarrow$ Trauma L1 $\longrightarrow$ Trauma L2

Table 13

Interaction between trauma problems and protective factor scores.

\begin{tabular}{llllll}
\hline Block & Predictor & B (SE) & OR & $95 \%$ CI & $X^{2}$ \\
\hline 1 & Trauma L1 & $0.16(.08)$ & 1.17 & {$[1.00,1.38]$} & $137.68^{* *}$ \\
& Trauma L2 & $-0.05(.11)$ & 0.95 & {$[0.76,1.18]$} & \\
& Protective Score & $-0.14(.01)^{* *}$ & 0.87 & {$[0.85,0.89]$} & \\
\hline 2 & Trauma L1 & $-0.08(.19)$ & 0.92 & {$[0.63,1.35]$} & 1.89 \\
& Trauma L2 & $-0.12(.22)$ & 0.89 & {$[0.57,1.37]$} & \\
& Protective Score & $-0.15(.02)^{* *}$ & 0.86 & {$[0.84,0.89]$} & \\
& Trauma L1*Protective & $0.04(.03)$ & 1.04 & {$[0.98,1.10]$} & \\
& Score & & & & \\
& Trauma L2*Protective & $0.01(.04)$ & 1.01 & {$[0.94,1.09]$} & \\
& Score & & & & \\
& & & & &
\end{tabular}

Note. OR = Odds Ratio; 95\% CI = 95\% Confidence Interval for Odds Ratio; $X^{2}=$ Chisquare. Trauma L1 $=$ coded as 1 . Trauma L2 $=$ coded as 2 . Trauma coded as 0 is reference category.

$* p<.05 ; * * p<.01$. 


\section{Study 2: Mental health}

\section{Mental health problems and DRAOR scores}

Total DRAOR scores. Overall, there was a significant difference in DRAOR scores relating from mental health problems, $F(2,3408)=357.93, p<.001, R^{2}=.17$. Higher mental health problems were associated with higher total DRAOR scores. There was a significant difference in DRAOR scores between individuals with no apparent mental health problems and slight mental health problems, $t=13.08, p<.001, r=.05$. Moving from no apparent mental health problems to slight mental health problems, total DRAOR scores increased by 3.58 units. There was also a significant difference in DRAOR scores between individuals with no apparent mental health problems and definite mental health problems, $t=26.41, p<.001, r=.17$. Moving from no apparent mental health problems to definite mental health problems, total DRAOR scores increased by 8.46 units (Table 14).

Table 14

Relationship between mental health problems and total DRAOR scores

\begin{tabular}{llllll}
\hline Mental Health Category & $\mathrm{B}(\mathrm{SE})$ & $t$-value & $p$-value & $95 \% \mathrm{CI}$ & $r$ \\
\hline $\begin{array}{l}\text { Slight mental health } \\
\text { problems }\end{array}$ & $3.58(.27)$ & 13.08 & $<.001$ & {$[3.05,4.12]$} & .05 \\
$\begin{array}{l}\text { Definite mental health } \\
\text { problems }\end{array}$ & $8.46(.32)$ & 26.41 & $<.001$ & {$[7.83,9.09]$} & .17 \\
\hline
\end{tabular}

Substance abuse scores. Substance abuse scores were calculated using the substance abuse item in the acute dynamic risk subscale. Overall, there was a significant difference in likelihood of substance abuse relating from mental health problems, $X^{2}(2$, $3411)=83.18, p<.001$. Higher mental health problems were related to higher odds of substance abuse. Individuals with slight mental health problems were 1.80 times more 
likely to have a substance abuse problem than those who had no apparent mental health problems, $p<.001$, indicating a small effect size. Individuals who had definite mental health problems were 2.64 times more likely to have a substance abuse problem than individuals with no apparent mental health problems, $p<.001$, indicting a small to moderate effect size.

Antisocial tendency scores. Antisocial tendency scores were calculated by summing scores from the peer associations, attitudes towards authority, and sense of entitlement items from the stable dynamic risk subscale. Overall, there was a significant difference in antisocial tendency scores relating from mental health problems, $F(2,3408)$ $=125.94, p<.001, R^{2}=.07$. Higher mental health problems were associated with higher antisocial tendency scores. There was a significant difference between no apparent mental health problems and slight mental health problems, $t=7.80, p<.001, r=.02$. Moving from no apparent mental health problems to slight mental health problems, antisocial tendency scores increased by .49 units. There was also a significant difference between no apparent mental health problems and definite mental health problems, $t=$ $15.66, p<.001, r=.07$. Moving from no apparent mental health problems to definite mental health problems, antisocial tendency scores increased by 1.14 units (Table 15).

\section{Table 15}

Relationship between mental health problems and antisocial tendency scores

\begin{tabular}{llclll}
\hline Mental Health Category & $\mathrm{B}(\mathrm{SE})$ & $t$-value & $p$-value & $95 \% \mathrm{CI}$ & $r$ \\
\hline $\begin{array}{l}\text { Slight mental health } \\
\text { problems }\end{array}$ & $0.49(.06)$ & 7.80 & $<.001$ & {$[0.37,0.61]$} & .02 \\
$\begin{array}{l}\text { Definite mental health } \\
\text { problems }\end{array}$ & $1.14(.07)$ & 15.66 & $<.001$ & {$[1.00,1.29]$} & .07 \\
\hline
\end{tabular}


Emotional distress scores. Emotional distress scores were calculated by summing the anger/hostility, negative mood, and impulse control items from both the stable dynamic risk and acute dynamic risk subscales. Overall, there was a significant difference in emotional distress scores relating from mental health problems, $F(2,3408)$ $=791.89, p<.001, R^{2}=.32$. Higher mental health problems were associated with higher emotional distress scores. There was a significant difference between no apparent mental health problems and slight mental health problems, $t=20.79, p<.001, r=.11$. Moving from no apparent mental health problems to slight mental health problems, emotional distress scores increased by 1.05 units. There was also a significant difference between no apparent mental health problems and definite mental health problems, $t=39.01, p<$ $.001, r=.31$. Moving from no apparent mental health problems to definite mental health problems, emotional distress scores increased by 2.29 units (Table 16).

Table 16

Relationship between mental health problems and emotional distress scores

\begin{tabular}{llllll}
\hline Mental Health Category & $\mathrm{B}(\mathrm{SE})$ & $t$-value & $p$-value & $95 \% \mathrm{CI}$ & $r$ \\
\hline $\begin{array}{l}\text { Slight mental health } \\
\text { problems }\end{array}$ & $1.05(.05)$ & 20.79 & $<.001$ & {$[0.95,1.14]$} & .11 \\
$\begin{array}{l}\text { Definite mental health } \\
\text { problems }\end{array}$ & $2.29(.06)$ & 39.01 & $<.001$ & {$[2.18,2.41]$} & .31 \\
\hline
\end{tabular}

\section{Mental health problems and recidivism}

Overall, there was a significant difference in likelihood of recidivating relating from mental health problems, $X^{2}=38.16, p<.001$. Higher mental health problems were related to higher odds of recidivism. Individuals who had slight mental health problems were 1.44 times more likely to recidivate than those with no apparent mental health problems, $p<.001$. Individuals with definite mental health problems were 1.66 times 
more likely to recidivate than those with no apparent mental health problems, $p<.001$.

Effect sizes were small for both comparisons.

\section{Mental health problems and incremental prediction}

On their own, mental health problems were not more predictive than total DRAOR scores at predicting recidivism. Mental health problems did not predict recidivism above chance $(\mathrm{AUC}=.556)$. Total DRAOR scores, in contrast, displayed moderate predictive ability $(\mathrm{AUC}=.643$; Table 17$)$. When added to the measurement of DRAOR total scores, mental health problems did not incrementally predict recidivism, $X^{2}$ $=3.91$, n.s.

Table 17

AUC Analyses of the Association Between Recidivism and both Mental Health Problems and Total DRAOR Scores, Separately

\begin{tabular}{lccccc}
\hline Scale & $\mathrm{N}$ & AUC & SE & $p$ & $95 \% \mathrm{CI}$ \\
\hline $\begin{array}{l}\text { Mental health } \\
\text { problems }\end{array}$ & 3411 & .56 & .01 & $<.001$ & {$[.54, .58]$} \\
Total DRAOR scores & 3411 & .64 & .01 & $<.001$ & {$[.62, .66]$} \\
\hline
\end{tabular}

\section{Interactions between mental health problems and DRAOR subscales}

Interactions were explored between mental health problems and stable dynamic subscale scores, acute dynamic subscale scores, and protective subscale scores.

Mental Health Problems and Stable Dynamic Risk Scores. There was a significant interaction between mental health problems and stable dynamic risk scores when comparing individuals with no apparent mental health problems to individuals with slight mental health problems (Figure 4; Table 18). When stable dynamic risk scores were low, individuals with no apparent mental health problems had lower odds of 
recidivating than individuals with slight mental health problems. As stable dynamic risk scores increased, odds of recidivating for individuals with no apparent mental health problems increased at a quicker rate than individuals with slight mental health problems, resulting in those with no apparent mental health problems eventually having higher odds. Additionally, there was a significant interaction between mental health problems and stable dynamic risk scores when comparing individuals with no apparent mental health problems to individuals with definite mental health problems (Figure 4; Table 18). Again, individuals with no apparent mental health problems had lower odds of recidivating when stable dynamic risk scores were low and higher odds of recidivating when stable dynamic risk scores were high compared to individuals with definite mental health problems. However, individuals with definite mental health problems showed a decrease in odds of recidivating as stable dynamic risk scores increased.

Figure 4

Interaction between mental health problems and stable dynamic risk scores.

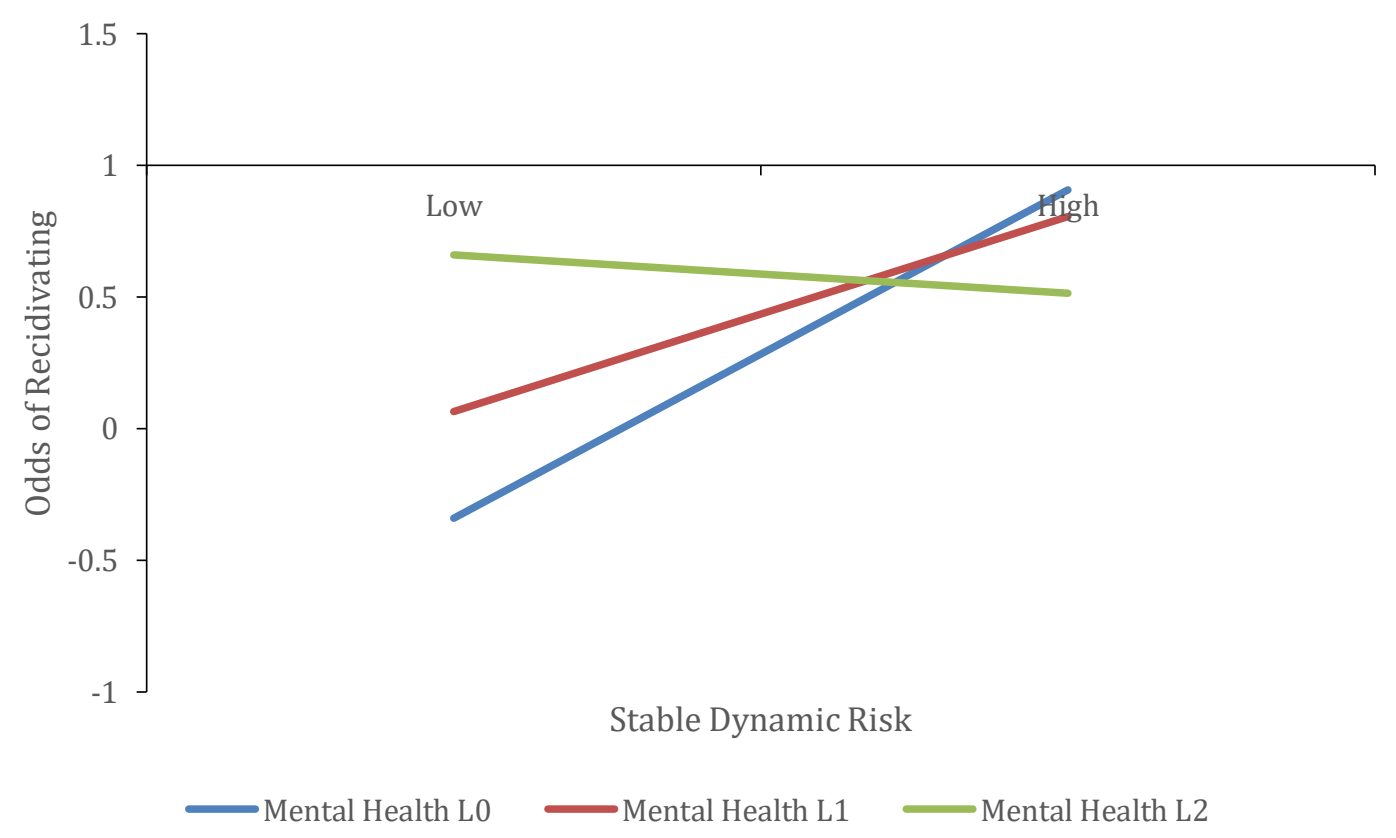


Table 18

Interaction between mental health problems and stable dynamic risk scores.

\begin{tabular}{llllll}
\hline Block & Predictor & B (SE) & OR & $95 \%$ CI & $X^{2}$ \\
\hline 1 & Mental Health L1 & $0.20(.08)^{*}$ & 1.22 & {$[1.04,1.44]$} & $196.33^{* *}$ \\
& Mental Health L2 & $0.09(.10)$ & 1.10 & {$[0.90,1.34]$} & \\
& Stable Dynamic Score & 0.16 & 1.18 & {$[1.15,1.21]$} & \\
& & $\left((.01)^{* *}\right.$ & & & \\
\hline 2 & Mental Health L1 & $0.65(.18)^{* *}$ & 1.91 & {$[1.34,2.72]$} & $14.13^{* *}$ \\
& Mental Health L2 & $0.83(.26)^{* *}$ & 2.29 & {$[1.37,3.84]$} & \\
& Stable Dynamic Score & $0.21(.02)^{* *}$ & 1.24 & {$[1.19,1.28]$} & \\
& Mental Health & $-0.09(.03)^{* *}$ & 0.92 & {$[0.87,0.97]$} & \\
& L1*Stable Dynamic & & & & \\
& Score & & & & \\
& Mental Health & $-0.12(.04)^{* *}$ & 0.90 & {$[0.83,0.95]$} & \\
& L2*Stable Dynamic & & & & \\
Score & & & & \\
\end{tabular}

Note. OR $=$ Odds Ratio; 95\% CI = 95\% Confidence Interval for Odds Ratio; $X^{2}=$ Chisquare. Mental Health L1 $=$ coded as 1 . Mental Health L2 = coded as 2. Mental Health coded as 0 is reference category.

$* p<.05 ; * * p<.01$.

Mental Health Problems and Acute Dynamic Risk Scores. There was a significant interaction between mental health scores and acute dynamic subscale scores when comparing individuals with no apparent mental health problems to individuals with definite mental health problems (Figure 5; Table 19). When acute dynamic risk subscale scores were low, individuals with no apparent mental health problems had lower odds of recidivating than individuals with definite mental health problems. As acute dynamic risk scores increased, odds of recidivating for individuals with no apparent mental health problems increased, whereas odds of recidivating for individuals with definite mental health problems decreased, resulting in those with no apparent mental health problems having higher odds. There was no significant interaction between mental health problems 
and acute dynamic risk scores when comparing individuals with no apparent mental health problems to individuals with slight mental health problems (Figure 5; Table 19).

Figure 5

Interaction between mental health problems and acute dynamic risk scores.

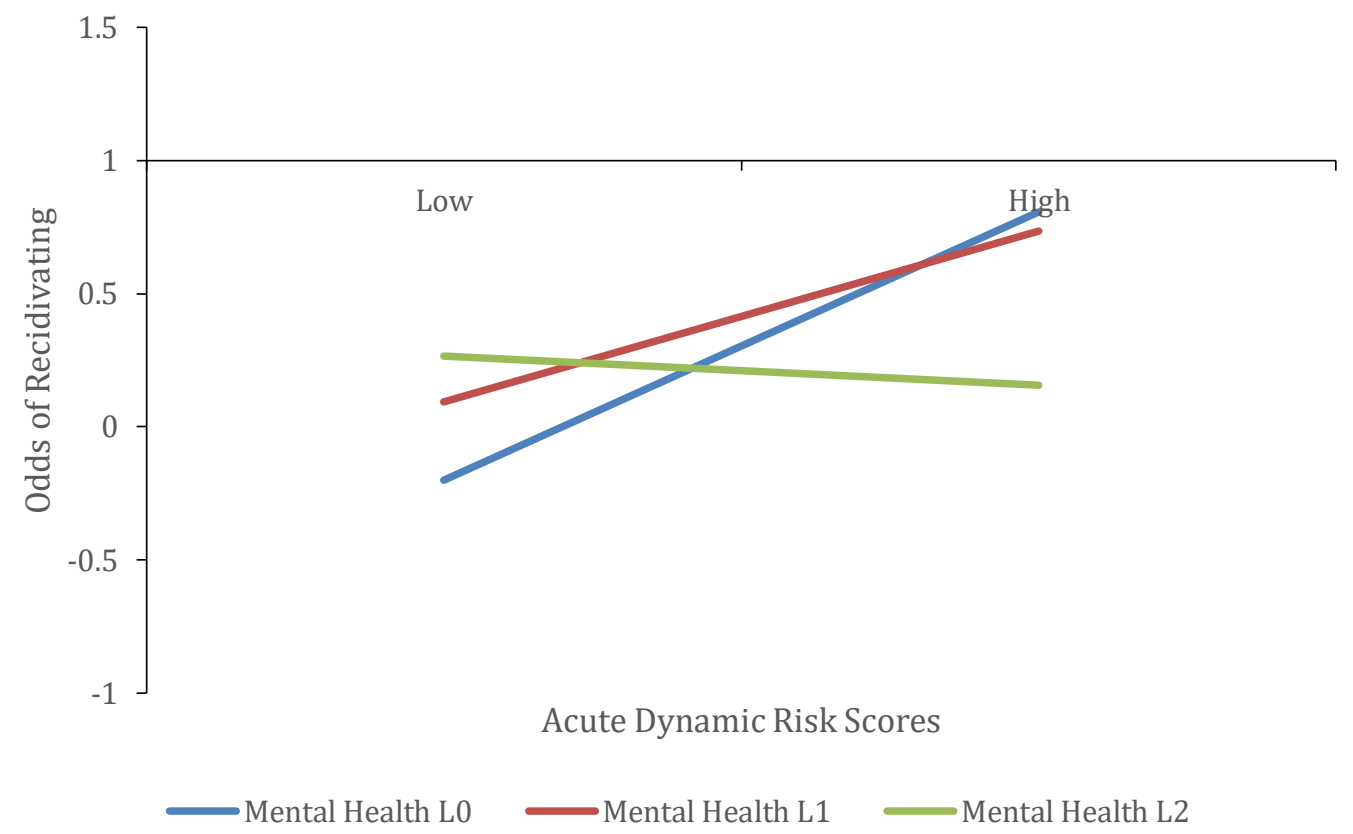

Table 19

Interaction between mental health problems and acute dynamic risk scores.

\begin{tabular}{llllll}
\hline Block & Predictor & B (SE) & OR & $95 \%$ CI & $X^{2}$ \\
\hline 1 & Mental Health L1 & $0.15(.08)$ & 1.17 & {$[0.99,1.37]$} & $136.06^{* *}$ \\
& Mental Health L2 & $0.02(.11)$ & 1.02 & {$[0.83,1.26]$} & \\
& Acute Dynamic Score & $0.12(.01)^{* *}$ & 1.14 & {$[1.11,1.17]$} & \\
\hline 2 & Mental Health L1 & $0.48(.20)^{*}$ & 1.62 & {$[1.10,2.39]$} & 5.91 \\
& Mental Health L2 & $0.53(.29)$ & 1.69 & {$[0.96,3.00]$} & \\
& Acute Dynamic Score & $0.17(.02)^{* *}$ & 1.18 & {$[1.14,1.23]$} & \\
& Mental Health & $-0.06(.03)$ & 0.94 & {$[0.89,1.00]$} & \\
& L1*Acute Dynamic & & & & \\
Score & & & & \\
Mental Health & $-0.07(.04)^{*}$ & 0.93 & {$[0.87,1.00]$} & \\
& L2*Acute Dynamic & & & & \\
Score & & & & & \\
\hline
\end{tabular}


Note. OR $=$ Odds Ratio $; 95 \% \mathrm{CI}=95 \%$ Confidence Interval for Odds Ratio; $X^{2}=$ Chisquare. Mental Health L1 $=$ coded as 1 . Mental Health L2 = coded as 2. Mental Health coded as 0 is reference category. $* p<.05 ; * * p<.01$.

Mental Health Problems and Protective Factor Scores. There was a significant interaction between mental health problems and protective factor subscale scores when comparing individuals with no apparent mental health problems to individuals with slight mental health problems (Figure 6; Table 20). Odds of recidivating were higher when protective factor scores were low compared to when scores were high for both groups. Odds of recidivating for individuals with no apparent mental health problems decreased at a steeper rate as protective factor scores increased compared to individuals with slight mental health problems. There was also a significant interaction between mental health problems and protective factor subscale scores when comparing individuals with no apparent mental health problems to individuals with definite mental health problems (Figure 6; Table 20). Individuals with no apparent mental health problems showed decreasing odds of recidivating as protective factor scores increased, whereas individuals with definite mental health problems showed consistently high odds of recidivating, regardless of protective factor scores. 
Figure 6

Interaction between mental health problems and protective factor scores.

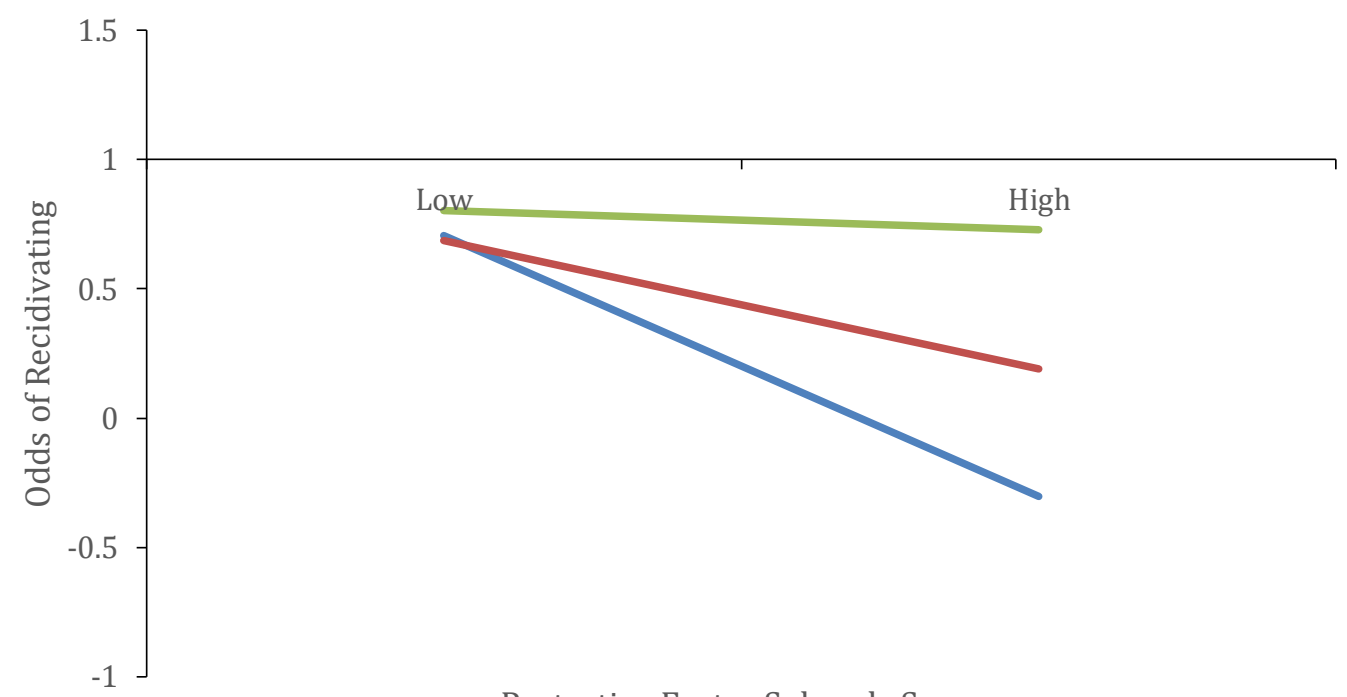

Protective Factor Subscale Score

$\longrightarrow$ Mental Health L0 $\longrightarrow$ Mental Health L1 $\quad$ Mental Health L2

Table 20

Interaction between mental health problems and protective factor scores.

\begin{tabular}{llllll}
\hline Block & Predictor & B (SE) & OR & $95 \%$ CI & $X^{2}$ \\
\hline 1 & Mental Health L1 & $0.27(.08)^{* *}$ & 1.30 & {$[1.11,1.53]$} & $146.61^{* *}$ \\
& Mental Health L2 & $0.27(.10)^{* *}$ & 1.31 & {$[1.08,1.59]$} & \\
& Protective Score & $-0.13(.01)^{* *}$ & 0.88 & {$[0.86,0.90]$} & \\
\hline 2 & Mental Health L1 & $-0.27(.20)$ & 0.77 & {$[0.52,1.12]$} & $10.84^{* *}$ \\
& Mental Health L2 & $-0.18(.20)$ & 0.84 & {$[0.56,1.24]$} & \\
& Protective Score & $-0.17(.02)^{* *}$ & 0.84 & {$[0.81,0.87]$} & \\
& Mental Health & $0.09(.03)^{* *}$ & 1.09 & {$[1.03,1.15]$} & \\
& L1*Protective Score & & & & \\
& Mental Health & $0.08(.03)^{*}$ & 1.08 & {$[1.01,1.16]$} & \\
& L2*Protective Score & & & & \\
\end{tabular}


Note. OR $=$ Odds Ratio $; 95 \% \mathrm{CI}=95 \%$ Confidence Interval for Odds Ratio; $X^{2}=$ Chisquare. Mental Health L1 = coded as 1 . Mental Health L2 = coded as 2. Mental Health coded as 0 is reference category.

$* p<.05 ; * * p<.01$.

\section{Study 3: Self-efficacy}

\section{Self-efficacy problems and DRAOR scores}

Total DRAOR scores. Overall, there was a significant difference in total DRAOR scores relating from self-efficacy problems, $F(2,3408)=833.70, p<.001, R^{2}=$ .33. Higher problems with self-efficacy were associated with higher total DRAOR scores. There was a significant difference between no apparent self-efficacy problems and slight self-efficacy problems, $t=27.32, p<.001, r=.18$. Moving from no apparent selfefficacy problems to slight self-efficacy problems, total DRAOR scores increased by 6.47 units. There was also a significant difference between no apparent self-efficacy problems and definite self-efficacy problems, $t=38.68, p<.001, r=.31$. Moving from no apparent self-efficacy problems to definite self-efficacy problems, total DRAOR scores increased by 12.40 units (Table 21 ).

\section{Table 21}

Relationship between self-efficacy problems and total DRAOR scores

\begin{tabular}{llllll}
\hline Self-efficacy Category & $\mathrm{B}(\mathrm{SE})$ & $t$-value & $p$-value & $95 \%$ CI & $r$ \\
\hline $\begin{array}{l}\text { Slight self-efficacy } \\
\text { problems }\end{array}$ & $6.47(.24)$ & 27.32 & $<.001$ & {$[6.01,6.94]$} & .18 \\
$\begin{array}{l}\text { Definite self-efficacy } \\
\text { problems }\end{array}$ & $\begin{array}{l}12.40 \\
(.32)\end{array}$ & 38.68 & $<.001$ & {$[11.77,13.02]$} & .31 \\
\hline
\end{tabular}


Substance abuse scores. Substance abuse scores were calculated using the substance abuse item in the acute dynamic risk subscale. Overall, there was a significant difference in likelihood of substance abuse relating from self-efficacy problems, $X^{2}(6$, $3411)=129.53, p<.001$. Higher problems with self-efficacy were related to higher odds of substance abuse. Individuals who had slight self-efficacy problems were 2.23 times more likely to have a substance abuse problem than those who had no apparent selfefficacy problems, $p<.001$, indicating a small to moderate effect size. Individuals who had definite self-efficacy problems were 3.53 times more likely to have a substance abuse problem than those with no apparent self-efficacy problems, $p<.001$, indicating a moderate effect size.

Antisocial tendency scores. Antisocial tendency scores were calculated by summing scores from the peer associations, attitudes towards authority, and sense of entitlement items from the stable dynamic risk subscale. Overall, there was a significant difference in antisocial tendency scores relating from self-efficacy problems, $F(2,3408)$ $=380.31, p<.001, \mathrm{R}^{2}=.18$. Higher self-efficacy problems were associated with higher antisocial tendency scores. There was a significant difference between no apparent selfefficacy problems and slight self-efficacy problems, $t=19.47, p<.001, r=.10$. Moving from no apparent self-efficacy problems to slight self-efficacy problems, antisocial tendency scores increased by 1.09 units. There was also a significant difference between no apparent self-efficacy problems and definite self-efficacy problems, $t=25.64, p<$ $.001, r=.16$. Moving from no apparent self-efficacy problems to definite self-efficacy problems, antisocial tendency scores increased by 1.95 units (Table 22). 
Table 22

Relationship between self-efficacy problems and antisocial tendency scores

\begin{tabular}{llllll}
\hline Self-efficacy Category & $\mathrm{B}(\mathrm{SE})$ & $t$-value & $p$-value & $95 \% \mathrm{CI}$ & $r$ \\
\hline $\begin{array}{l}\text { Slight self-efficacy } \\
\text { problems }\end{array}$ & $1.09(.06)$ & 19.47 & $<.001$ & {$[0.98,1.20]$} & .10 \\
$\begin{array}{l}\text { Definite self-efficacy } \\
\text { problems }\end{array}$ & $1.95(.08)$ & 25.64 & $<.001$ & {$[1.80,2.10]$} & .16 \\
\hline
\end{tabular}

Emotional distress scores. Emotional distress scores were calculated by summing the anger/hostility, negative mood, and impulse control items from both the stable dynamic risk and acute dynamic risk subscales. Overall, there was a significant difference in emotional distress scores relating from self-efficacy problems, $F(2,3408)=$ $368.37, p<.001, \mathrm{R}^{2}=.18$. Higher problems with self-efficacy were related to higher emotional distress scores. There was a significant difference between no apparent selfefficacy problems and slight self-efficacy problems, $t=17.85, p<.001, r=.09$. Moving from no apparent self-efficacy problems to slight self-efficacy problems, emotional distress scores increased by .95 units. There was also a significant difference between no apparent self-efficacy problems and definite self-efficacy problems, $t=25.84, p<.001, r$ $=.15$. Moving from no apparent self-efficacy problems to definite self-efficacy problems, emotional distress scores increased by 1.85 units (Table 23).

Table 23

Relationship between self-efficacy problems and emotional distress scores

\begin{tabular}{llllll}
\hline Self-efficacy Category & $\mathrm{B}(\mathrm{SE})$ & $t$-value & $p$-value & $95 \% \mathrm{CI}$ & $r$ \\
\hline $\begin{array}{l}\text { Slight self-efficacy } \\
\text { problems }\end{array}$ & $0.95(.05)$ & 17.85 & $<.001$ & {$[0.84,1.05]$} & .09 \\
$\begin{array}{l}\text { Definite self-efficacy } \\
\text { problems }\end{array}$ & $1.85(.07)$ & 25.84 & $<.001$ & {$[1.71,2.00]$} & .15 \\
\hline
\end{tabular}




\section{Self-efficacy problems and recidivism}

Overall, there was a significant difference in likelihood of recidivating relating from self-efficacy problems, $X^{2}(2,3411)=126.34, p<.001$. Higher problems with selfefficacy were related to higher odds of recidivism. Individuals who had slight selfefficacy problems were 2.03 times more likely to recidivate than those with no apparent self-efficacy problems, indicating a small effect size. Individuals with definite selfefficacy problems were 2.67 times more likely to recidivate than those with no apparent self-efficacy problems, indicating a small to moderate effect size.

\section{Self-efficacy problems and incremental prediction}

On their own, self-efficacy problems had similar moderate predictive ability to DRAOR total scores $(\mathrm{AUC}=.601$ and $\mathrm{AUC}=.643$, respectively; Table 24). The addition of self-efficacy to total DRAOR scores significantly incrementally predicted recidivism, $X^{2}(2,3411)=18.75, p<.001$. When considering both self-efficacy problems and total DRAOR scores, higher problems with self-efficacy were related to lower odds of recidivating. Individuals who had slight problems with self-efficacy were 1.44 times more likely to recidivate than those with no apparent self-efficacy problems, $p<.001$, indicating a small effect. Individuals with definite self-efficacy problems were 1.37 times more likely to recidivate than those with no apparent self-efficacy problems, $p=.014$, indicating a small effect.

Table 24

AUC analyses of the association between recidivism and both self-efficacy problems and total DRAOR scores, separately

\begin{tabular}{lccccc}
\hline Scale & $\mathrm{N}$ & AUC & $\mathrm{SE}$ & $p$ & $95 \% \mathrm{CI}$ \\
\hline Self-efficacy problems & 3411 & .60 & .01 & $<.001$ & {$[.58, .62]$}
\end{tabular}




\begin{tabular}{lllllll} 
Total DRAOR Scores & 3411 & .64 & .01 & $<.001$ & {$[.62, .66]$} \\
\hline
\end{tabular}

\section{Interactions between self-efficacy problems and DRAOR subscales}

Interactions were explored between self-efficacy problems and stable dynamic subscale scores, acute dynamic subscale scores, and protective subscale scores.

Self-efficacy problems and stable dynamic risk scores. There was a significant interaction between self-efficacy problems and stable dynamic risk scores when comparing individuals with no apparent self-efficacy problems to individuals with slight self-efficacy problems (Figure 7; Table 25). When stable dynamic risk scores were low, individuals with no apparent self-efficacy problems had lower odds of recidivating compared to individuals with slight self-efficacy problems. As stable dynamic risk scores increased, odds of recidivating for both groups increased, with individuals with no apparent self-efficacy problems' scores increasing at a faster rate. This resulted in both groups having similar odds of recidivating when stable dynamic risk scores were high. There was also a significant interaction between stable dynamic risk scores and selfefficacy problems when comparing individuals with no apparent self-efficacy problems to individuals with definite self-efficacy problems (Figure 7; Table 25). Whereas individuals with no apparent self-efficacy problems had lower odds of recidivating when stable dynamic risk scores were low, with odds increasing as stable dynamic risk scores increased, individuals with definite self-efficacy problems had higher odds of recidivating when stable dynamic risk scores were low, with odds decreasing as stable dynamic risk scores increased. 
Figure 7

Interaction between self-efficacy problems and stable dynamic risk scores.

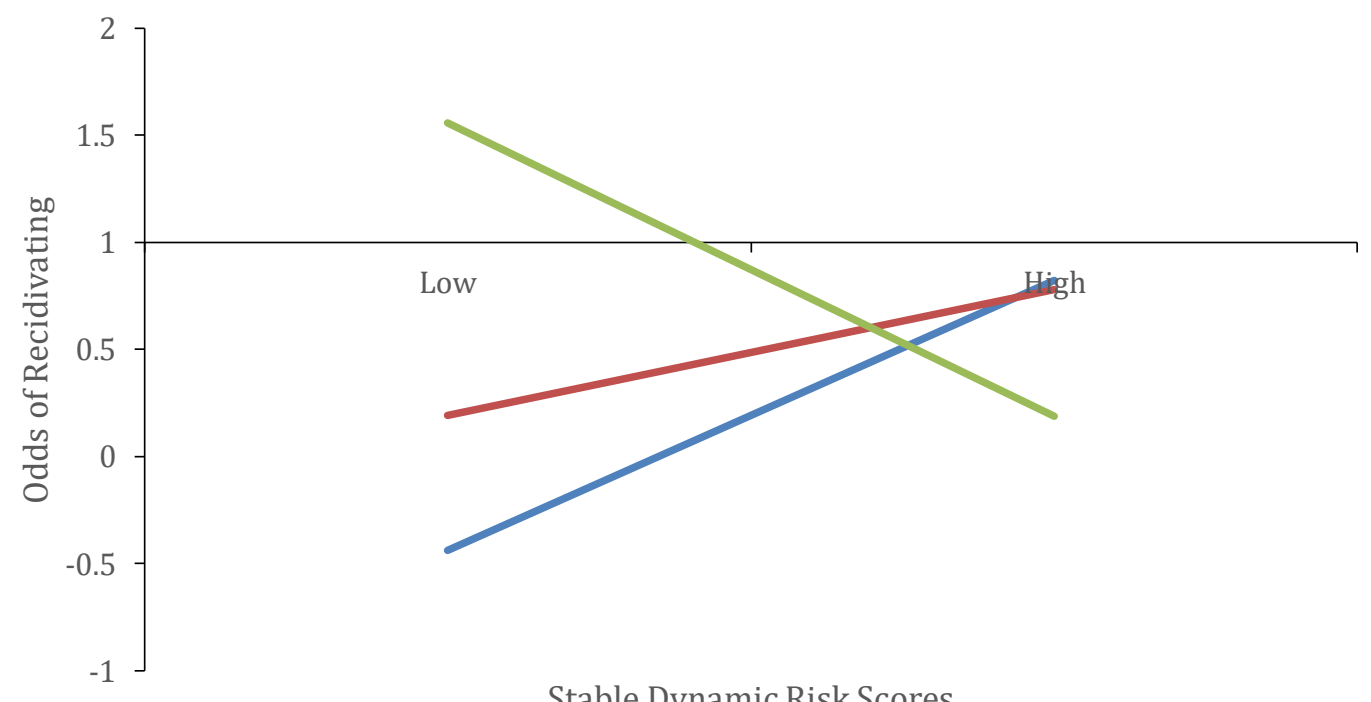

Stable Dynamic Risk Scores

- Self-efficacy L0 —

Table 25

Interaction between self-efficacy problems and stable dynamic risk scores.

\begin{tabular}{llllll}
\hline Block & Predictor & B (SE) & OR & $95 \%$ CI & $X^{2}$ \\
\hline 1 & Self-efficacy L1 & $0.41(.08)^{* *}$ & 1.51 & {$[1.29,1.78]$} & $216.92^{* *}$ \\
& Self-efficacy L2 & $0.44(.12)^{* *}$ & 1.55 & {$[1.22,1.97]$} & \\
& Stable Dynamic Score & $0.13(.01)^{* *}$ & 1.14 & {$[1.11,1.18]$} & \\
\hline 2 & Self-efficacy L1 & $0.95(.18)^{* *}$ & 2.58 & {$[1.82,3.66]$} & $23.17 * *$
\end{tabular}




$\begin{array}{lccc}\text { Self-efficacy L2 } & 1.67(.35)^{* *} & 5.31 & {[2.69,10.48]} \\ \text { Stable Dynamic Score } & 0.21(.02)^{* *} & 1.24 & {[1.18,1.30]} \\ \text { Self-efficacy L1*Stable } & -0.11(.03)^{* *} & 0.89 & {[0.84,0.95]} \\ \begin{array}{l}\text { Dynamic Score } \\ \text { Self-efficacy L2*Stable }\end{array} & -0.19(.05)^{* *} & 0.83 & {[0.76,0.90]} \\ \text { Dynamic Score } & & & \end{array}$

Note. OR $=$ Odds Ratio; $95 \% \mathrm{CI}=95 \%$ Confidence Interval for Odds Ratio; $X^{2}=$ Chisquare. Self-efficacy L1 $=$ coded as 1 . Self-efficacy L2 $=$ coded as 2 . Self-efficacy coded as 0 is reference category.

${ }^{*} p<.05 ; * * p<.01$.

Self-efficacy problems and acute dynamic risk scores. There was a significant interaction between acute dynamic risk scores and self-efficacy problems when comparing individuals with no apparent self-efficacy problems to individuals with definite self-efficacy problems (Figure 8; Table 26). For individuals with no apparent self-efficacy problems, odds of recidivating were lower when acute dynamic risk scores were low, and then increased as acute dynamic risk scores increased. In contrast, for individuals with definite self-efficacy problems, odds of recidivating were higher when acute dynamic risk scores were low, and then decreased as acute dynamic risk scores increased. Odds of recidivating stayed consistently higher for individuals with definite self-efficacy problems compared to individuals with no apparent self-efficacy problems, regardless of acute dynamic risk scores. There was not a significant interaction between acute dynamic risk scores and self-efficacy problems when comparing individuals with no apparent self-efficacy problems and individuals with slight self-efficacy problems (Figure 8; Table 26). 
Figure 8

Interaction between self-efficacy problems and acute dynamic risk scores.

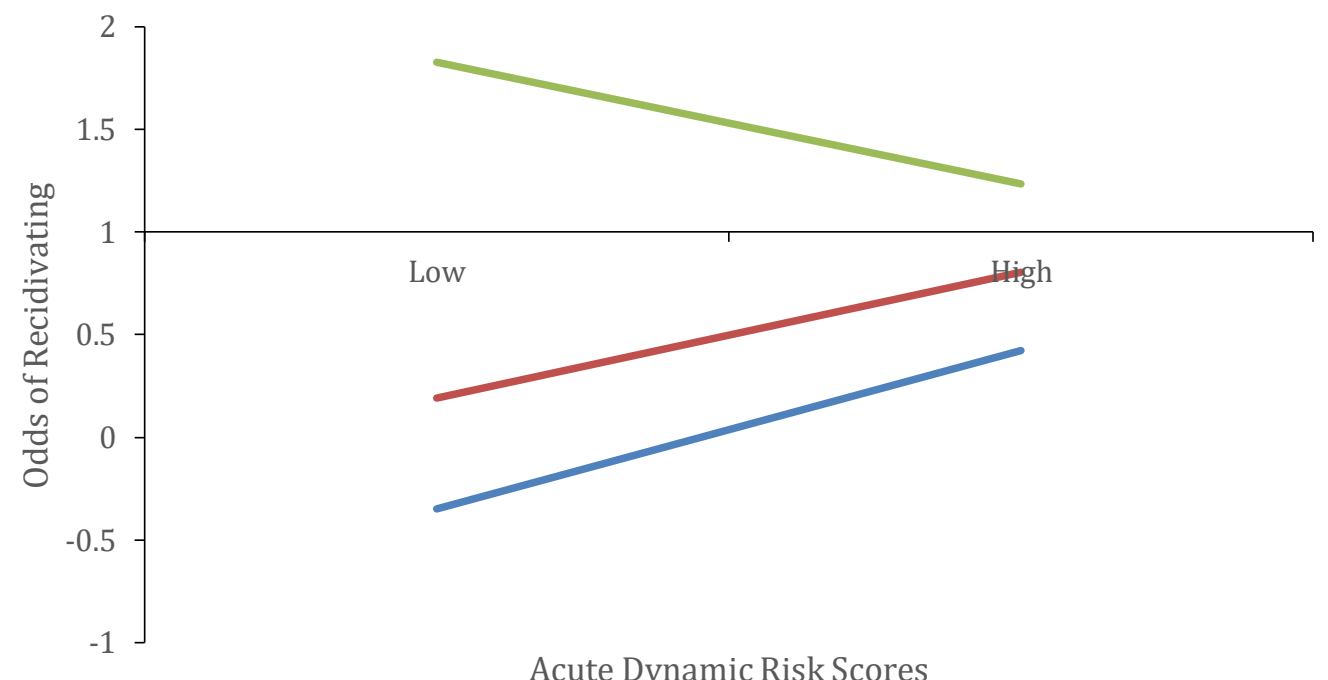

Acute Dynamic Risk Scores

- Self-efficacy L0 - Self-efficacy L1 - Self-efficacy L2

Table 26

Interaction between self-efficacy problems and acute dynamic risk scores.

\begin{tabular}{llllll}
\hline Block & Predictor & B (SE) & OR & $95 \%$ CI & $X^{2}$ \\
\hline 1 & Self-efficacy L1 & $0.52(.08)^{* *}$ & 1.67 & {$[1.42,1.96]$} & $178.68^{* *}$ \\
& Self-efficacy L2 & $0.61(.12)^{* *}$ & 1.84 & {$[1.45,2.32]$} & \\
& Acute Dynamic Score & $0.10(.01)^{* *}$ & 1.10 & {$[1.07,1.13]$} & \\
\hline 2 & Self-efficacy L1 & $0.61(.18)^{* *}$ & 1.84 & {$[1.29,2.64]$} & $7.67^{*}$ \\
& Self-efficacy L2 & $1.44(.33)^{* *}$ & 4.23 & {$[2.23,8.02]$} & \\
& Acute Dynamic Score & $0.12(.02)^{* *}$ & 1.13 & {$[1.09,1.18]$} & \\
& Self-efficacy L1*Acute & $-0.02(.03)$ & 0.98 & {$[0.92,1.03]$} & \\
& Dynamic Score & & & &
\end{tabular}


Self-efficacy L2*Acute $\quad-0.11(.04)^{* *} \quad 0.90 \quad[0.83,0.97]$

Dynamic Score

Note. OR = Odds Ratio; $95 \%$ CI $=95 \%$ Confidence Interval for Odds Ratio; $X^{2}=$ Chisquare. Self-efficacy L1 $=$ coded as 1 . Self-efficacy L2 $=$ coded as 2 . Self-efficacy coded as 0 is reference category.

${ }^{*} p<.05 ; * * p<.01$.

Self-efficacy problems and protective factor scores. There was a significant interaction between self-efficacy problems and protective factor scores when comparing individuals with no apparent self-efficacy problems to individuals with slight selfefficacy problems (Figure 9; Table 27). Both groups had higher odds of recidivating when protective factor scores were lower, with odds decreasing as protective factor scores increased. However, odds of recidivating for individuals with no apparent selfefficacy problems decreased at faster rate, leading to a greater discrepancy in odds when protective factor scores were high. There was not a significant interaction between selfefficacy problems and protective factor scores when comparing individuals with no apparent self-efficacy problems to individuals with definite self-efficacy problems (Figure 9: Table 27).

Figure 9

Interaction between self-efficacy problems and protective factor scores. 


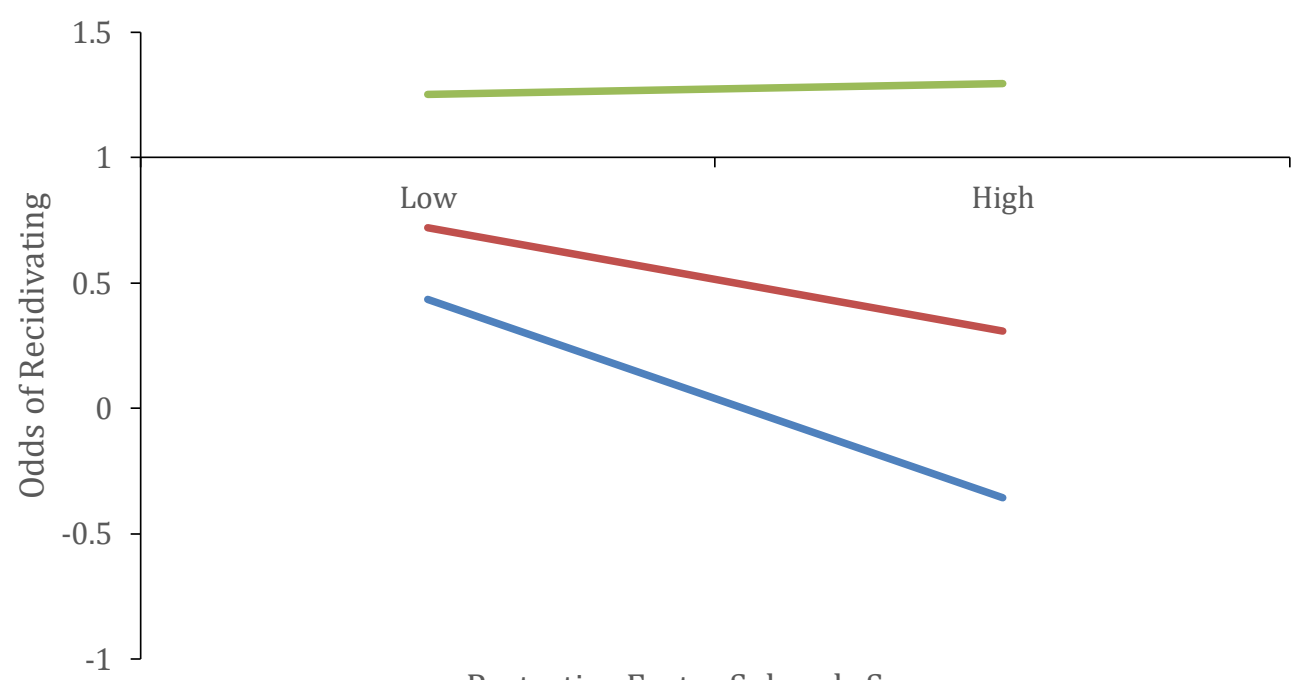

Protective Factor Subscale Scores

Self-efficacy L0 —Self-efficacy L1 $\longrightarrow$ Self-efficacy L2

Table 27

Interaction between self-efficacy problems and protective factor scores.

\begin{tabular}{llclll}
\hline Block & Predictor & B (SE) & OR & $95 \%$ CI & $X^{2}$ \\
\hline 1 & Self-efficacy L1 & $0.52(.08)^{* *}$ & 1.68 & {$[1.43,1.97]$} & $178.72^{* *}$ \\
& Self-efficacy L2 & $0.59(.12)^{* *}$ & 1.80 & {$[1.42,2.28]$} & \\
& Protective Score & $-0.01(.01)^{* *}$ & 0.91 & {$[0.88,0.93]$} & \\
\hline 2 & Self-efficacy L1 & $0.10(.21)$ & 1.11 & {$[0.74,1.67]$} & 5.68 \\
& Self-efficacy L2 & $0.21(.22)$ & 1.23 & {$[0.80,1.90]$} & \\
& Protective Score & $-0.13(.02)^{* *}$ & 0.88 & {$[0.84,0.91]$} & \\
& Self-efficacy & $0.06(.03)^{*}$ & 1.07 & {$[1.001,1.13]$} & \\
& L1*Protective Score & & & & \\
& Self-efficacy & $0.07(.04)$ & 1.07 & {$[0.99,1.16]$} & \\
& L2*Protective Score & & & & \\
\hline
\end{tabular}

Note. OR $=$ Odds Ratio; $95 \%$ CI $=95 \%$ Confidence Interval for Odds Ratio; $X^{2}=$ Chisquare. Self-efficacy L1 $=$ coded as 1 . Self-efficacy L2 $=$ coded as 2 . Self-efficacy coded as 0 is reference category.

$* p<.05 ; * * p<.01$.

\section{Study 4: Model fitting}

The best model for predicting recidivism rates included DRAOR total scores, selfefficacy, and trauma, $X^{2}(5,3411)=232.08, p<.001$. With all other variables held 
constant, individuals with higher total DRAOR scores were 1.06 times more likely to recidivate than individuals with lower total DRAOR scores. With all other variables held constant, individuals who had slight self-efficacy problems were 1.47 times more likely to recidivate than individuals with no apparent self-efficacy problems. With all other variables held constant, individuals with definite self-efficacy problems were 1.43 times more likely to recidivate than individuals with no apparent self-efficacy problems.

Finally, with all other variables held constant, individuals with definite trauma problems were 0.72 times less likely to recidivate than individuals with no apparent trauma problems. All effect sizes were small. There was not a significant effect of trauma on recidivism when comparing individuals with no apparent trauma problems to those with slight trauma problems (Table 28). Mental health was not included as significant in the final model.

Table 28

Final model for predicting recidivism

\begin{tabular}{llllll}
\hline & Predictor & B (SE) & OR & $95 \%$ CI & $X^{2}$ \\
\hline Step 1 & Total DRAOR Score & $0.07(.01)^{* *}$ & 1.07 & {$[1.06,1.08]$} & $204.94^{* *}$ \\
\hline Step 2 & Total DRAOR Score & $0.06(.01)^{* *}$ & 1.06 & {$[1.05,1.07]$} & $223.68^{* *}$ \\
& Self-efficacy L1 & $0.37(.09)^{* *}$ & 1.44 & {$[1.22,1.70]$} & \\
& Self-efficacy L2 & $0.31(.13)^{*}$ & 1.37 & {$[1.06,1.76]$} & \\
\hline Step 3 & Total DRAOR Score & $0.06(.01)^{* *}$ & 1.06 & {$[1.05,1.07]$} & $232.08^{* *}$ \\
& Self-efficacy L1 & $0.38(.09)^{* *}$ & 1.47 & {$[1.24,1.74]$} & \\
& Self-efficacy L2 & $0.36(.13)^{* *}$ & 1.43 & {$[1.11,1.85]$} & \\
& Trauma L1 & $-0.01(.09)$ & 0.99 & {$[0.83,1.17]$} & \\
& Trauma L2 & $-0.33(.12)^{* *}$ & 0.72 & {$[0.57,0.90]$} & \\
\hline
\end{tabular}

Note. OR $=$ Odds Ratio; $95 \%$ CI $=95 \%$ Confidence Interval for Odds Ratio; $X^{2}=$ Chisquare. $\mathrm{L} 1=$ variable coded as $1 . \mathrm{L} 2=$ variable coded as 2. Self-efficacy/trauma coded as 0 is reference category.

$* p<.05 ; * * p<.01$.

\section{Results Summary}

For further clarity, see Table 29 for a summary of all results. 
Table 29

Summary of Results

\begin{tabular}{lccc}
\hline Outcome Variable & Trauma & Mental Health & Self-efficacy \\
\hline Total DRAOR Score & $+^{*}$ & $+^{*}$ & $+^{*}$ \\
Substance Abuse & $+^{*}$ & $+*$ & $+^{*}$ \\
Antisocial Tendencies & $+^{*}$ & $+^{*}$ & $+^{*}$ \\
Emotional Distress & $+^{*}$ & $+^{*}$ & $+^{*}$ \\
Recidivism & $+^{*}$ & $+^{*}$ & + \\
Incremental Prediction & $+^{*}$ & & + \\
Interactions & & & + \\
Stable Dynamic Risk & & + & + \\
Acute Dynamic Risk & & + & $+^{*}$ \\
Protective & & & + \\
Best Fitting Model & $+^{*}$ & & +
\end{tabular}

Note. * Denotes consistency with hypothesis for research questions where a hypothesis was proposed

\section{Discussion}

\section{Study 1: Trauma}

The goal of study 1 was to broadly explore the relationship between trauma, DRAOR scores, and recidivism. Consistent with previous research (Maschi et al., 2018; Wolff \& Baglivio, 2017; Barrett et al., 2014), trauma was a positive predictor of recidivism, wherein higher rates of trauma problems were associated with higher odds of recidivism. Consistent with hypotheses, justice-involved persons who were higher in trauma problems had higher total DRAOR scores. However, contrary to the hypothesis, higher rates of recidivism were only found for individuals with lower rates of trauma (i.e., slight problems). This is particularly surprising and raises concerns regarding the rating of trauma in this study since high rates of trauma would not be presumed to be protective. First, it may be that a three-point scale is insensitive to adequately measuring the construct. Second, it is possible that clients are reluctant to disclose information regarding histories of and symptoms relating to trauma. Having a measure of clients' 
views of their working relationship with probation staff would be important to better understand these contradictory findings. Poor working relationship would raise concerns regarding the staff ratings that are essentially based on client self-reports. Third, this research reflects clients' baseline assessments. Assessments repeated following multiple interviews may have greater validity.

Additionally, trauma was positively related to substance abuse, antisocial tendencies, and emotional distress, suggesting that trauma plays a role in not only recidivism risk as a whole, but also individual components of or pathways to it. This is in alignment with previous research where trauma was associated with higher rates of substance use (Martin et al., 2015; Sadeh \& McNeil, 2015). This is also in alignment with research showing trauma is associated with lower distress tolerance and higher antisocial behaviours (Armstrong et al., 2008; Vujanovic et al., 2011). Though trauma on its own was not more predictive than chance, it did improve recidivism prediction when added to the DRAOR, as hypothesized, suggesting that this supplemental item should continue to be used when conducting DRAOR assessments. Trauma did not interact with any DRAOR subscales, suggesting that it is more associated with recidivism in general. Clarification of the importance of trauma relative to DRAOR content warrants further examination.

Because this study used baseline assessments completed within one year of release, it may be that trauma severity was not accurately being captured. Given that this was the first assessment being done, officers and their clients may not have yet built up a working relationship in which the justice-involved person feels comfortable disclosing traumatic events that would have warranted a higher rating (i.e., a rating of 2). Despite 
this, these results still suggest that trauma is a relevant item to include in assessments. Of note, those with no history of trauma appear to be different than those who have even some history of trauma (i.e., a rating of 1) with respect to recidivism propensity. These associations with both DRAOR risk scores and recidivism highlight the importance of adopting trauma-informed correctional care strategies in ongoing case management.

\section{Study 2: Mental health}

The goal of study 2 was to broadly explore the relationship between mental health, DRAOR scores, and recidivism. Consistent with hypotheses, justice-involved persons who had higher rates of mental health problems also had higher total DRAOR scores. Additionally, mental health problems were associated with higher rates of substance abuse, higher rates of antisocial tendencies, and higher rates of emotional distress. Given that the link between mental health problems and recidivism is exacerbated by substance use (Smith \& Trimboli, 2010; Wilson et al., 2011; Guebert \& Olver, 2014), it is not surprising to find this association within this sample of justiceinvolved persons and speaks to the multifaceted aspect of these issues. This is also in alignment with previous research showing associations between mental health and both antisocial behaviours and emotional intelligence (Hertel et al., 2009; Ogloff et al., 2015; Yu et al., 2012). Consistent with research by Smith \& Trimboli (2010), justice-involved persons with higher mental health problems also had higher odds of recidivating. However, the mental health item on its own was not predictive above chance of recidivism and did not incrementally predict recidivism when combined with the DRAOR. 
Both acute and stable dynamic risk subscales showed similar associations with mental health problems. For stable dynamic risk factors (i.e., less changeable), higher stable dynamic risk was associated with higher odds of recidivating when mental health problems were slight or not apparent, whereas higher stable dynamic risk was associated with lower odds of recidivating when mental health problems were definitely present (i.e., stronger). This reduction in odds of recidivating when mental health problems are high may be due to treatment needs being met. When problems are most apparent, individuals may be more likely to be referred to and have access to treatments (i.e., medication, therapy, etc.) compared to when their problems are not as apparent and may be more easily missed by their parole officer and other supports. Unfortunately, treatment referral and completion information were unavailable to examine this explanation. As well, the results may also be due to a relatively small subset of justice-involved persons who fall under both high mental health problems and high risk. Similarly surprisingly, as acute dynamic risk scores (i.e., readily changing) increased, odds of recidivating increased when mental health problems were low (i.e., a score of 0 or 1 ) and decreased when mental health problems were high (i.e., a score of 2). In slight contrast to stable dynamic risk scores, this effect was only found for acute dynamic risk scores when looking at no apparent mental health problems and definite mental health problems, suggesting that mental health and short-term risks for reoffending influence each other only when mental health concerns are extreme.

The hypothesis that individuals who are high in mental health problems and high in protective factors would have lower odds of recidivating than individuals who are high in mental health problems and low in protective factors was not supported. Protective 
factor scores and mental health did not appear to be influencing each other when individuals were high in mental health problems. Rather, odds of recidivism were reduced when individuals had lower levels of mental health problems. It may be that the protective factor items in the DRAOR are not relevant for justice-involved persons with mental health concerns. However, it is difficult to go beyond speculation due to the limited of research on the predictive efficacy of protective factors for individuals with high mental health problems (Dickens \& Shea, 2018; Wardrop, 2020).

\section{Study 3: Self-efficacy}

The goal of study 3 was to broadly explore the relationship between self-efficacy, DRAOR scores, and recidivism. Consistent with hypotheses, justice-involved persons who had higher rates of self-efficacy problems had higher total DRAOR scores. Additionally, higher rates of self-efficacy problems were associated with higher rates of substance abuse, higher rates of antisocial tendencies, and higher rates of emotional distress. This is in alignment with previous research showing associations between selfefficacy and substance abuse as well as emotional distress (Kadden \& Litt, 2011; Lacour et al., 2020). Given the lack of research on self-efficacy from a correctional lens, the findings that it is associated with antisocial tendencies are rather novel. Consistent with previous research (Benda, 2001; Carroll et al., 2013), higher problems with self-efficacy were also associated with higher odds of recidivating. On its own, self-efficacy was as equally predictive of recidivism as the DRAOR, and incrementally predictive when added to the DRAOR, validating its usefulness within a case management framework. This suggests that more research needs to be done examining the relationship between self-efficacy and risk for reoffending as these two constructs do appear to be associated 
with one another. These findings also support a strengths-based approach wherein justiceinvolved persons who have high self-efficacy, and thus feel empowered, will be more likely to seek change (Schlager, 2018).

All three DRAOR subscales showed varying associations with self-efficacy. Selfefficacy interacted with acute and stable risk factors in a similar way to mental health. When looking at stable dynamic risk (i.e., less changeable), higher stable dynamic risk was associated with higher risk for recidivating when self-efficacy problems were low or not apparent. Higher stable dynamic risk was associated with lower odds of recidivating when self-efficacy problems were higher. When looking at acute dynamic risk (i.e., readily changing), again, higher acute dynamic risk was associated with higher risk for recidivating when self-efficacy problems were low, whereas higher acute dynamic risk was associated with lower risk for recidivating when self-efficacy problems were high. Similar to mental health, this was only found when looking at no apparent self-efficacy problems and definite self-efficacy problems, suggesting that self-efficacy and acute dynamic risks for reoffending interactions are only apparent when self-efficacy problems are at an extreme. Also similar to mental health, these findings that higher self-efficacy problems were related to lower odds of reoffending may be due to increased treatment referrals and intervention or a relatively small subset of justice-involved persons falling under both high self-efficacy problems and high risk. Protective factors appeared to have the strongest influence when there were no apparent problems with self-efficacy. Additionally, the interactions with protective factors were only apparent for those with lower levels of self-efficacy problems. Justice-involved persons with high problems with self-efficacy had high odds of recidivating, regardless of level of protective factors. This 
suggests that protective factors measured in the DRAOR are insufficient to buffer the effects of poor self-efficacy in justice-involved persons. Taken altogether, these findings highlight the importance of looking at self-efficacy from a correctional lens and incorporating it into case management assessments and practice.

\section{Study 4: Model fitting}

The goal of study 4 was to explore the best model for predicting recidivism when considering DRAOR total scores, trauma, mental health, and self-efficacy, with the expectation that all predictors would be predictive of recidivism rates. This hypothesis was only partially supported, as the best fitting model included only total DRAOR scores, trauma, and self-efficacy. Mental health was not determined to be predictive in the overall model. This may not be surprising, given that mental health did not incrementally predict recidivism when added to the DRAOR. Though past research has shown strong links between mental health and risk for reoffending (Smith \& Trimboli, 2010; Grann et al., 2008), this, again, may be due to a lack of sensitivity of the mental health item.

\section{Overall discussion}

The present study demonstrates the usefulness of these supplemental items with the DRAOR as they all displayed associations with recidivism and constructs related to recidivism (e.g., substance use, antisocial tendencies and emotional distress). The fact that the overall best model does not include the mental health item despite its associations with recidivism suggests that it may need revision to better capture the impact mental health problems is having on justice-involved persons. However, given that these items are currently used as supplemental items and are not being integrated into the DRAOR scale when calculating scores, a case can be made to keep the mental health item as is 
with the understanding that a parole officer would have greater insight into the specifics of the mental health problems in question that this study was not able to access.

Looking beyond the use of the DRAOR specifically, this study highlights the importance of considering responsivity factors and attending to these needs in case management planning. Research has shown that responsivity factors are not often addressed in case management planning (Holloway et al., 2018; Luong \& Wormith, 2011; Singh et al., 2014). Luong and Wormith (2011), in particular, found that only 20\% of case plans assessed matched responsivity factors in intervention. Additionally, Vieria and colleagues (2009) found that those with low needs match were up to 18 times more likely to reoffend compared to those with high needs match. While considerable research has examined the effectiveness of the RNR model, its effectiveness depends on the level of risk, the type of treatment, and the needs of the client (Smith et al., 2009) and little has been done looking at specific responsivity factors, especially relating to mental health factors. This study sheds light on the importance of paying attention to a broader consideration of responsivity to understand client outcome. Case planning and management should take a holistic approach by considering justice-involved persons as a whole, with individual needs requiring personalized plans, rather than just compiling information on generalized risk factors. Training and policy within corrections departments should focus on these individual needs and responsivity factors when conducting training and implementing measures for assessing and managing risk.

\section{Limitations and future directions}

Though the present study highlights the usefulness of attending to responsivity factors, it is not without its limitations. Using archival data, in particular, has limitations 
that must be acknowledged. The supplemental items are quite blunt measurements being used for these responsivity constructs. Further, there was no examination of reliability possible. Also, as they are only measured on three-point scales, they may be relatively insensitive to change and meaningful information may be lost. As well, their measurement reflects a single point in time. This loss of information could be leading to the small effect sizes seen with this sample of justice-involved persons (Fok \& Henry, 2015). As well, the supplemental items in their current state for trauma and mental health provided limited information, despite the fact that they measure complex constructs. In the case of trauma, studies have found differences in strength of association to recidivism as well as types of recidivism when trauma is broken down into subtypes (e.g., childhood maltreatment or troubles-related trauma; Barrett et al., 2014; Dalsklev et al., 2019; Lattimore et al., 1995). Additionally, the current trauma item does not differentiate between individuals with trauma problems and individuals with a PTSD diagnosis, potentially leaving out valuable contextual information in assessing risk. In the case of mental health, while studies have found mental health in general to be associated with offending and recidivism (Grann et al., 2008; James \& Glaze, 2006; Swanson et al., 2001), mental health is a broad category that encompasses many diagnoses which may have different prevalence and different recidivism outcomes (Bonta et al., 2014; Fazel \& Danesh, 2002; McReynolds, et al., 2010; Short et al., 2013).

Another potential limitation to this study concerns measurement error in the way that DRAOR assessments are conducted within the Iowa Department of Corrections. Though all staff have had training, there is no information provided concerning how they complete assessments, their level of experience, how recent their training was, their level 
of commitment to their job, nor their belief in the utility of the DRAOR, all of which can impact the reliability and validity of an assessment measure (Latessa \& Lovins, 2010; Schaefer \& Williamson, 2018; Schlagger, 2018).

Given that it is the first to examine these supplemental items, the current study was done using only male justice-involved persons to simplify analyses. As research has shown differences between male and female justice-involved persons in regards to responsivity factors such as trauma and mental health (Erwin et al., 2000; McReynolds et al., 2010; Miller \& Najavits, 2012; Short et al., 2013), future studies should examine the usefulness of these supplemental items with a female sample to obtain a more complete picture of best practices for case planning and management. In addition to gender, future studies should expand on this research by examining these effects when broken down by race/ethnicity, given that research has demonstrated associations between demographics and recidivism risk (Piquero et al., 2015; Schwalbe et al., 2006; Skeem \& Lowenkamp, 2016)

Though it seems potentially plausible that individuals with high mental health and self-efficacy problems experienced decreasing odds of recidivism as stable and acute risk increased because of treatment needs being met, the limited information provided for this study makes it impossible to go beyond speculation and assign significant efficacy for clinical interventions that may be unwarranted. Future research should aim to include information regarding access to treatment as well as skill set of parole officers in order to account for these important variables and obtain a more complete picture of recidivism risk. 
Additionally, the present study only examined interactions between the responsivity factors of interest and varying measurements of risk (i.e., DRAOR subscales). In addition to the suggestion above, future research should expand on this by examining interactions between these responsivity factors of interest (i.e., trauma, mental health, and self-efficacy) in relation to odds of recidivating. Given that previous studies have found that trauma is associated with mental health issues and, in turn, higher rates of recidivism (Martin et al., 2015), as well as studies showing justice-involved persons with mental illness are at a significantly higher risk of trauma exposure (Chilcoat \& Breslau, 1998; Choe et al., 2008; Goff et al., 2007; MacManus et al., 2012; Mueser et al., 1998; Sadeh et al., 2014; Teplin et al., 2015), assessing interactions between these factors for justice-involved persons may add insight and aid best practices for case management with justice-involved persons.

\section{Conclusion}

This study is the first to examine the importance of the supplemental items when assessing risk and conducting case planning and management in the Iowa Department of Corrections. The findings suggest that specific responsivity factors do indeed play an important role in both the risk-needs-responsivity model and recidivism outcomes. Moving forward, case management practices should adopt a trauma-informed correctional care lens, account for mental health issues with their clients, and pay attention to strengths-based responsivity factors like self-efficacy that relate to justiceinvolved persons' motivation for change. 


\section{References}

American Psychological Association. (2020, February 22). Trauma. American Psychological Association. https://www.apa.org/topics/trauma/

Anda, R. F., Felitti, V. J., Bremmer, J. D., Walker, J. D., Whitfield, C., Perry, B. D., Dube, S. R., \& Giles, W. H. (2006). The enduring effects of abuse and related adverse experiences in childhood: A convergence of evidence from neurobiology and epidemiology. European Archives of Psychiatry Clinical Neuroscience, 256(3), 174-186. https://doi.org/10.1007/s00406-005-0624-4.

Anda, R. F., Butchart, A., Felitti, V. J., \& Brown, D. W. (2010). Building a framework for global surveillance of the public health implications of adverse childhood expectations. American Journal of Preventative Medicine, 39(1), 93-98. https://doi.org/10.1016/j.amepre.2010.03.015

Andrews, D. A. \& Bonta, J. (2006). The psychology of criminal conduct (4th ed.). LexisNexis/Matthew Bender

Andrews, D. A. \& Bonta, J. (2010). Rehabilitating criminal justice policy and practice. Psychology, Public Policy, and Law, 16(1), 39-55. https://doi.org/10.1037/a0018362

Andrews, D. A., Bonta, J., \& Wormith, J. S. (2006). The recent past and near future of risk and/or need assessment. Crime \& Delinquency, 52(1), 7-27. http://doi.org/10.1177/0011128705281756

Ardino, V., Milani, L., \& Di Blasio, P. (2013). PTSD and re-offending risk: The mediating role of worry and a negative perception of other people's support. 
European Journal of Psychotraumatology, 4(1), 1-12.

https://doi.org/10.3402/ejpt.v4i0.21382

Armstrong, G. J. \& Kelley, S. D. M. (2008). Early trauma and subsequent antisocial behavior in adults. Brief Treatment and Crisis Intervention, 8(4), 294-303. https://doi.org/10.1093/brief-treatment/mhn016

Baglivio, M. T. \& Epps, N. (2016). The interrelatedness of adverse childhood experiences among high-risk juvenile offenders. Youth Violence and Juvenile Justice, 14(3), 179-198. https://doi.org/10.1177/1541204014566286

Baglivio, M. T., Epps, N., Swartz, K., Huqh, M. S., Sheer, A., \& Hardt, N. S. (2014). The prevalence of adverse childhood experiences (ACE) in the lives of juvenile offenders. Journal of Juvenile Justice, 3(2), 1-17. https://www.prisonpolicy.org/scans/Prevalence_of_ACE.pdf

Baillargeon, J., Binswanger, I. A., Penn, J. V., Williams, B. A., \& Murray, O. J. (2009). Psychiatric disorders and repeat incarcerations: The revolving prison door. American Journal of Psychiatry, 166, 103-109. https://doi.org/10.1176/appi.ajp.2008.08030416

Bandura, A. (1977). Self-efficacy: Toward a unifying theory of behavioral change. Psychological Review, 84(2), 191-215. http://citeseerx.ist.psu.edu/viewdoc/download?doi=10.1.1.315.4567\&rep=rep1\&t ype $=$ pdf

Bandura, A. (1978). Reflections on self-efficacy. Advances in Behavior Research and Therapy, 1, 237-269. https://doi.org/10.1016/0146-6402(78)90012-7 
Bandura, A. (1994). Self-efficacy. In V. S. Ramachaudran (Ed.), Encyclopedia of human behavior (71-81). Academic Press.

Bandura, A. \& Locke, E. A. (2003). Negative self-efficacy and goal effects revisited. Journal of Applied Psychology, 88(1), 87-99. https://doi.org/10.1037/00219010.88.1.87

Barrett, D. E., Katsiyannis, A., Zhang, D., \& Zhang, D. (2014). Delinquency and recidivism: A multicohort, matched-control study of the role of early adverse experiences, mental health problems, and disabilities. Journal of Emotional and Behavioral Disorders, 22(1), 3-15. https://doi.org/10.1177/1063426612470514

Bassi, M., Steca, P., Delle Fave, A., \& Caprara, G. V. (2007). Academic self-efficacy beliefs and quality of experience in learning. Journal of Youth and Adolescence, 36, 301-312. https://doi.org/10.1007/s10964-006-9069-y

Bellis, M. A., Lowey, H., Leckenby, N., Hughes, K., \& Harrison, D. (2013). Adverse childhood experiences: Retrospective study to determine their impact on adult health behaviours and health outcomes in a UK population. Journal of Public Health, 36(1), 81-91. https://doi.org/10.1093/pubmed/fdt038

Benda, B. B. (2005). Gender differences in life-course theory of recidivism: A survival analysis. International Journal of Offender Therapy and Comparative Criminology, 49(3), 325-342. https://doi.org/10.1177/0306624X04271194

Benda, B. B. \& Toombs, N. J. (2002). Two preeminent theoretical models: A proportional hazard rate analysis of recidivism. Journal of Criminal Justice, 30, 217-228. https://doi.org/10.1016/S0047-2352(01)00137-4

Bonta, J. (1996). Risk-needs assessment and treatment. In A. T. Harland (Ed.), Choosing 
correctional options that work: Defining the demand and evaluating the supply (pp. 18-32). Sage.

Bonta, J. \& Andrews, D. A. (2007). Risk-Need-Responsivity Model for Offender Assessment and Rehabilitation. Public Safety Canada. http://www.courtinnovation.org/sites/default/files/documents/RNRModelForOffe nderAssessmentAndRehabilitation.pdf

Bonta, J., Blais, J., \& Wilson, H. A. (2014). A theoretically informed meta-analysis of the risk for general and violent recidivism for mentally disordered offenders. Aggression and Violent Behavior, 19, 278-287. https://doi.org/10.1016/j.avb.2014.04.014

Bonta, J., Law, M., \& Hanson, K. (1998). The prediction of criminal and violent recidivism among mentally disordered offenders: A meta-analysis. Psychological Bulletin, 123(2), 123-142. https://www.researchgate.net/profile/RKarl_Hanson/publication/51316669_The_ Prediction_of_Criminal_and_Violent_Recidivism_among_Mentally_Disordered Offenders_A_Meta-Analysis/links/0a85e539cf0f7857a3000000.pdf

Briere, J., Agee, E., \& Dietrich, A. (2016). Cumulative trauma and current posttraumatic stress disorder status in general population and inmate samples. Psychological Trauma: Theory, Research, Practice, and Policy, 8(4), 439-446. https://doi.org/10.1037/tra0000107

Briere, J. N., \& Scott, C. (2013). Principles of trauma therapy: A guide to symptoms, evaluation and treatment (2nd ed.). Sage. 
Campbell, M. A., French, S., \& Gendreau, P. (2009). The prediction of violence in adult offenders: A meta-analytic comparison of instruments and methods of assessment. Criminal Justice and Behavior, 36(6), 567-590. https://doi.org/10.1177/0093854809333610

Carroll, A., Gordon, K., Haynes, M., \& Houghton, S. (2013). Goal setting and selfefficacy among delinquent, at-risk and not at-risk adolescents. Journal of Youth and Adolescence, 42, 431-443. https://doi.org/10.1007/s10964-012-9799-y

Chadwick, N. (2014). Validating the dynamic risk assessment for offender re-entry (DRAOR) in a sample of U.S. probationers and parolees (Unpublished master's thesis). Carleton University, Ottawa, Canada. https://curve.carleton.ca/system/files/etd/f43f2b17-42cf-4792-8ddc351682dee8bf/etd_pdf/8d62344989677d92606d69f69843364d/chadwickvalidatingthedynamicriskassessmentforoffender.pdf

Chartier M. J., Walker, J. R., \& Naimark, B. (2010). Separate and cumulative effects of adverse childhood experiences in predicting adult health and health care utilization. Child Abuse \& Neglect, 34(6), 454-464. https://doi.org/10.1016/j.chiabu.2009.09.020

Chen, W., Propp, J., deLara, E., \& Corvo, K. (2011). Child neglect and its association with subsequent juvenile drug and alcohol offense. Child and Adolescent Social Work Journal, 28, 273-290. https://doi.org/10.1007/s10560-011-0232-2

Chilcoat, H. D. \& Breslau, N. (1998). Posttraumatic stress disorder and drug disorders: Testing causal pathways. Archives of General Psychiatry, 55, 913-917. https://doi.org/10.1001/archpsyc.55.10.913 
Choe, J. Y., Teplin, L. A., \& Abram, K. M. (2008). Perpetration of violence, violent victimization, and severe mental illness: Balancing public health concerns. Psychiatric Services, 59(2), 153-164. https://ps.psychiatryonline.org/doi/pdf/10.1176/ps.2008.59.2.153

Cicchetti, D., \& Manly, J. T. (2001). Operationalizing child maltreatment: Developmental processes and outcomes. Developmental Psychopathology, 13, 755-757. https://doi.org/10.1017/S0954579401004011

Cook, S. L., Smith, S. G., Tusher, C. P., \& Raiford, J. (2005). Self-reports of traumatic events in a random sample of incarcerated women. Women \& Criminal Justice, 16, 107-126. https://doi.org/10.1300/J012v16n01_05

Cox, S. M., Kochol, P., \& Hedlund, J. (2018). The exploration of risk and protective score differences across juvenile offending career types and their effects on recidivism. Youth Violence and Juvenile Justice, 16(1), 77-96. https://doi.org/10.1177/1541204016678439

Dalsklev, M. Cunningham, T., Travers, A., McDonagh, T., Shannon, C., Downes, C., \& Hanna, D. (2019). Childhood trauma as a predictor of reoffending in a Northern Irish probation sample. Child Abuse \& Neglect, 97, 1-9. https://doi.org/10.1016/j.chiabu.2019.104168

DiClemente, C. C. (1981). Self-efficacy and smoking cessation maintenance: A preliminary report. Cognitive Therapy and Research, 5(2), 175-187. https://link.springer.com/article/10.1007/BF01172525

Dickens, G. L. \& O’Shea, L. E. (2018). Protective factors in risk assessment schemes for adolescents in mental health and criminal justice populations: A systematic 
review and meta-analysis of their predictive efficacy. Adolescent Research Review, 3, 95-112. https://doi.org/10.1007/s40894-017-0062-3

Dong, M., Anda, R. F., Felitti, V. J., Dube, S. R., Williamson, D. F., Thompson, T. J., Loo, C. M., \& Giles, W. H. (2004). The interrelatedness of multiple forms of childhood abuse, neglect, and household dysfunction. Child Abuse \& Neglect, 28, 771-784. https://doi.org/10.1016/j.chiabu.2004.01.008

Dube, S. R., Felitti, V. J., Dong, M., Chapman, D. P., Giles, W. H., \& Anda, R. F. (2003). Childhood abuse, neglect, and household dysfunction and the risk of illicit drug use: The adverse childhood experiences study. Pediatrics, 111(3), 564-572. https://doi.org/10.1542/peds.111.3.564

Duke, N. N., Pettingell, S. L., McMorris, B. J., \& Borowsky, I. W. (2010). Adolescent violence perpetration: Associations with multiple types of adverse childhood experiences. Pediatrics, 125, e778-e786. https://doi.org/10.1542/peds.2009-0597

Erwin, B. A., Newman, E., McMackin, R. A., Morrissey, C., \& Kaloupek, D. G. (2000). PTSD, malevolent environment, and criminality among criminally involved male adolescents. Criminal Justice and Behavior, 27(2), 196-215. https://doi.org/10.1177/0093854800027002004

Fazel, S. \& Danesh, J. (2002). Serious mental disorder in 23,000 prisoners: A systematic review of 62 surveys. Lancet, 359, 545-550. https://doi.org/10.1016/S01406736(02)07740-1

Felitti, V. J., Anda, R. F., Nordenberg, D., Williamson, D. F., Spitz, A. M., Edwards, V., Koss, M. P., \& Marks, J. S. (1998). Relationship of childhood abuse and household dysfunction to many of the leading causes of death in adults: The 
adverse childhood experiences (ACE) study. American Journal of Preventative Medicine, 14(4), 245-258. https://doi.org/10.1016/j.amepre.2019.04.001

Fisher, W. H., Hartwell, S. W., Deng, X., Pinals, D. A., Fulwiler, C., \& Roy-Bujnowski, K. (2014). Recidivism among released state prison inmates who received mental health treatment while incarcerated. Crime \& Delinquency, 60(6), 811-832. https://doi.org/10.1177/0011128714541204

Fitzpatrick, K. M. (1997). Fighting among America's youth: A risk and protective factors approach. Journal of Health and Social Behavior, 38(2), 131-148. https://doi.org/10.2307/2955421

Fok, C. C. \& Henry, D. (2015). Increasing the sensitivity of measures to change. Prevention Science, 16(7), 978-986. https://doi.org/10.1007/s11121-015-0545-z

Fox, B. H., Perez, N., Cass, E., Baglivio, M. T., \& Epps, N. (2015). Trauma changes everything: Examining the relationship between adverse childhood experiences and serious, violent and chronic juvenile offenders. Child Abuse \& Neglect, 46, 163-173. https://doi.org/10.1016/j.chiabu.2015.01.011

Freedman, D. \& Hemenway, D. (2000). Precursors of lethal violence: A death row sample. Social Science \& Medicine, 50, 1757-1770. https://doi.org/10.1016/S0277-9536(99)00417-7

Gendreau, P., Goggin, C., French, S., \& Smith, P. (2006). Practicing psychology in correctional settings. In A. K. Hess \& I. B. Weiner (Eds.), The handbook of forensic psychology (Third edition). Wiley.

Gendreau, P., Smith, P., \& French, S. (2006). The theory of effective correctional intervention: Empirical status and future directions. In Cullen, F., Wright, M., \& 
Coleman, M. (Eds.). Taking stock: The status of criminology theory (pp. 419446). Transaction Press.

Goff, A., Rose, E., Rose, S., \& Purves, D. (2007). Does PTSD occur in sentenced prison populations? A systematic literature review. Criminal Behaviour and Mental Health, 17, 152-162. https://doi.org/10.1002/cbm.653

Gonida, E. N. \& Leondari, A. (2011). Patterns of motivation among adolescents with biased and accurate self-efficacy beliefs. International Journal of Educational Research, 50, 209-220. https://doi.org/10.1016/j.ijer.2011.08.002

Grann, M., Danesh, J., \& Fazel, S. (2008). The association between psychiatric diagnosis and violent re-offending in adult offenders in the community. BMC Psychiatry, 8(92), 1-7. https://doi.org/10.1186/1471-244X-8-92

Guebert, A. F. \& Olver, M. E. (2014). An examination of criminogenic needs, mental health concerns, and recidivism in a sample of violent young offenders: Implications for risk, need, and responsivity. International Journal of Forensic Mental Health, 13(4), 295-310. https://doi.org/10.1080/14999013.2014.955220

Gutman, L. M. \& Midgley, C. (2000). The role of protective factors in supporting the academic achievement of poor African American students during the middle school transition. Journal of Youth and Adolescence, 29(2), 223-248. https://deepblue.lib.umich.edu/bitstream/handle/2027.42/45287/10964_2004_Arti cle_222514.pdf?sequence $=1$

Hanby, L. (2013). A longitudinal study of dynamic risk, protective factors, and criminal recidivism: Change over time and the impact of assessment timing (Unpublished doctoral dissertation). Carleton University, Canada. 
https://curve.carleton.ca/system/files/etd/b6aa7d5d-f44b-48d6-9ea95d0f92b8f7a7/etd_pdf/a7fc1a78dfe694530e8937c422d4851e/hanbyalongitudinalstudyofdynamicriskprotective.pdf

Hanson, R. K. \& Harris, A. J. (2000). Where should we intervene? Dynamic predictors of sexual offense recidivism. Criminal Justice and Behavior, 27(1), 6-35. https://doi.org/10.1177/0093854800027001002

Hanson, R. K. \& Morton-Bourgon, K. E. (2009). The accuracy of recidivism risk assessments for sexual offenders: A meta-analysis of 118 prediction studies. Psychological Assessment, 21(1), 1-21. https://doi.org/10.1037/a0014421

Hanson, R. K. (2009). The psychological assessment of risk for crime and violence. Canadian Psychology, 50(3), 172-182. https://doi.org/10.1037/a0015726

Hanson, R. K., Harris, A. J., Scott, T., \& Helmus, L. (2007). Assessing the risk of sexual offenders on community supervision: The Dynamic Supervision Project (Vol. 5). Ottawa, Ontario, Canada: Public Safety Canada. https://ccoso.org/sites/default/files/import/risk-assessment.pdf

Harris, A. J. \& Hanson, R. K. (2010). Clinical, actuarial and dynamic risk assessment of sexual offenders: Why do things keep changing? Journal of Sexual Aggression, 16(3), 296-310. https://doi.org/10.1080/13552600.2010.494772

Harris, G. T., \& Rice, M. E. (2015). Progress in violence risk assessment and communication: Hypothesis versus evidence. Behavioral Sciences and the Law, 33(1), 128-145. https://doi.org/10.1002/bs1.2157 
Hart, S. D. \& Logan, C. (2011). Formulation of violence risk using evidence-based assessments: The structured professional judgment approach. In Sturmey, P. \& McMurran, M. (Eds.), Forensic Case Formulation. Wiley-Blackwell.

Herman, J. (1997). Trauma and recovery: The aftermath of violence - from domestic abuse to political terror. Basic Books.

Hertel, J., Schutz, A., \& Lammers, C. (2009). Emotional intelligence and mental disorder. Journal of Clinical Psychology, 65(9), 942-954. https://doi.org/10.1002/jclp.20597

Hien, D., Litt, L. C., Cohen, L. R., Miele, G. M., \& Campbell, A. (2009). Trauma services for women in substance abuse treatment: An integrated approach. American Psychological Association.

Iowa Department of Corrections. (2019a). Quarterly Quick Facts. https://doc.iowa.gov/data/quick-facts

Iowa Department of Corrections. (2019b). FY2019 Annual Report. https://doc.iowa.gov/sites/default/files/documents/2019/11/fy2019_doc_a nnual_report.pdf

James, D. J., \& Glaze, L. E. ([2003] 2006). Bureau of justice statistics special report: Mental health problems of prison and jail inmates (NCJ 213600). Washington, DC: Bureau of Justice Statistics, Office of Justice Programs, US Department of Justice.

Kadden, R. M. \& Litt, M. D. (2011). The role of self-efficacy in the treatment of substance use disorders. Addictive Behaviors, 36(12), 1120-1126. https://doi.org/10.1016/j.addbeh.2011.07.032 
Kim, E. Y., Park, J., \& Kim, B. (2016). Type of childhood maltreatment and the risk of criminal recidivism in adult probationers: A cross-sectional study. $B M C$ Psychiatry, 16, 1-9. https://doi.org/10.1186/s12888-016-1001-8

Kubiak, S. P. (2004). The effects of PTSD on treatment adherence, drug relapse, and criminal recidivism in a sample of incarcerated men and women. Research on Social Work Practice, 14(6), 424-433. https://doi.org/10.1177/1049731504265837

Lacour, O., Morina, N., Spaaij, J., Nickerson, A., Schnyder, U., von Kanel, R., Bryant, R. A., \& Schick, M. (2020). Prolonged grief disorder among refugees in psychological treatment - Association with self-efficacy and emotional regulation. Frontiers in Psychiatry, 11, 1-10. https://doi.org/10.3389/fpsyt.2020.00526

Lattimore, Visher, \& Linster, 1995 Lattimore, P. K., Visher, C. A., \& Linster, R. L. (1995). Predicting rearrest for violence among serious youthful offenders. Journal of Research in Crime and Delinquency, 32(1), 54-83. https://journals.sagepub.com/doi/pdf/10.1177/0022427895032001003?casa_token =_yf9Ep47gQsAAAAA:Be0Cr8tU6AX761_F_lizq2Gi4O8s0t6MjO7mGw23B7a iAifivvPB54Pfvs0ExKYXw0bpS7DeQ6wcFA

Lee, M. Y., Uken, A., \& Sebold, J. (2007). Role of self-determined goals in predicting recidivism in domestic violence offenders. Research on Social Work Practice, 17(1), 30-41. https://doi.org/10.1177/1049731506294375

Locke, E. A. \& Latham, G. P. (1990). Work motivation and satisfaction: Light at the end of the tunnel. Psychological Science, 1(4), 240-246. https://doi.org/10.1111/j.1467-9280.1990.tb00207.x 
Lodewijks, H., Ruiter, C., \& Doreleijers, T. (2010). The impact of protective factors in desistance from violent reoffending: A study in three samples of adolescent offenders. Journal of Interpersonal Violence, 25(3), 568-587. https://doi.org/10.1177/0886260509334403

Lovell, D., Gagliardi, G. J., \& Peterson, P. D. (2002). Recidivism and use of services among persons with mental illness after release from prison. Psychiatric Services, 53, 1290-1296. https://doi.org/10.1176/appi.ps.53.10.1290

MacManus, D., Dean, K., Al Bakir, M., Iversen, A. C., Hull, L. Fahy, T., Wessely, S., \& Near, N. T. (2012). Violent behaviour in UK military personnel returning home after deployment. Psychological Medicine, 42, 1663-1673. https://doi.org/10.1017/S0033291711002327

Madera, J. E. E. (2016). The cumulative impact of trauma exposure and recidivism after incarceration among black men [unpublished $\mathrm{PhD}$ thesis]. The City University of New York, New York. https://academicworks.cuny.edu/gc_etds/1557?utm_source=academicworks.cuny. edu/gc_etds/1557\&utm_medium=PDF\&utm_campaign=PDFCoverPages

Martin, M. S., Eljdupovic, G., McKenzie, K., \& Colman, I. (2015). Risk of violence by inmates with childhood trauma and mental health needs. Law and Human Behavior, 29(6), 614-623. https://doi.org/10.1037/lhb0000149

Maruna, S. (2001). Making good: How ex-convicts reform and rebuild their lives. American Psychological Association, Washington, DC. https://doi.org/10.1037/10430-000 
Maschi, T. (2006). Trauma and violent delinquent behavior among males: The moderating role of social support. Stress, Trauma, and Crisis, 9(1), 45-72. https://doi.org/10.1080/15434610500506233

Maschi, I., Morgen, K., Leibowitz, G., \& Rees, J. (2018). Exploring the relationship between cumulative trauma and recidivism among older adults: Does race and offense history matter? Traumatology, 1-10. https://doi.org/10.1037/trm0000167

Maschi, T., Morgen, K., Zgoba, K., Courtney, S., \& Ristow, J. (2011). Age, cumulative trauma and stressful life events, and post-traumatic stress symptoms among older adults in prison: Do subjective impressions matter? The Gerontologist, 51(5), 675-686. https://doi.org/10.1093/geront/gnr074

Maschi, T., Viola, D., \& Koskinen, L. (2015). Trauma, stress, and coping among older adults in prison: Towards a human rights and intergenerational family justice action agenda. Traumatology, 21(3), 188-200. https://doi.org/10.1037/trm0000021

McReynolds, L. S., Schwalbe, C. S., \& Wasserman, G. A. (2010). The contribution of psychiatric disorder to juvenile recidivism. Criminal Justice and Behavior, 37(2), 204-216. https://doi.org/10.1177\%2F0093854809354961

Miles-McLean, H. A., LaMotte, A., Semiatin, J. N., Farzan-Kashani, J., Torres, S., \& Poole, G. M. (2019). PTSD as a predictor of treatment engagement and recidivism in partner abusive men. Psychology of Violence, 9(1), 39-47.

https://doi.org/10.1037/vio0000161 
Miller, N. A. \& Najavits, L. M. (2012). Creating trauma-informed correctional care: A balance of goals and environment. European Journal of Psychotraumatology, 3(1), 1-8. https://doi.org/10.3402/ejpt.v3i0.17246

Moylan, C. A., Herrenkohl, T. I., Sousa, C., Tajima, E. A., Herrenkohl, R. C., \& Russo, M. J. (2010). The effects of child abuse and exposure to domestic violence on adolescent internalizing and externalizing behavior problems. Journal of Family Violence, 25, 53-63. https://doi.org/10.1007/s10896-009-9269-9

Mueser, K. T., Goodman, L. B., Trumbetta, S. L., Rosenberg, S. D., Osher, F. Vidaver, R., Auciello, P., \& Foy, D. W. (1998). Trauma and posttraumatic stress disorder in severe mental illness. Journal of Consulting and Clinical Psychology, 66(3), 493-499. https://doi.org/10.1037/0022-006X.66.3.493

National Center for Injury Prevention and Control: Division of Violence Prevention. (2013). Child maltreatment: Facts at a glance. https://www.cdc.gov/violenceprevention/pdf/childmaltreatment-facts-at-aglance.pdf

Ogloff, J. R. P., Talveski, D., Lemphers, A., Wood, M., \& Simmons, M. (2015). Cooccurring mental illness, substance use disorders, and antisocial personality disorder among clients of forensic mental health services. Psychiatric Rehabilitation Journal, 38(1), 16-23. https://doi.org/10.1037/prj0000088

Otto, R. K., \& Douglas, K. S. (Eds.). (2010). Handbook of violence risk assessment tools. Routledge.

Piquero, A. R., Jennings, W. G., Diamond, B., \& Reingle, J. M. (2015). A systematic review of age, sex, ethnicity, and race as predictors of violent recidivism. 
International Journal of Offender Therapy and Comparative Criminology, 59(1), 5-26. https://doi.org/10.1177/0306624X13514733

Polaschek, D. L. L. (2016). Desistance and dynamic risk factors belong together. Psychology, Crime \& Law, 22, 171-189. https://doi.org/10.1080/1068316X.2015.1114114

Pomaki, G., Karoly, P., \& Maes, S. (2009). Linking goal progress to subjective wellbeing at work: The moderating role of goal-related self-efficacy and attainability. Journal of Occupational Health Psychology, 14(2), 206-218. https://doi.org/10.1037/a0014605

Richard, K. M. (2004). Predicting persistence and desistence of recidivism in youth offenders: The role of risk and protective factors in criminal offending (Unpublished doctoral dissertation). Carleton University, Ottawa, Ontario. https://curve.carleton.ca/system/files/etd/c3fc9ddf-9576-4879-9c97d1b9558c1158/etd_pdf/d549ab09953f22799f0581b8b2f08edb/richardpredictingpersistenceanddesistenceofrecidivism.pdf

Sadeh, N., Binder, R. L., \& McNiel, D. E. (2014). Recent victimization increases risk for violence in justice-involved persons with mental illness. Law and Human Behavior, 38(2), 119-125. https://doi.org/10.1037/lhb0000043

Sadeh, N. \& McNiel, D. E. (2015). Posttraumatic stress disorder increases risk of criminal recidivism among justice-involved persons with mental disorders. Criminal Justice and Behavior, 42(6), 573-586. https://doi.org/10.1177/0093854814556880

Sampson, R. J., \& Laub, J. H. (2005). A life-course view of the development of crime. 
Annals of the American Academy of Political and Social Science, 602, 12-45. https://doi.org/10.1177/0002716205280075

Santiago, P. N., Ursano, R. J., Gray, C. L., Pynoos, R. S., Spiegel, D., Lewis-Fernandez, R., Friedman, M. J., \& Fullerton, C. S. (2013). A systematic review of PTSD prevalence and trajectories in DSM-5 defined trauma exposed populations: Intentional and non-intentional traumatic events. Plos One, 8(4), 1-5. https://doi.org/10.1371/journal.pone.0059236

Schlager, M. D. (2018). Through the looking glass: Taking stock of offender reentry. Journal of Contemporary Criminal Justice, 34(1), 69-80. https://doi.org/10.1177/1043986217750443

Schwalbe, C. S., Fraser, M. W., Day, S. H., \& Cooley, V. (2006). Classifying juvenile offenders according to risk of recidivism. Criminal Justice and Behavior, 33(3), 305-324. https://doi.org/10.1177/0093854806286451

Scott, W. D., Dearing, E., Reynolds, W. R., Lindsay, J. E., Baird, G. L., \& Hamill, S. (2008). Cognitive self-regulation and depression: Examining academic selfefficacy and goal characteristics in youth of a northern plains tribe. Journal of Research on Adolescence, 18(2), 379-394. https://doi.org/10.1111/j.15327795.2008.00564.x

Serin, R. C. (2007, 2015, 2017). The Dynamic Risk Assessment Scale for Offender Reentry (DRAOR): Guidelines for case planning and risk management using structured assessment of dynamic risk and protective factors. Unpublished usermanual.

Serin, R. C., \& Chadwick, N. (2017). Proposed DRAOR decision rules and case plan 
strategies. Unpublished user-manual.

Serin, R. C., Chadwick, N., \& Lloyd, C. D. (2016). Dynamic risk and protective factors. Psychology, Crime \& Law, 22(1-2), 151-

170. https://doi.org/10.1080/1068316X.2015.1112013

Serin, R. C., Gobeil, R., Lloyd, C. D., Chadwick, N., Wardrop, K., \& Hanby, L. (2016). Using dynamic risk to enhance conditional release decisions in prisoners to improve their outcomes. Behavioral Sciences and the Law, 34, 321-336. https://doi.org/10.1002/bsl.2213

Serin, R. C. \& Lloyd, C. D. (2009). Examining the process of offender change: The transition to crime desistance. Psychology, Crime, and Law, 15(4), 347-364. https://10.180/1068316080-2261078

Serin, R. C., Mailloux, D., \& Wilson, N. (2010). Practice manual for use with Dynamic Risk Assessment for Offender Re-entry (DRAOR) scale: Revised version. Unpublished manuscript, Carleton University, Ottawa, Canada.

Serin, R. C. \& Prell, L. (2012). Pathways to crime desistance for probationers. Paper Presented at American Psychology-Law Society Annual Conference, March, San Juan, Puerto Rico.

Sheier, L. M., Botvin, G. J., Griffin, K. W., \& Diaz, T. (2000). Dynamic growth models of self-esteem and adolescent alcohol use. Journal of Early Adolescence, 20(2), 178-209. https://doi.org/10.1177/0272431600020002004

Short, T., Thomas, S., Mullen, P., \& Ogloff, J. (2013). Comparing violence in schizophrenia patients with and without comorbid substance-use disorders to 
community controls. Acta Psychiatr Scand, 128, 306-313.

https://doi.org/10.1111/acps. 12066

Skeem, J. L., Emke-Francis, P., \& Louden, J. E. (2006). Probation, mental health, and mandated treatment: A national survey. Criminal Justice and Behavior, 33(2), 158-184. https://doi.org/10.1177/0093854805284420

Skeem, J. L. \& Lowenkamp, C. T. (2016). Risk, race, and recidivism: Predictive bias and disparate impact. Criminology, 54(4), 680-712. https://doi.org/10.1111/17459125.12123

Skeem, J. L., Manchak, S., \& Peterson, J. K. (2011). Correctional policy for offenders with mental illness: Creating a new paradigm for recidivism reduction. Law and Human Behavior, 35, 110-126. https://doi.org/10.1007/s10979-010-9223-7

Smith, C. \& Thornberry, T. P. (1995). The relationship between childhood maltreatment and adolescent involvement in delinquency. Criminology, 33(4), 451-481. https://doi.org/10.1111/j.1745-9125.1995.tb01186.x

Smith, N. \& Trimboli, L. (2010). Comorbid substance and non-substance mental health disorders and re-offending among NSW prisoners. Crime and Justice, 140, 1-16. https://pdfs.semanticscholar.org/113b/4a3ce9e386899c3e1db4699815c172ed1560 .pdf

Smith P., Gendreau, P., and Swartz, K. (2009). Validating the principles of effective intervention: A systematic review of the contributions of meta-analysis in the field of corrections. Victims and Offenders, 4(2), 148-169.

https://doi.org/10.1080/15564880802612581 
Swanson, J. W., Borum, R., Swartz, M. S., Hiday, V. A., Wagner, H. R., \& Burns, B. J. (2001). Can involuntary outpatient commitment reduce arrests among persons with severe mental illness? Criminal Justice and Behavior, 28(2), 156-189. https://doi.org/10.1177/0093854801028002002

Tabachnick, B. G. \& Fidell, L. S. (2013). Using multivariate statistics: Pearson new international edition (6th ed.). Pearson.

Teplin, L. A., McClelland, G. M., Abram, K. M., \& Weiner, D. A. (2005). Crime victimization in adults with severe mental illness: Comparison with the national crime victimization survey. Archives in General Psychiatry, 62, 911-921. https://doi.org/10.1001/archpsyc.62.8.911

van der Kolk, B. A. (2014). The body keeps the score: Brain, mind, and body in the healing of trauma. Viking.

van der Kolk, B. A., McFarlane, A. C., \& Weisaeth, L. (Eds.). (2007). Traumatic stress: The effects of overwhelming experience on mind, body, and society. The Guilford Press.

Ullrich, S. \& Coid, J. (2011). Protective factors for violence among released prisoners Effects over time and interactions with static risk. Journal of Consulting and Clinical Psychology, 79(3), 381-390. https://doi.org/10.1037/a0023613

Ventura, L. A., Cassel, C. A., Jacoby, J. E., \& Huang, B. (1998). Case management and recidivism of mentally ill persons released from jail. Psychiatric Services, 49(10), 1330-1337). https://doi.org/10.1176/ps.49.10.1330

Viljoen, J. L., Beneteau, J. L., Gulbransen, E., Brodersen, E., Desmarais, S. L., Nicholls, T. L., \& Cruise, K. R. (2012). Assessment of multiple risk outcomes, strengths, 
and change with the START:AV: A short-term prospective study with adolescent offenders. International Journal of Forensic Mental Health, 11(3), 165-180. https://doi.org/10.1080/14999013.2012.737407

Vujanovic, A. A., Bonn-Miller, M. O., Potter, C. M., Marshall, E. C., \& Zvolensky, M. J. (2011). An evaluation of the relation between distress tolerance and posttraumatic stress within a trauma-exposed sample. Journal of Psychopathology and Behavioral Assessment, 33(1), 129-135. https://doi.org/10.1007/s10862-0109209-2

Wardrop, K. (2020). A validation of the Dynamic Risk for Offender Re-entry (DRAOR) for use with offenders with mental disorder (Unpublished master's thesis). Carleton University, Ottawa, Canada.

Wells-Parker, E., Kenne, D. R., Spratke, K. L., \& Williams, M. T. (2000). Self-efficacy and motivation for controlling drinking and drinking/driving: An investigation of changes across a driving under the influence (DUI) intervention program and of recidivism prediction. Addictive Behaviors, 25(2), 229-238.

https://doi.org/10.1016/S0306-4603(99)00042-8

Wilson, C. M., Desmarais, S. L., Nicholls, T. L., Hart, S. D., \& Brink, J. (2013). Predictive validity of dynamic factors: Assessing violence risk in forensic psychiatric inpatients. Law and Human Behavior, 37(6), 377-388. https://doi.org/10.1037/lhb0000025

Wilson, A. B., Draine, J., Hadley, T., Metraux, S., \& Evans, A. (2011). Examining the impact of mental illness and substance use on recidivism in a county jail. 
International Journal of Law and Psychiatry, 34, 264-268.

https://doi.org/10.1016/j.ijlp.2011.07.004

Wolff, K. T. \& Baglivio, M. T. (2017). Adverse childhood experiences, negative emotionality, and pathways to juvenile recidivism. Crime \& Delinquency, 63(12), 1495-1521. https://doi.org/10.1177/0011128715627469

Wolff, K. T., Baglivio, M. T., \& Piquero, A. R. (2017). The relationship between adverse childhood experiences and recidivism in a sample of juvenile offenders in community-based treatment. International Journal of Offender Therapy and Comparative Criminology, 61(11), 1210-1242. https://doi.org/10.1177/0306624X15613992

Wong, S. C. P. \& Gordon, A. (2006). The validity and reliability of the violence risk scale: A treatment-friendly violence risk assessment tool. Psychology, Public Policy, and Law, 12(3), 279-309. https://doi.org/10.1037/1076-8971.12.3.279

Yesberg, J. A. \& Polaschek, D. L. L. (2015). Assessing dynamic risk and protective factors in the community: Examining the validity of the Dynamic Risk Assessment for Offender Re-entry. Psychology, Crime \& Law, 21(1), 80-99. https://doi.org/10.1080/1068316X.2014.935775

Yesberg, J. A., Scanlan, J. M., Hanby, L. J., Serin, R. C., \& Polaschek, D. L. L. (2015). Predicting women's recidivism: Validating a dynamic community-based 'genderneutral' tool. Probation Journal, 1-16. https://doi.org/10.1177/0264550514562851

Yu, R., Geddes, J. R., \& Fazel, S. (2012). Personality disorders, violence, and antisocial behavior: A systematic review and meta-regression analysis. Journal of 
Personality Disorders, 26(5), 775-792.

https://doi.org/10.1521/pedi.2012.26.5.775

Yu-Ling Chiu, Y. L., Ryan, J. P., \& Herz, D. C. (2011). Allegations of maltreatment and delinquency: Does risk of juvenile arrest vary substantiation status? Children and Youth Services Review, 33, 855-860.

https://doi.org/10.1016/j.childyouth.2010.12.007 
Appendix A

Dynamic Risk Assessment for Offender Re-Entry (DRAOR)

\begin{tabular}{|c|c|c|c|c|}
\hline \multicolumn{5}{|c|}{ Stable Risk Indicators } \\
\hline Indicator & \multicolumn{4}{|c|}{ Score (omit if unknown) } \\
\hline Peer Associations & $\begin{array}{c}0 \\
\text { Not a problem }\end{array}$ & $\begin{array}{c}1 \\
\begin{array}{c}\text { Slight/possible } \\
\text { problem }\end{array}\end{array}$ & $\begin{array}{c}2 \\
\text { Definite } \\
\text { problem }\end{array}$ & \\
\hline $\begin{array}{l}\text { Attitudes Towards } \\
\text { Authority }\end{array}$ & $\begin{array}{c}0 \\
\text { Not a problem }\end{array}$ & $\begin{array}{c}1 \\
\begin{array}{c}\text { Slight/possible } \\
\text { problem }\end{array}\end{array}$ & $\begin{array}{c}2 \\
\text { Definite } \\
\text { problem }\end{array}$ & \\
\hline Impulse Control & $\begin{array}{c}0 \\
\text { Not a problem }\end{array}$ & $\begin{array}{c}1 \\
\begin{array}{c}\text { Slight/possible } \\
\text { problem }\end{array}\end{array}$ & $\begin{array}{c}2 \\
\text { Definite } \\
\text { problem }\end{array}$ & \\
\hline Problem Solving & $\begin{array}{c}0 \\
\text { Not a problem }\end{array}$ & $\begin{array}{c}1 \\
\begin{array}{c}\text { Slight/possible } \\
\text { problem }\end{array} \\
\end{array}$ & $\begin{array}{c}2 \\
\text { Definite } \\
\text { problem }\end{array}$ & \\
\hline $\begin{array}{l}\text { Sense of } \\
\text { Entitlement }\end{array}$ & $\begin{array}{c}0 \\
\text { Not a problem }\end{array}$ & $\begin{array}{c}1 \\
\begin{array}{c}\text { Slight/possible } \\
\text { problem }\end{array}\end{array}$ & $\begin{array}{c}2 \\
\text { Definite } \\
\text { problem }\end{array}$ & \\
\hline $\begin{array}{l}\text { Attachment with } \\
\text { Others }\end{array}$ & $\begin{array}{c}0 \\
\text { Not a problem }\end{array}$ & $\begin{array}{c}1 \\
\begin{array}{c}\text { Slight/possible } \\
\text { problem }\end{array}\end{array}$ & $\begin{array}{c}2 \\
\text { Definite } \\
\text { problem }\end{array}$ & \\
\hline & & Tot & le risk score & \\
\hline
\end{tabular}




\begin{tabular}{|c|c|c|c|c|}
\hline \multicolumn{5}{|c|}{ Acute Risk Factors } \\
\hline Indicator & \multicolumn{4}{|c|}{$\begin{array}{l}\text { Score (omit if unknown) } \\
\end{array}$} \\
\hline Substance Abuse & $\begin{array}{c}0 \\
\text { Not a } \\
\text { problem }\end{array}$ & $\begin{array}{c}1 \\
\text { Slight/possible } \\
\text { problem }\end{array}$ & $\begin{array}{c}2 \\
\text { Definite } \\
\text { problem }\end{array}$ & \\
\hline Anger/Hostility & $\begin{array}{c}0 \\
\text { Not a } \\
\text { problem }\end{array}$ & $\begin{array}{c}1 \\
\begin{array}{c}\text { Slight/possible } \\
\text { problem }\end{array}\end{array}$ & $\begin{array}{c}2 \\
\text { Definite } \\
\text { problem }\end{array}$ & \\
\hline $\begin{array}{l}\text { Opportunity/Access } \\
\text { to Victims }\end{array}$ & $\begin{array}{c}0 \\
\text { Not a } \\
\text { problem }\end{array}$ & $\begin{array}{c}1 \\
\text { Slight/possible } \\
\text { problem }\end{array}$ & $\begin{array}{c}2 \\
\text { Definite } \\
\text { problem }\end{array}$ & \\
\hline Negative Mood & $\begin{array}{c}0 \\
\text { Not a } \\
\text { problem }\end{array}$ & $\begin{array}{c}1 \\
\begin{array}{c}\text { Slight/possible } \\
\text { problem }\end{array}\end{array}$ & $\begin{array}{c}2 \\
\text { Definite } \\
\text { problem }\end{array}$ & \\
\hline Employment & $\begin{array}{c}0 \\
\text { Not a } \\
\text { problem }\end{array}$ & $\begin{array}{c}1 \\
\text { Slight/possible } \\
\text { problem }\end{array}$ & $\begin{array}{c}2 \\
\text { Definite } \\
\text { problem }\end{array}$ & \\
\hline $\begin{array}{l}\text { Interpersonal } \\
\text { Relationships }\end{array}$ & $\begin{array}{c}0 \\
\text { Not a } \\
\text { problem }\end{array}$ & $\begin{array}{c}1 \\
\text { Slight/possible } \\
\text { problem }\end{array}$ & $\begin{array}{c}2 \\
\text { Definite } \\
\text { problem }\end{array}$ & \\
\hline Living Situation & $\begin{array}{c}0 \\
\text { Not a } \\
\text { problem }\end{array}$ & $\begin{array}{c}1 \\
\text { Slight/possible } \\
\text { problem }\end{array}$ & $\begin{array}{c}2 \\
\text { Definite } \\
\text { problem }\end{array}$ & \\
\hline & & Tota & te risk score & \\
\hline
\end{tabular}




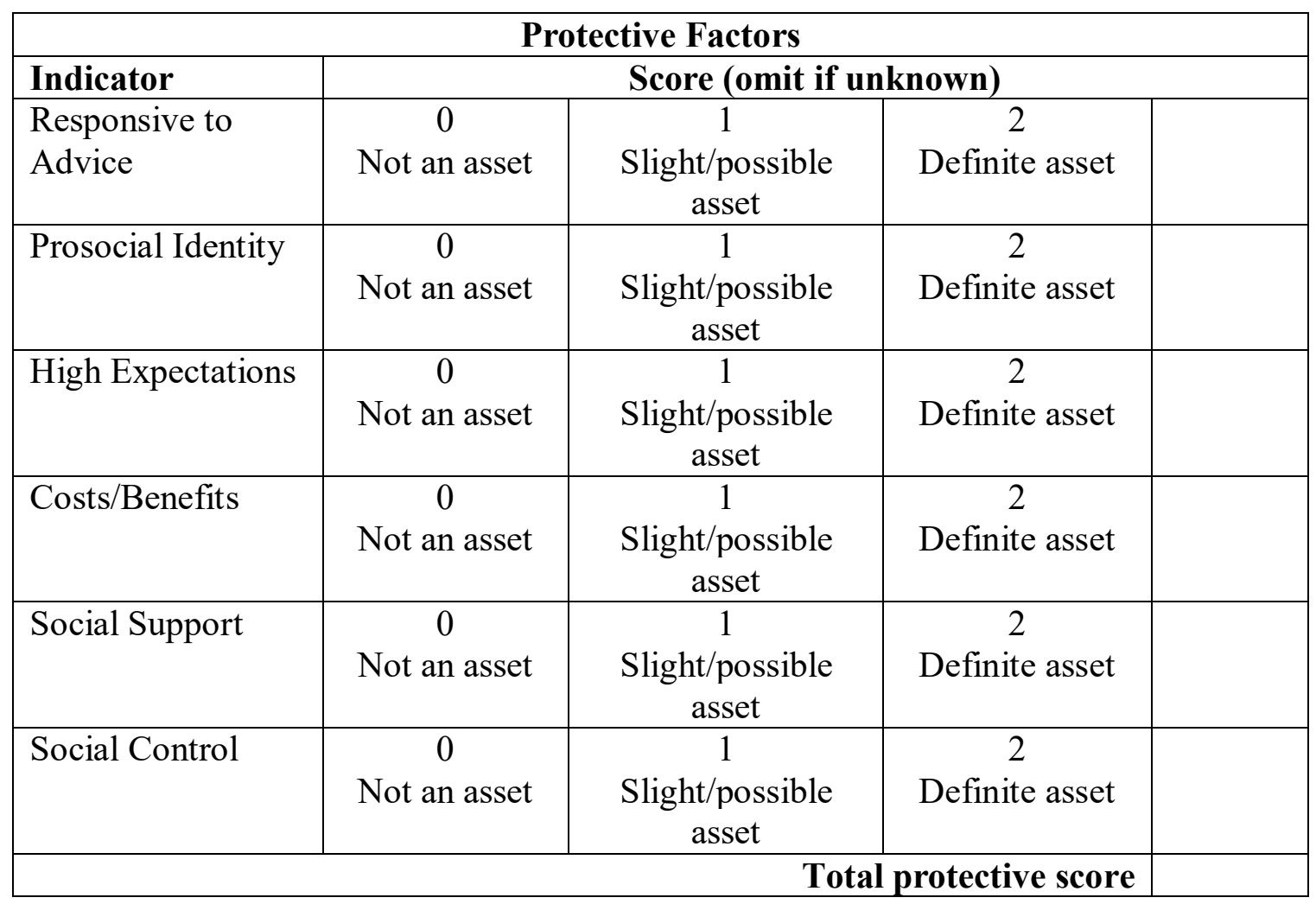

\begin{tabular}{|l|l|}
\hline \multicolumn{1}{|c|}{ Risk Level } & \multicolumn{1}{c|}{ DRAOR Cut-off } \\
\hline Low & $\leq 2$ \\
\hline Moderate & 3 to 9 \\
\hline Moderate/High & 10 to 22 \\
\hline High & $\geq 23$ \\
\hline
\end{tabular}


Appendix B

Description of DRAOR Items ${ }^{1}$

\section{Stable Subscale}

1. Peer Associations: This item refers to the nature and frequency of associations with criminal individuals. Peers can be partners, family members, friends, or acquaintances with whom the client spends free time. Criminal peers may be those who have committed crime in the past, or would likely accept the client if the client were to commit criminal behavior in the present. is ispeps

2. Attitudes Towards Authority: This item refers to having a hostile, oppositional, antagonistic, or defiant attitude toward those in authority. Attitude refers to beliefs that authority figures (a) do not deserve to have power over them, (b) do not have a legitimate role to play in keeping order or enforcing rules, (c) do not "play fair" specifically when it comes to the client, or (d) do not deserve respect or consideration from the client. Also, (e) a client may describe avoiding their responsibilities or lying to authority figures as a "game" that everyone plays, suggesting that authority figures do not enforce rules for any higher purpose than to manipulate others and "win"

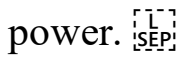

3. Impulse Control: This item refers to either a pattern of (a) the client "doing the first thing that comes into their head" without thinking about the consequences, or (b) the client feeling so overwhelmed by impulses that they tend to give in and behave in

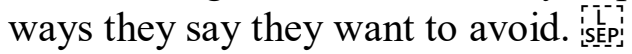

4. Problem Solving: This item refers to the client's ability to find solutions to their life problems in a way that takes them away from risk situations and criminal behavior. Good problem solving involves (a) a desire to find non-criminal solutions to problems, (b) thinking through options to decide on the best prosocial solution, and (c) taking action to make the prosocial solution a reality, which involves following through to find new solutions if setbacks come up in the process. Poor problem solving involves (a) a preference for criminal solutions to problems, (b) remaining inactive rather than engaging in proactive solution- finding, or (c) attempting to fix life problems in a way that causes more serious problems (e.g., puts the individual at risk for new crime, or the solution involves criminal activity). [iscep]

5. Sense of Entitlement: This item refers to an attitude of self-regard and selfcenteredness, at the expense of regard for other's rights. Attitude refers to the clients' personal belief that (a) they deserve to get what they want, no matter the expense to others, (b) others will manipulate, coerce, or deceive them, if they don't manipulate, coerce, or deceive others first, (c) it's only fair that those who fight for their own rights will win out over those who are not as strong, and (d) people who lose out had

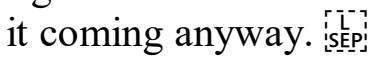

6. Attachment with Others: This item refers to a characteristic, ongoing lack of concern for others, resulting in social disconnection or problematic interpersonal attachments. Poor attachment with others may express as (a) general inattention or indifference to the emotions or needs of others, (b) a callous disregard for the ways others may feel

${ }^{1}$ Obtained from Serin $(2007,2015,2017)$ 
hurt or betrayed by the client's actions, (c) short-term, superficial relationships

characterized by opportunistic exploitation, or (d) complete disinterest toward feeling close to or maintaining relationships with others.

\section{Acute Subscale}

1. Substance Abuse: This item refers to use of unauthorized substances, including illegal drugs and substances banned by supervision order, and the misuse of other substances, including prescription drugs and alcohol. is-pi]

2. Anger/Hostility: This item refers to the presence of either (a) "hot" emotions, such as high irritability, exasperation, fury, or rage (for example), or (b) attitudes that support the degradation of others, harm to others, or dehumanization of others. Both (a) anger and (b) hostility result in the client presenting as antagonistic, either by (a) behaving antagonistically, showing signs of a bad temper (i.e., clenched fists, speaking loudly, angry facial expressions), or (b) verbal expressions that others (specific individuals, or groups of individuals) do not deserve fair, ethical, or kind treatment. Unlike sadness (anxiety, depression), anger is focused outward, such that the client reports feeling upset at others (but, both types of emotions can occur simultaneously). [iép]

3. Opportunity/Access to Victims: This item refers to the immediate availability of opportunities for crime. This is especially important to consider if the client has history victimizing a preferred victim (either one individual, such as an expartner, or a specified group of individuals, such as a sex offender with preference for child victims).

4. Negative Mood: This item refers to the presence of unpleasant emotions, especially agitation, distress, anxiety, stress, or sadness. Unlike the "hot emotions" (anger), the focus of these negative moods is turned inward, such that the client reports feeling unsettled and upset inside of themselves (but both types of emotions can

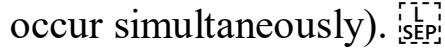

5. Employment: This item primarily assesses whether or not the client is currently employed. Other considerations surrounding employment have additional relevance. Specifically, (a) employability (i.e., does the client have the necessary skills to join the workforce?), (b) engagement (i.e., is the client currently satisfied with existing employment?), and (c) effort (i.e., is the client motivated to gain or maintain employment?). is iscep

6. Interpersonal Relationships: This item refers to current problems in close interpersonal relationships in the client's life (which can include antagonism, victimization, breakdown, disconnection, social pressure to engage in criminal activity, etc.). The primary consideration should focus upon romantic partnerships, but close other relationships (with family, housemates, business partners, etc.) deserve consideration in the absence of a romantic partnership, or when there is severe 
distress or the breakdown of a prosocial relationship that is important to the client.

7. Living Situation: This item primarily assesses whether or not the client is currently living in stable, long-term housing. Stable housing can be considered on a continuum from lack of any suitable housing, or homelessness (a definite problem), temporary or possibly problematic housing situations, such as residence at a halfway house, or "couch surfing" (a possible problem), to safe, suitable, long-term housing (not a problem). However, residing at a halfway house may be rated as definite problem if the client should currently be putting in effort to find other suitable housing, but is not doing so. Alternately, living in a supported residence may be rated as not a problem if the current situation may serve as a stable long- term solution, or the client has already made plans to enter safe, stable housing after leaving the residence.

\section{Protective Subscale}

1. Responsive to Advice: This item refers to the client expressing openness to receive and take guidance for making lifestyle changes that will lead toward a long-term, crime-free lifestyle. This is the "Do I care, do I listen, and do I act?" component of the beliefs that support a process of desisting from crime.

2. Prosocial Identity: This item refers to the client's internal self-image. This is the "Who am I?" component of the beliefs that support a process of desisting from crime. The purpose of this item is to assess whether the client can imagine and articulate a "future self" that feels comfortable, fulfilled, and satisfied in a fully non-

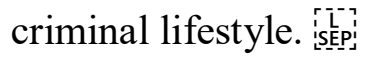

3. (Realistic) High Expectations: This item refers to clients' attitude toward change. Attitude refers to two specific beliefs about change that are particularly relevant. First, do clients have a high sense of hope that they will be able to make the prosocial changes they desire to make in their lives? Second, do they believe that change will take time and require personal effort, such that they need to work at creating personal change and re-gaining the trust of others? Combining these two beliefs, do they have a sense of hope that they have the skills it will take to work to achieve the non-criminal life they want?

4. Costs/Benefits (Supportive of Staying Crime-free): This item refers to clients' attitude toward the personal value of crime, and how this attitude compares or contrasts with their attitude toward the value of extending effort t-o stay crime-free. For this item, attitude refers to beliefs that bad outcomes will happen if choices are made to commit crime in the future, but good outcomes will happen if effort is extended toward staying crime-free. For example, the client who is characterized by prosocial costs/benefit beliefs can articulate that (a) they will lose something important to them if they ever commit another crime, because the consequences of crime have high drawbacks to them, and (b) they will gain something important to them if they put effort into staying crime-free, even if it is difficult or 
unfamiliar to them at first. istepin

5. Social Support: This item refers to whether clients have any meaningful relationships with non-criminal individuals, especially individuals who assist the client by offering relational (and/or material) support to the client. This item refers to the nature and frequency of associations with prosocial individuals. These individuals can be partners, family members, friends, or acquaintances with whom the client spends free time. A key feature that identifies a prosocial individual is that they would be unlikely to view the client favorably if the client were to commit new criminal behavior. istepí

6. Social Control: This item refers to the effects that existing prosocial relationships are having on clients who have supportive, non-criminal individuals in their lives. This item extends beyond the simple existence of prosocial others in the client's life, and refers to the influence these individuals have on the client. 


\section{Appendix C}

\section{Description of Supplemental Items}

The supplemental factors were added to the DRAOR by Iowa DOC for case planning purposes. These items came about due to gender responsivity research and through continued use of this category, these items were shown to also impact males as well as females. The items are scored the same as the other DRAOR factors (Stable, Acute, and Responsivity), but do not affect the overall DRAOR score.

Trauma: This item relates to trauma experienced or as it relates to vicarious trauma. Trauma is a very difficult or unpleasant experience that causes someone to have mental or emotional problems usually for a long time.

Mental Health: This item considers mental health issues and diagnosis as part of daily routine and living. This item is specific to a mental health diagnosis.

Self-efficacy: This item pertains to the ability to set goals to increase success potential. Confidence is a good predictor of change. 